\title{
The predominant teaching strategies in Year 8 and Year 9 Mathematics classrooms
}

By

Kay Jacqueline Matheson

Thesis submitted to the Victoria University of Wellington in partial fulfillment of the requirements for the degree of Master of Teaching

Victoria University of Wellington

2009 


\section{Abstract}

In New Zealand most students change schools at age 12-14 from an intermediate school to a secondary school. This usually involves a transition from a school that is organised by students having a home room with one teacher for most of their subjects to a school that is organised by students changing classrooms and teachers for every subject. Across this transition period research internationally and in New Zealand suggests that mathematics achievement and engagement is negatively affected. Lesson content, interschool communication, social class, ethnicity, and gender have been identified as factors that may influence the negative effect of transition.

This research looks at another possible factor affecting achievement and engagement at transition in mathematics: the teaching strategies used. Teaching strategies have been defined in this research to be those strategies used in classroom instruction as indicated by teacher talk, activity style, and equipment use.

This research is based on a purposive sample of one secondary school and one of its feeder intermediate schools. Three teachers of mathematics at Year 9 from the secondary school and three Year 8 teachers from the intermediate school were then selected to be videoed, each for three lessons. The video recorded lessons were then transcribed, analysed using content analysis, and the teaching strategies evident in the classroom identified. The teaching strategies were categorised based on previous research such as that by Fraivillig, Murphy and Fuson (1999) to find any similarities or differences in teaching strategies used in the Year 8 and Year 9 mathematics classroom.

Year 8 teachers used facilitating and eliciting questions more often than the Year 9 teachers. The Year 8 teachers used instructional statements as a teaching strategy. There appeared to be more intra-school variation in teaching strategies at the Year 8 level.

Year 9 teachers were found to be more teacher-centred than Year 8 teachers in their choice of strategies with teacher initiated right/wrong questioning the most frequent interaction type used. Instructional and control statements were also a feature of the Year 9 mathematics classrooms.

This study indicates that across the transition period, from Year 8 to Year 9, students' experience changes in the types of teaching strategies used in the mathematics classroom. The focus shifts from student-centred learning to teacher-centred learning. This may be a 
contributing factor in the decline in mathematics achievement that has been shown to occur at this phase of education in New Zealand.

Implications from this research include:

- the possible need for schools across a transition to communicate more to align their teaching strategies;

- the need for best practice teaching strategies to be implemented in all schools; and

- the possibility of schools across a transition working together and developing a programme which may allow students to integrate better into the secondary school. 


\section{Acknowledgements}

I would like to acknowledge the following people for all their help and support. My supervisor Robin Averill has been of tremendous support with her encouragement, advice, knowledge, and positiveness. Other academic assistance has been provided by Dr Angela Ward and Julie Brangwin, who have helped with proof reading, and the research assistants at the Victoria University Library Distance section.

This thesis would not have been possible without the support, in the form of a study grant, from the New Zealand Teacher's Council and my own secondary school who released me for the university year.

My family has offered continual encouragement and support throughout the time I have spent on this thesis. Cooking meals and doing housework may seem trivial but are a great help in allowing me to focus on the research process.

The schools who allowed me to trial my research and those who took part in the final project must be acknowledged. Their support of education research shows that as teachers we are continually trying to improve ourselves and encourage others to improve. 


\section{Contents}

Abstract

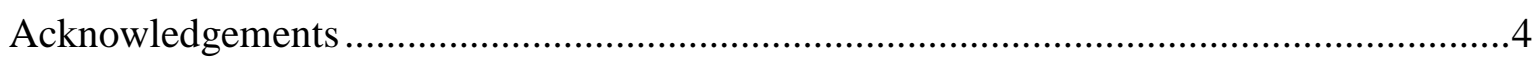

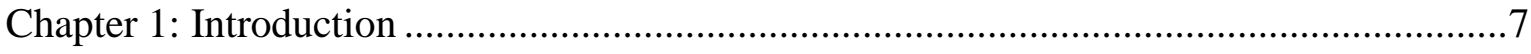

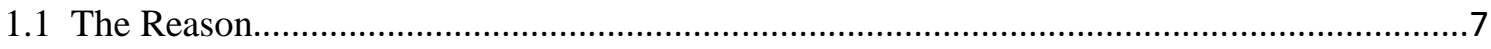

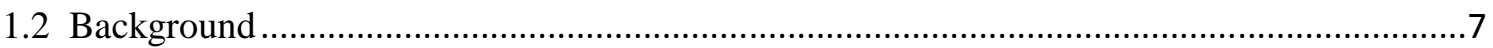

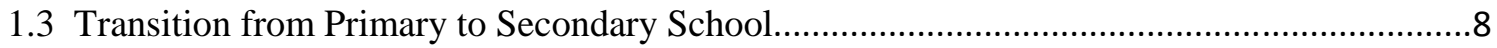

1.4 Impact of Mathematics Curricula on Teaching Strategies ......................................................

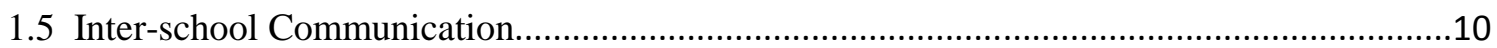

1.6 Summary and Research Questions...............................................................................

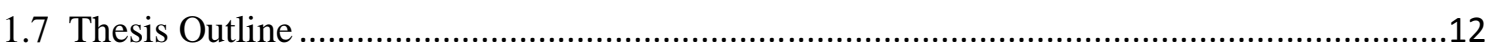

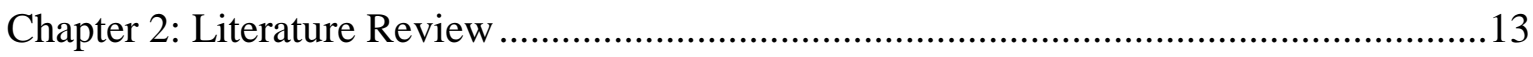

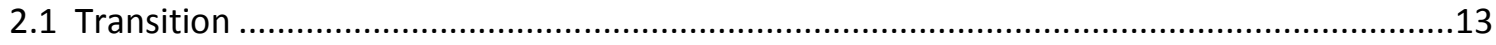

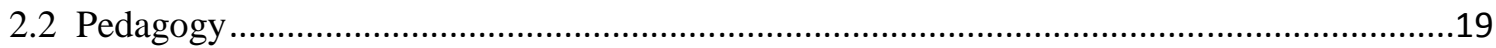

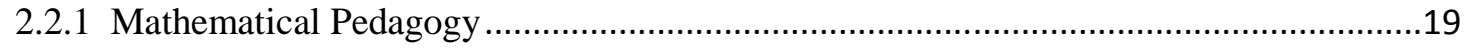

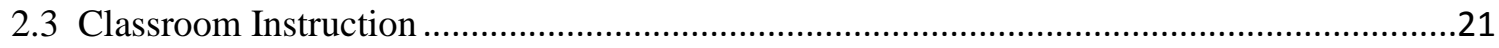

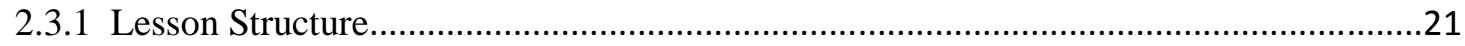

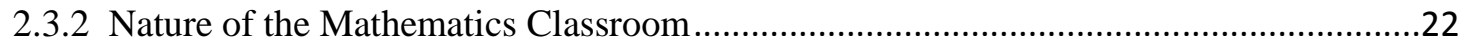

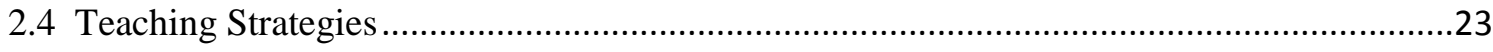

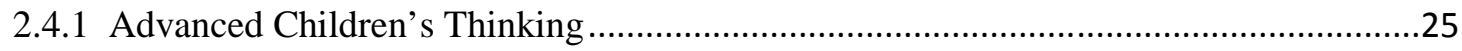

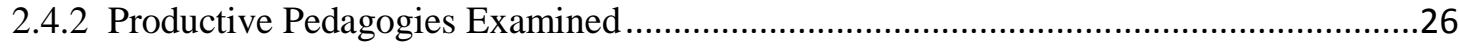

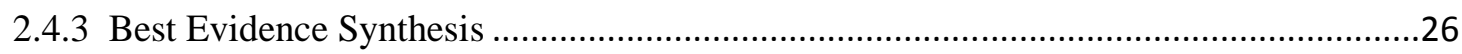

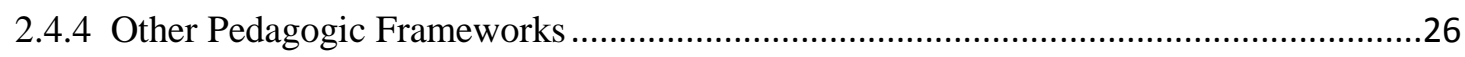

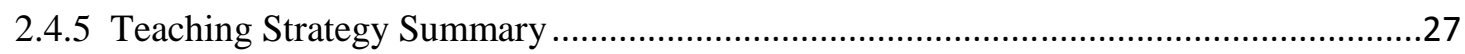

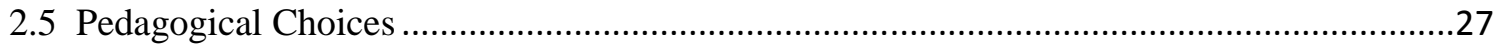

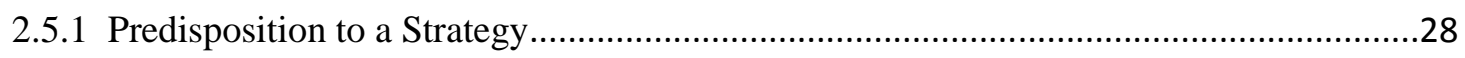

2.5.2 New Zealand Teaching Strategy Context ..................................................................29

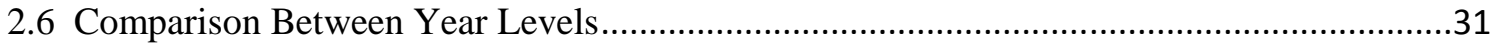

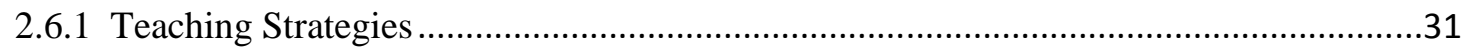

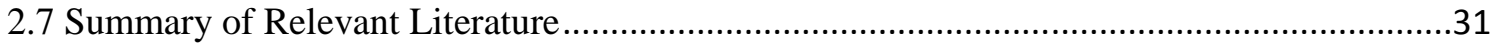

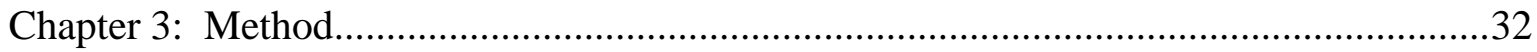

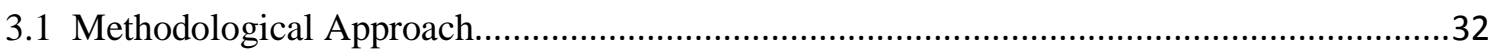




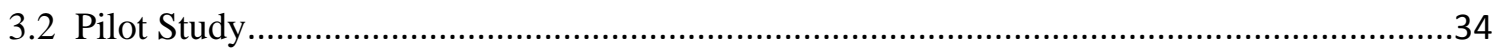

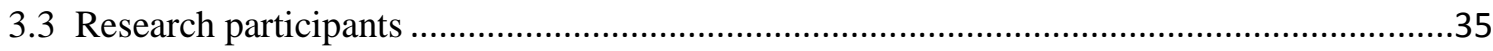

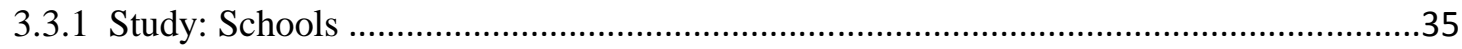

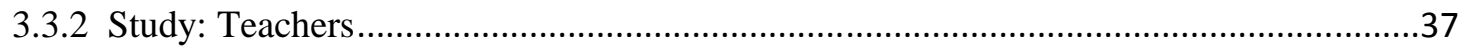

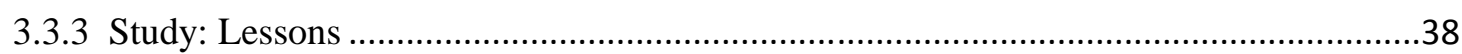

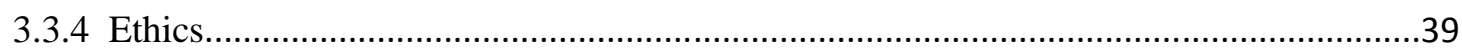

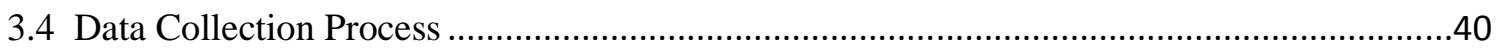

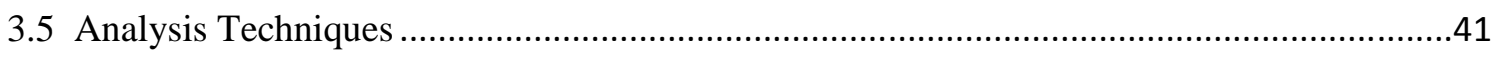

Chapter 4: Teaching Strategies Compared 1 ..................................................................4

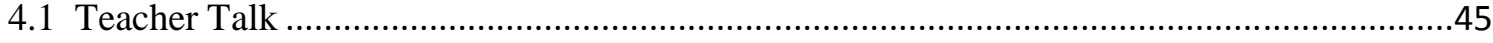

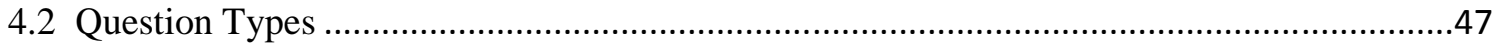

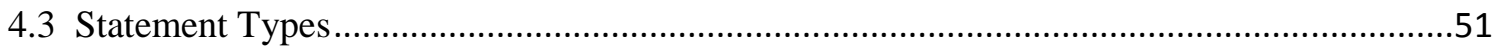

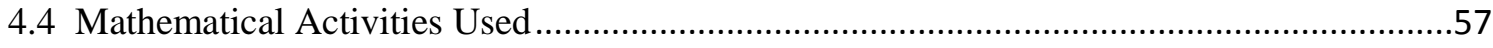

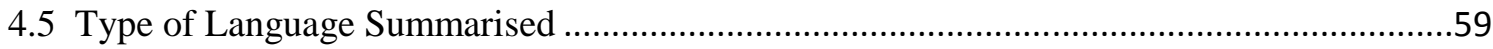

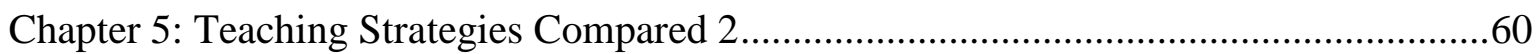

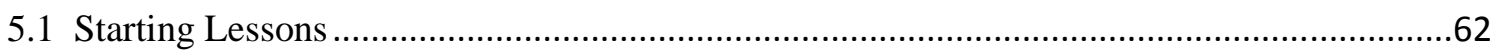

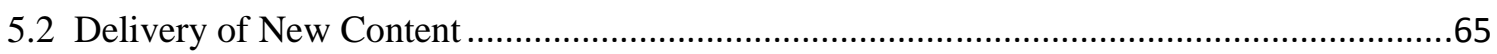

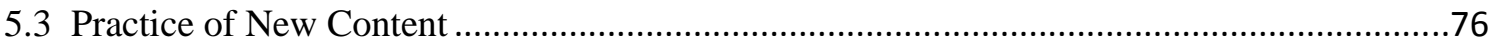

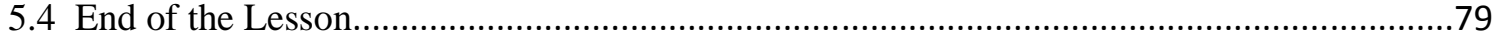

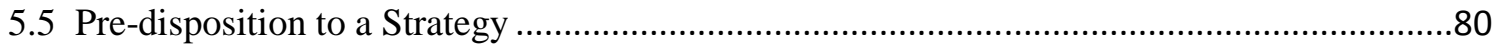

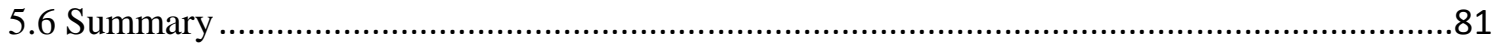

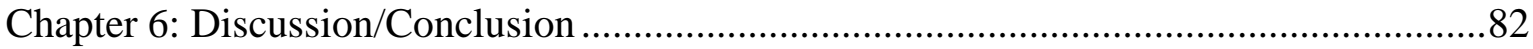

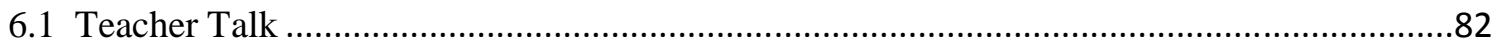

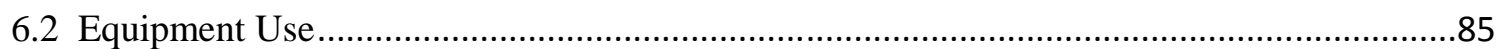

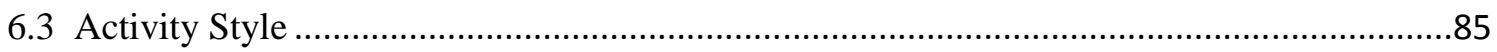

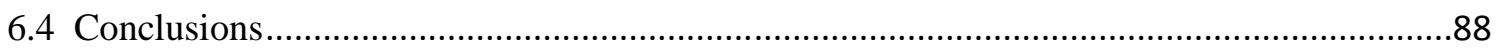

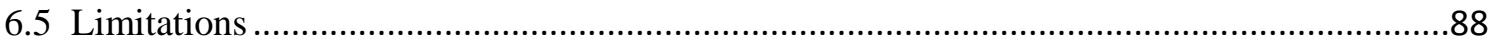

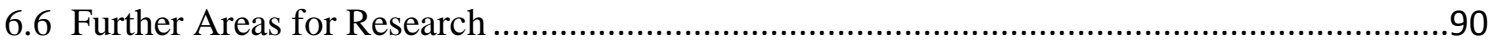

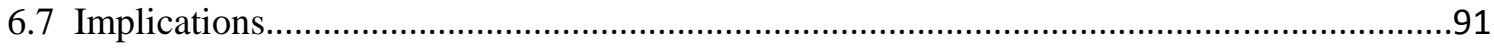

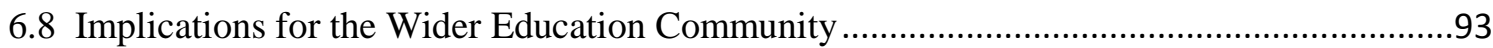

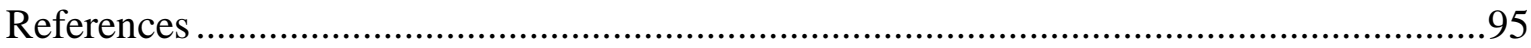

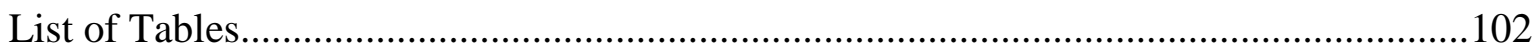

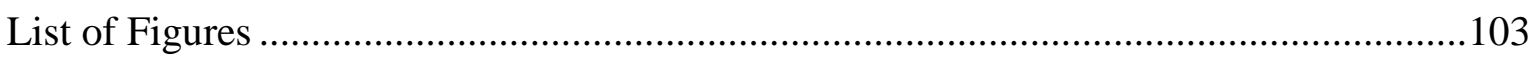

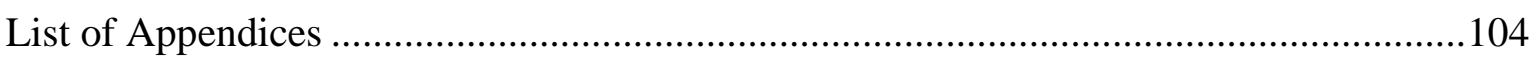




\section{Chapter 1: Introduction}

\subsection{The Reason}

In New Zealand, as in most countries in the world, students undergo at least one transition stage in their educational lives. Transition in this research has been defined as the student's movement to a higher level of schooling involving relocation to a different physical premise. The schools before and after transition often have different ways of structuring the school day and curriculum delivery. At a New Zealand intermediate school, students are generally grouped into year level form classes and are assigned a single teacher who instructs them in most curriculum subjects. They will stay with this teacher for the majority of their school day. In a New Zealand secondary school, students generally have a different teacher for each curriculum area and may interact with five or more teachers on any given day.

The period of transition has been studied from many aspects. This thesis explores one of the least often explored: the similarities and differences in teaching strategies used by mathematics teachers across a transition period for New Zealand students. The particular transition studied in this thesis is that undergone by students aged 12 to 14 , from an intermediate school to a secondary school.

This chapter will outline the researcher's background and the rationale for undertaking this research. The precise transitional stage undertaken by the students concerned will be defined. The New Zealand education system is explained so that the teaching strategies can be looked at in context. Inter-school linkages will be explored, as these may affect students' progress over the transition phase.

Finally, the research questions are introduced.

\subsection{Background}

In my role as a Co-Head of the Mathematics Department in a New Zealand secondary school I have become increasingly aware that a large number of students coming into New Zealand Year 9 mathematics classrooms may have different expectations of mathematics classroom teaching from those of their secondary school teachers. This is exacerbated by the fact that students' prior experiences in mathematics are varied, as they often come from several different schools and many different teachers. In New Zealand students entering a 
single secondary school may come from as many as ten different primary schools. For example in the school I teach in we have students from eleven different feeder schools. ${ }^{1}$

This has led, in my school, to two prevailing types of concerns from Year 9 parents: that their child is bored as they are not finding the Year 9 programme stimulating for their children; or their child is finding that the pace of work is too demanding. These complaints are possibly a result of the lack of communication between my secondary school and its feeder schools, regarding what and how mathematics is taught in the respective mathematics classrooms.

The New Zealand curriculum developed by the Ministry of Education in consultation with teachers provides for a learning progression from entry into the state school system at age 5 until students leave the school system at age 16-18. The curriculum states learning objectives for each of the eight learning levels (Ministry of Education, 2007). Underlying the curriculum is a philosophy which outlines key competencies for students, the values that underpin the New Zealand education system, and the principles that should be taught in the classroom.

The seamless nature of the New Zealand curriculum may have contributed to the teachers in my secondary school assuming what mathematical knowledge, skills, and understandings students will enter Year 9 with. Studies of mathematics teaching after transition to secondary school have shown that we are not the only secondary school to do this (Galton, Gray and Ruddock, 1999; Huggins and Knight, 1997).

The challenge for the Year 9 mathematics teachers in my secondary school is to keep all students motivated, interested, and achieving in mathematics. Examining teaching strategies across the transition period may provide an aid to realising this challenge.

\subsection{Transition from Primary to Secondary School}

Compulsory education systems around the world often involve a progression through different schools, as students advance through the grades, levels, or stages of schooling. In the United States, Great Britain, Japan, Norway, and New Zealand, for example, this often means a transition from one physical school site to another. The time of transition often

\footnotetext{
${ }^{1}$ Schools that terminate at a particular age and their students move to a higher level school.
} 
occurs between primary (first school) and secondary (post-primary) school. Transfers ${ }^{2}$ and transitions have been identified as leading to a dip in attainment and a decrease in enthusiasm for mathematics in Germany, Ireland, Italy, Scotland, Spain, and Tasmania (Australia) as well as in England (Galton, Gray, Ruddock with others, 2003). New Zealand research shows that New Zealand students experience a similar dip in achievement (Anthony \& Walshaw, 2007).

In the New Zealand situation most students undergo a change in schools between Year 8 and Year 9. This is a move from a primary school that covers Year 1 to Year 8 (approximately ages 5-11), or an intermediate school, Years 7 and 8 (approximately ages 9-11) to a secondary school that caters for Years 9 to 13 (approximately ages 12-18). This is the transition period on which this research was focused.

\subsection{Impact of Mathematics Curricula on Teaching Strategies}

The mathematics curriculum taught in many countries is set at the national level. In the 2003 Trends in International Mathematics and Science Study (subsequently referred to as TIMSS 2003) 23 of the 26 countries surveyed at the fourth grade level and 44 of the 47 countries surveyed at the eighth grade level had a national curriculum for mathematics (Mullis, Martin, Gonzalez \& Chrostowski, 2004). In some cases the curriculum is also supported by instructional guidelines and specifically states which textbooks to use (Mullis et al., 2004, p. 7). In the United Kingdom the introduction of a national curriculum in 1989, was thought to be a chance to improve the transition process by providing continuity across the primary-secondary partition. It was felt that if the content progressed in an orderly manner through the year levels then students may feel more comfortable with the transition to a different school. Huggins and Knight (1997) showed that implied seamlessness to the curricula did not improve the negative effects of transition as expected. That it might not be the curricula that is of concern but how teachers deliver it was suggested by Willocks (1983) following a five year study on transition to secondary school. The teaching strategies used to deliver content are the focus of this research.

The New Zealand Ministry of Education introduced a new curriculum into New Zealand schools in 1993. This started the promotion of the seamless nature of learning and the progression of students through levels of understanding. It was designed to provide

\footnotetext{
${ }^{2}$ This is the word used in Great Britain for what has been defined in this thesis as transition
} 
consistency of learning and pedagogy in classroom programmes throughout New Zealand from Year 1-13 (Ministry of Education, 2007). This consistency in mathematics teaching and learning was scaffolded by the introduction of the Numeracy Development Project (subsequently referred to as NDP) into primary schools (started in 2000) and some secondary schools (started in 2005).

The NDP has two elements, one targeted at primary schools and one at secondary schools (tki.org.nz, 2008). The NDP has the aim of improving student performance in mathematics through improving the subject and pedagogical knowledge of teachers. One of the goals of the NDP is to improve teachers' understanding of number concepts, student strategies, and instructional practice with a view to improving achievement (tki.org.nz, 2008, I[17).

The NDP encourages a pedagogical shift from away from algorithmic teaching to conceptual teaching (Young-Loveridge, 2007). Teachers who have been involved with the NDP for over three years emphasise that it is the process and not the product that is important (Young-Loveridge, 2007, p118). The NDP emphasises that it is how students think in order to achieve the outcome that is important not just the use of an algorithm to solve a problem. In order to help teachers move from a behaviourist teaching strategy to the more constructivist one required in the NDP, teachers undertook a comprehensive training programme. Many teachers had three one-day workshops, followed by Numeracy experts giving feedback on their teaching, and modelling best practice for the classroom teachers to emulate. Lead teachers in each school involved were allocated time to aid staff to practice the new strategies involved. Teachers have also been provided with some teaching strategies to use in the classroom, these give learning objectives and how to teach them (Ministry of Education, 2001). A potential outcome of the provision of explicit lessons may be to increase the similarity of teaching strategies evident in the mathematics classrooms of those involved. This has not been researched to date that I can find.

Schools not involved in the NDP may still teach in an algorithmic way, relying heavily on outcomes, and a set method to solve problems. It was an objective of the NDP to try to change the way mathematics was taught (Annan, 2006, p. 120).

\subsection{Inter-school Communication}

In most cities in New Zealand students at an intermediate school move on to a secondary school within the same geographical area. One intermediate school, in conjunction with 
others in the city, may feed three to four large secondary schools. It would be expected that the linkages and communication between the schools would therefore be relatively strong.

International and New Zealand based research shows the contrary. Secondary school mathematics teachers in England were found to be uninformed of, and to a large extent uninterested in, what was occurring in the Year 8 classroom (Evangelou, Taggart, Sylva, Melhuish, Sammons \& Siraj-Blackford, 2008). This lack of communication despite a unified curriculum has caused different approaches to learning and teaching to evolve in the different phases of education in England (Department for Children, Schools and Families [England], 2008).

Communication across the transition period, which discusses teaching styles, was identified as an important factor in aiding students to settle into the new school in Britain (McGhee, Ward, Gibbons and Harlow, 2004). In a small case study of New Zealand schools (McGhee, 1989), found that few Year 9 teachers made any contact with the primary teachers of their students. Today the ease of communication via technology and the seamless nature of the education system may have altered this.

The relationship between my school and our feeder schools involves little communication regarding the incoming students' prior mathematics learning. I felt that I had little information with respect to what the students coming into Year 9 had previously encountered in their mathematical history. This is one of the reasons why I felt that a study across the transition period was important.

\subsection{Summary and Research Questions}

In order to improve understanding of what occurs in New Zealand Year 8 and Year 9 classrooms, and to provide a starting point for further communication between schools, this research project was designed to explore teaching strategies in the Year 8 and Year 9 classrooms of two schools. Through a comparative research process this study aimed to identify differences or similarities between the year levels, which may help to explain the decrease in mathematics achievement and enthusiasm at transition to a secondary school. This knowledge may help to create a Year 9 mathematics programme that does not have a negative impact on students' achievement in, or enthusiasm for, mathematics.

The focus of this research was whether the nature of the Year 8 mathematics classroom is pedagogically different, as determined by the teaching strategies used, to the Year 9 
mathematics classroom. The aim of this research was to investigate teaching strategies used in Year 8 and Year 9 mathematics classrooms by answering the following questions.

- What are the prevalent teaching strategies ${ }^{3}$ (with specific focus on each of teacher talk $^{4}$, equipment use, and activity style) used in Year 8 mathematics classrooms?

- What are the prevalent teaching strategies (with specific focus on each of teacher talk, equipment use, and activity style) used in Year 9 mathematics classrooms? And hence

- How do the teaching strategies used in Year 8 and Year 9 mathematics classrooms compare?

These questions will be answered by identifying and categorising the teacher talk, equipment use, and activity style that support the pedagogical practices of Year 8 and Year 9 mathematics teachers. The intention is then to compare them to look for similarities and differences in teaching strategies.

\subsection{Thesis Outline}

Chapter 1 provided an introduction of why I wanted to learn more about mathematics teaching strategies across the transition in New Zealand from Year 8 to Year 9. Chapter 2 will outline previous research that has been carried out in this field, both internationally and within New Zealand. How the study was conducted and the underlying methodology of the data collection and analysis will be elucidated in Chapter 3. The analysis of data, vignettes that illustrate different teaching strategies, and explanations of the significance of results will be explained in Chapters 4 and 5. How the results of this study add to the field of knowledge in this area and the significance of this research for teaching mathematics in New Zealand at Years 8 and 9 is the focus of Chapter 6.

\footnotetext{
${ }^{3}$ Informed in particular by analysing how teachers encourage mathematical thinking (Fraivillig, Murphy \& Fuson, 1999) as discussed in Chapter 2.

${ }^{4}$ Verbal communication from the teacher during the lesson, includes delivery of instruction, questioning and any conversation with students
} 


\section{Chapter 2: Literature Review}

In order to frame the study this chapter is split into six sections. Section 2.1 deals with the process of transition and its impact on students. A comprehensive review of the research into the transition period both internationally and within New Zealand highlighted areas of concern for transition students (McGhee et al., 2004). This review was the starting point for my investigation into problems across transition.

The second section explores pedagogy and provides the working definition of the term 'pedagogy' as used in this research. In producing a working definition I have relied heavily on the work of Anthony and Walshaw's (2007) integration of a wide range of research into effective pedagogy for mathematics teachers.

What happens in the classroom, particularly the teaching strategies employed by mathematics teachers, is the focus of sections 2.3 and 2.4. Two studies and one report for the description of the teaching strategies that were observed were particularly useful in developing this study. The first, Advancing Children's Thinking (subsequently referred to as ACT), produced, from a case study of a skillful first grade teacher in the United States, a pedagogical framework for the description of mathematical teaching strategies (Fraivillig, Murphy \& Fuson, 1999). The second study was undertaken in Queensland, Australia and called the Queensland School Reform Longitudinal Study (subsequently referred to as QSRLS) (School of Education, University of Queensland, 2001). In total 975 classroom lessons across 24 schools were observed over three years in the QSRLS study, and pedagogies were identified that enhanced student achievement. The Mathematics Best Evidence Synthesis (subsequently referred to as BES) report is an amalgamation of 660 pieces of research, with a primary focus on New Zealand research, summarising the best evidence of effective pedagogy in mathematics (Anthony and Walshaw, 2007).

Section 2.5 deals with the background philosophies and governing principles that may inform the pedagogical choices of teachers and in particular those teachers in New Zealand schools. Other research comparing Year 8 and Year 9 mathematics classrooms across the transition period is looked at in Section 2.6.

\subsection{Transition}

The particular transition involved in this research was outlined in Section 1.3. Whilst this research is concerned with a transition that occurs in New Zealand, international research into transition is also relevant. A transition to a different school has been identified as a 
potential cause of a decrease in achievement, motivation, and general interest in schooling. This section looks at the factors that previous researchers have identified as affecting students across the transition period.

Much research into the effects of school transition (e.g., Anderson, Jacobs, Schramm \& Splittberger, 2000; Barone, Aguire-Deaudreis \& Trickett, 1991; Birmingham Core Skills Development Partnership, 1998; Education Review Office, 2002; National Middle School Association, 2006) has found that the transition into the first year of secondary school from a primary school can have a negative influence on students' academic achievement. Student motivation has also been found to decrease after transition as a result of the structure (e.g. different teachers for different subjects) of the secondary school (Cocklin, 1999).

These decreases in achievement and motivation may occur for a variety of reasons. Possible explanations for such declines are thought to include: repetition of topics from primary school lessons; not using the information sent from feeder schools; teaching to aim the lessons at "the middle or lower third of the class" (Suffolk Education Department, 1997, p. 5); and ignorance of what happens at other levels (Office of Her Majesty's Chief Inspector of Schools, 2002; Ward, 2000). Other studies have identified factors that have a high degree of correlation to the negative aspects of transition but which teachers are unable to influence such as: being of the minority race/ethnicity; lower social class; and disadvantaged gender (Anderson et al., 2000; Barone et al., 1991).

When mathematics alone was the subject for comparison, post-transition, a negative slide in students' attitudes to, and results in, mathematics was found to occur (Galton et al., 1999; Office of Her Majesty's Chief Inspector of Schools, 2002; Mullins \& Irvin, 2000). Evidence in the United Kingdom, focusing on mathematics learning, suggests "that around $40 \%$ of pupils experience a hiatus in progress during school transfer" (Galton, Morrison \& Pell, 2000, p. 341). This pause in progress was thought to be attributable to students' experiences in the mathematics classroom. McGhee et al. (2004) found that world-wide, most secondary mathematics classes are characterised by: a greater emphasis on teacher control and discipline with fewer opportunities for student decision making; being less personal and teacher friendly; and being more likely to use whole class tasks, than primary school mathematics classes. 
In the New Zealand context, Irwin and Niederer's (2002) report to the Ministry of Education, based on a study involving twelve secondary schools and six intermediate schools located in six New Zealand centres, shows that Year 8 students outperform Year 9 students in basic numeracy concepts. In a contrasting New Zealand study, looking at competencies in mathematics, Wylie, Hogden and Ferral's (2006) study of around 500 students in the Wellington region found no evidence from their sample that "the transition to secondary school negatively affected students levels of performance" (p. 75). However, Wylie et al. (2006) added that their unit of measure of performance was different to that used in other studies (e.g. Galton et al., 1999) therefore prior results should not be discounted.

Several New Zealand schools that recognised such a negative impact on students' achievement at transition started a communication process between schools across transition to try to counteract the negative impact of transition (Education Review Office, 2002). The secondary schools involved listened to the feeder schools and used the information gained to provide an environment they believed to be more suited to their new arrivals. This has had a positive effect on students and negated, to a certain extent, the detrimental effect of transition for these students (Education Review Office, 2002).

In their overview of the literature on transition, McGhee et al. (2004) identified factors that affected students during the transition period. These can be split into two general fields: physical aspects of transition (school structure, subject choice, size); and subjective aspects (level of students' engagement, students' feelings towards school, students' views on learning). These aspects of transition can be further delineated into those that occur as a result of the environment and those that occur as a result of the type of instruction used.

The physical and social environment itself is thought to be partly responsible for negative aspects of transition. The physical attributes of the classroom itself may impact on learning. Light, space, and ownership of the classroom are important aspects of a student's environment (Pointon, 2000). Light and space are fixed by the provision of the building but student ownership can be developed. Student ownership of a classroom can occur at the intermediate school as students may have their own desks or work spaces and be part of the decision process regarding what decorates the walls.

In the secondary classroom, a student only possesses a desk for the period of instruction and may not always sit in the same place. The walls may be decorated with some of the student's work but as the classroom is shared by five or more other classes, ownership of 
the wall space is tenuous. This lack of ownership or sense of belonging may impact on the student's enthusiasm and interest in the lesson. A sense of belonging may be augmented at primary or secondary level by the teacher encouraging a community of learning with their teaching strategies.

The social aspects of a school classroom environment may also be detrimental for secondary school students. According to person-environment fit theory alignment between characteristics of people and their environment result in positive outcomes (Sekichuci, 2004). The classroom post-transition is likely to be especially harmful to the student as it is often characterized by competition, social comparison, decreased decision making, lowerlevel cognitive strategies, and disrupted social networks (Eccles \& Wigfield, 1997; Eccles, Wigfield, Midgley, Rueman, MacIver, \& Feldlaufer, 1993; Mizelle \& Mullins, 1997) at a time when adolescents have a growing desire for autonomy, heightened self-focus, increased higher-level thinking abilities, and a desire to belong. The type of strategies teachers use may alleviate the impact of this aspect of transition.

A second aspect to the social adjustment students must make at transition are the teaching strategies used. In the secondary school, because of the specialist subject nature of the teacher, there is a tendency to be focused on examination attainment (Ward, 2000). Teachers tended to spend more time talking and asking students to copy notes at the secondary school than students were used to in the primary school (Ward, 2000, p. 370). Secondary teachers in England were also found to be more likely to use whole class task organisation and between class ability grouping than primary school teachers (Eccles \& Wigfield, 1997). Delamont (1983) in a study of classes after transition found that the schools had instructed the teachers to:

start in basic subjects at a point which was repetitive and too easy for some pupils, while for others it was too hard, too advanced or simply strange (p. 117).

This variation in the lesson content delivery (skills needed, mathematical knowledge required, etc.) can impact on student learning.

A third aspect to classroom social environment is the teacher and how they teach. Whilst a systemic change is inevitable as students move to a secondary school from a primary school, what occurs in the classroom does not have to be such a radical change. Mathematics teachers after transition have been shown to be perceived as less friendly and supportive of students (Midgely, Feldlaufer \& Eccles, 1989) than their primary 
counterparts. The nature of the teacher and the type of teaching has been shown to be one of the main issues for secondary teachers to address post-transition (Cocklin, 1999).

New Zealand secondary school mathematics learning environments were found not always to be conducive to learning.

According to students, reasons for increased disengagement and less positive attitudes to subjects included: having to cope with work that was at an inappropriate level of difficulty; finding subject content irrelevant or uninteresting; finding how they were learning dry and boring; and experiencing learning environments that were not conducive to learning (too noisy or disruptive; relationship issues with teachers or other students) (Ministry of Education, 2008, p. 6).

The students surveyed by the Ministry of Education wanted the work to be less 'copy' and have more variety, with the importance of concepts emphasized.

The New Zealand Ministry of Education (2008) research also highlights the fact that students reported that they often found the work in Year 9 at an inappropriate level of difficulty, and often irrelevant to them. However, in their study only the mathematical skills taught in the lesson were analysed, not the strategies used by the teachers.

Lack of curriculum continuity (secondary teachers ignoring prior learning) has been thought to be a factor in the negative effects of transition (Galton et al., 2000). In a review of research, Galton et al. (2000) found that teachers at all stages of schooling had stereotypical views about what happens at other schools. Generally, secondary teachers were shown not to 'trust' the data provided to them from the primary schools (Evangelou et al., 2008). This often led to a lack of curriculum continuity and Year 9 teachers repeating topics previously learnt by students (Office of Her Majesty's Chief Inspector of Schools, 2002). Research in the United Kingdom has shown teachers' attitudes to be changing as teachers now generally want to have more information and understanding of the different approaches to teaching between primary and secondary school (Evangelou et al., 2008).

In order to improve the communication and therefore the continuity between schools a programme has been trialed in the United Kingdom that covers the transition period, equivalent to that explored in this study. The 'Bridging the Gap' programme (www.coreskills.co.uk, 1998) has tried to influence the teaching strategies across transition by developing learning modules that are taught in the last few weeks of primary school and 
the first few weeks of secondary school. In the few schools in the trial, the modules have been thought to help the transition process by allowing students to have similar learning experiences in their last term at primary school and their first term at secondary school (Birmingham Core Skills Development Partnership, 1998; Evangelou et al., 2008). Similar approaches are increasingly being used to aid multi-lingual students in the United Kingdom, with primary and secondary schools consulting and devising similar schemes of work (Collins \& Harrison, 1999).

Galton et al. (1999) focused on the content of mathematics lessons across transition and not the teaching strategies they used. They attributed the decrease in attitude to boredom (repetition of previous work) or incomprehension (students learning a different method of doing the same thing) as secondary teachers ignored previous learning.

The strategies that teachers use in their classrooms are thought to be accountable at least in part for some of the difficulties students face in transition (Galton, 1983). This aspect is highlighted by an Australian case study of students' transition from a small primary school to a larger secondary school (Cocklin, 1999). Teaching strategies employed at primary and secondary schools directly affected the students' attitude to subjects. "I hated that class so much - I used to put on a sicky and go to sick bay" (Cocklin, 1999, If 14) was a student's response to teaching actions she found off-putting. However, as Clarke (1985) found in a case study, spanning the transition from primary to secondary, a single teaching style would not be sufficient to meet the needs of students entering secondary school mathematics.

How teachers teach is important.

It could be argued that learning is based on what happens in the classroom, and thus, learning is dependent on how the teacher structures the learning environment and not what the student does (Fennema \& Franke, 1992, p. 155).

The importance of the teacher's instructional techniques to maintain motivation after transition is reinforced in a Finnish study (Pietarinen, 2000), in which a student stated:

Teaching has been quite boring at secondary school, quite different from what it was at primary school. At primary school we had more possibilities to take part in action; here it is mainly the teachers who just teach (Pietarinen, 2000, p. 390).

Galton et al. (2000) concluded from their analysis of research into transition that the then current practice had been to look after students socially and personally. They felt that it 
was time to increases focus on curriculum and pedagogy. Whilst more attention is starting to be paid to pedagogical issues at the transition stage (Galton et al., 2003) it has not been researched in New Zealand between Year 8 and Year 9 mathematics classrooms. This study is looking at the teaching strategies used in the Year 8 and Year 9 classroom as a possible reason for the slide in mathematics achievement.

\subsection{Pedagogy}

Pedagogy is the art of teaching. It encompasses all that happens in the classroom, plus the belief system that defines the teacher, their interaction with learners, and the community. It is the determinant of teachers' thoughts and actions and the process through which the production of knowledge occurs (Anderson, 2005; Anthony \& Walshaw, 2007; Brown \& Smith, 1997; Hayes, Mills, Christie \& Lingard, 2006; School of Education, Queensland University, 2001; Sellar \& Cormack, 2006). "Functionally, pedagogy is about teaching in schools" (Anderson, 2005, p. 54). As pedagogy is about teaching, it involves all learning that takes place, both inside and outside the classroom.

Pedagogy must also take into account the ways of knowing and thinking, language, and discursive registers within all the contexts that teaching is embedded. Pedagogy extends beyond the classroom to the family and whannau (extended family), the institution and its governance procedures, and the historical and economic situation of the learners/teachers (Anthony \& Walshaw, 2007).

Anthony \& Walshaw (2007) define an effective pedagogical system as one that includes a non-threatening classroom atmosphere, instructional tasks, tools and representations, and classroom discourse. For the purpose of this research the term 'pedagogy' is defined as those aspects of pedagogy that relate to a teacher's classroom behaviour: the teaching strategies used, in particular teacher talk, equipment use, and activity style. Consideration of the nature of the classroom atmosphere is outside the bounds of this study due to researcher concerns regarding subjectivity, therefore will not be commented on.

\subsubsection{Mathematical Pedagogy}

Mathematical pedagogy involves those teaching strategies that have been shown to be particularly relevant for the teaching of mathematics. Pedagogy as it relates to the teaching of mathematics has been an area of reform in recent years. In the United States teachers in the early nineties were asked to use technology and instructional materials to explain 
concepts, to choose amongst a variety of classroom organisational models, and to involve students in the learning process by use of discourse (Farrell, 1993). Triadic discourse where dialogue has three key parts: "the teacher initiates a question to which the students usually know the answer; a student responds, and the teacher evaluates the student's response" (Zevenbergen, 2000, p. 212) is being discouraged. Constructivism, where the role that activity plays in mathematical learning and development is highlighted, is being promoted. Active construction is encountered when students are engaged in mathematical processes as a way of learning. Strategies that promote constructivism will be discussed more fully in Section 2.5.

The reform movement in the United States is promoting a:

change from traditional classrooms that focus on students acquiring proficiency in reproducing existing solution methods to classrooms that support instructional goals of helping students construct personally meaningful conceptions of mathematical topics (Fraivillig, Murphy \& Fuson, 1999, p. 149).

The New Zealand situation is no different with various reforms being undertaken with the intent of improving mathematics learning. The latest are the introduction of the NDP and a new mathematics curriculum (Ministry of Education, 2007). Anthony and Walshaw (2006) found that the NDP brought with it a new language and teachers experimented with problem-based tasks that changed their beliefs about learning and therefore their teaching of mathematics.

Ball (1993) reinforces that teaching should incorporate "thoughtful consideration of students current ideas and interests" (p. 384). Brown and Smith (1997) observed mathematical pedagogy in their case study teacher. They described his actions as giving students opportunities to think and reason, to discuss their learning, to use multiple representations, and supported student exploration of mathematical ideas. Ball and Bass (2000) in reference to teacher whole class discussions, note that the teacher rather than the students is the decision maker regarding which ideas are developed during the discussion. These teacher talk occurrences are strategies that can involve eliciting and supportive behaviour.

Mathematical teaching practices have been studied in various contexts using instructional activities as a base (e.g., Telese, 2004). The broad terms of these instructional activities were often not defined in detail; however, they may inform further studies including this 
one. Instructional activities may be deemed to be the teaching strategies that a teacher uses in the classroom. The application of a teaching strategy should not be universally applied; as shown by Hayes, Lingard and Mills (2000) in their review of what constitutes 'productive pedagogies'; different situations require different strategies and there is no one 'right' strategy that should be employed.

\subsection{Classroom Instruction}

This section deals with what actually occurs in mathematics lessons. The structure of mathematics lessons and how the teacher creates an environment that promotes mathematics learning are discussed.

\subsubsection{Lesson Structure}

The TIMSS was a project whereby Boston University undertook to collect four yearly data samples from approximately 50 countries. The first year of this four year cycle of data collection was 1995. The 2003 study looked at two groups (10-11 year olds and $14-15$ year olds) and offered comparisons between the two groups. One aspect of their data collection in 2003 included the instructional practices teachers used in the classroom. The TIMSS 2003 study (Mullis et al., 2004) found that across all countries:

the three most common instructional activities were teacher lecture, teacher-guided student practice, and students working on problems on their own (Mullis et al., 2004, p. 10).

Similarly Stigler and Hiebert (1999) compared worldwide teaching patterns and found that the structure of a mathematics lesson was fairly universal across teachers. Classes reviewed previous material, the problems for the day were presented, and then the students solved the problems.

Lesson instruction can be split into three phases: pre-active (planning); interactive (monitoring and regulating); and post-active (assessing and revising) (Artzt \& ArmourThomas, 1998). The pre-active phase is typified by the schemes and lesson plans that teachers use. The interactive phase was observed in this research to analyse teaching strategies. The actual work of the classroom is in the activities chosen and these are a direct result of the teaching strategies the teachers are predisposed towards.

The TIMSS 2003 study (Mullis et al., 2004) found that activities presented in the classroom were relatively international but the strategies employed by teachers in engaging 
students with an activity varied. What varied in different countries was the role these activities played. In Germany, the presentation of the problem involved a long development of a solution procedure by the whole class with guidance from the teacher. In Japan, students worked individually or in groups to solve the problem with little teacher direction. In the United States, the teacher presented the problem, showed the solution, and then the students practised similar problems.

The teacher's choice of activity has a significant influence on the promotion of mathematical thinking:

the most productive tasks and activities are those that allow students to access important mathematical concepts and relationships, to investigate mathematical structure, and to use techniques and notations appropriately (Anthony and Walshaw, 2007, p. 3).

The expectation of this study was that the structure of the lessons would be similar in New Zealand to world teaching patterns (i.e. review, new problems, and student practice). Year 8 and Year 9 classrooms would therefore follow comparable formats and any differences present were expected to be in the teaching strategies used to develop mathematical concepts.

\subsubsection{Nature of the Mathematics Classroom}

How teachers talk to students also has an impact on how students react to their teachers. In a review of teacher-initiated teacher-pupil dialogue in England by Kyriacou \& Issit (2008), based on 15 studies, found that traditional initiation-response feedback (subsequently referred to as IRF) dominated in mathematics classrooms at Key Stage 2 and 3 (ages 8 14). IRF is a classroom dialogue where the teacher initiates a dialogue, the student responds, and the teacher gives feedback. This can lead to teachers asking questions that Cazden (2001) deems 'inauthentic'. The questions asked by teachers often are used to test students' knowledge and are used to break what would otherwise be a teacher lecture. This type of questioning is referred to in the analysis chapters of this study as right/wrong questions.

Boaler and Greeno (2000) found that many mathematics classrooms were didactic. Didactic classrooms they defined as those in which student participation is defined by using text books, rules, and procedures. Students are presented with easily solved problems and procedures of how to solve them; they are not engaged by the teacher in any mathematical thinking. 


\subsection{Teaching Strategies}

The classroom is a place of learning. How learning is facilitated is the responsibility of the teacher and the strategies they use. The instructional approach used by a teacher ultimately determines how much and what kind of mathematics a student learns (Mullis et al., 2004).

How the ACT research (Fraivillig, Murphy \& Fuson, 1999) impacts on this study is outlined in Section 2.4.1. The categories for teaching strategies developed by the Productive Pedagogies research (Ailwood et al., 1999; School of Education, University of Queensland, 2001) are explained in Section 2.4.2. Further categorisation of teaching strategies was made using the Mathematics BES study (Anthony \& Walshaw, 2007).

Both the ACT and QSRLS studies and the Mathematics BES report highlight the relationship between mathematical thinking and teaching strategies. In developing the observation tool for this study the definitions provided by the ACT components of teaching strategies were linked to the QSRLS productive pedagogies and evidence of effective teaching synthesised in the Mathematics BES. Table 2.1 shows the links between ACT categories, the QSRLS productive pedagogies, and the Mathematics BES definition of an effective teacher. Components of the table will be further discussed in Sections 2.4.1, 2.4.2 and 2.4.3.

Table 2.1: Outline of major studies that informed categorising teaching strategies in this study

\begin{tabular}{|l|l|l|}
\hline $\begin{array}{l}\text { Advanced Children's } \\
\text { Thinking (Fraivillig, Murphy } \\
\text { \& Fuson, 1999) }\end{array}$ & $\begin{array}{l}\text { Productive Pedagogies } \\
\text { (Ailwood et al., 1999; } \\
\text { School of Education, } \\
\text { University of Queensland, } \\
\text { 2001) }\end{array}$ & $\begin{array}{l}\text { Best Evidence Synthesis } \\
\text { (Anthony \& Walshaw, } \\
\text { 2007) }\end{array}$ \\
\hline $\begin{array}{l}\text { Eliciting } \\
\text { - eliciting many solutions } \\
\text { to one problem } \\
\text { conveying an accepting } \\
\text { attitude towards student } \\
\text { efforts } \\
\text { promoting collaborative } \\
\text { problem solving } \\
\text { monitoring student } \\
\text { engagement }\end{array}$ & $\begin{array}{l}\text { Analysing and building } \\
\text { on students existing } \\
\text { conceptions }\end{array}$ \\
$\begin{array}{l}\text { using student } \\
\text { explanations as part of }\end{array}$ & & \\
\hline
\end{tabular}




\begin{tabular}{|c|c|c|}
\hline the lesson & & \\
\hline 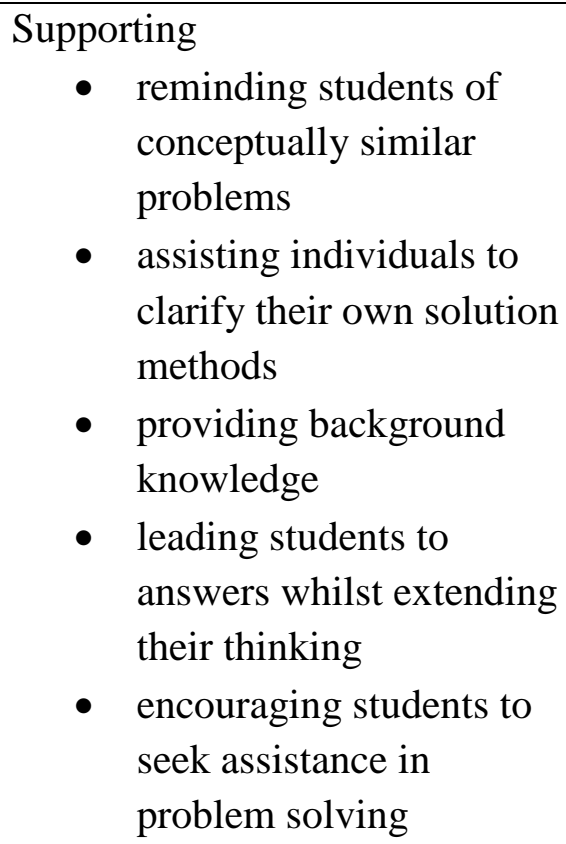 & $\begin{array}{l}\text { Supportive classroom } \\
\text { environment } \\
\text { - } \text { students are all } \\
\text { engaged in } \\
\text { mathematics } \\
\text { - } \text { their behaviour is on } \\
\text { task and self- } \\
\text { regulating } \\
\text { - } \text { where the pace of } \\
\text { work is set by the } \\
\text { students } \\
\text { where the students } \\
\text { are all engaged in } \\
\text { mathematics }\end{array}$ & $\begin{array}{l}\text { Creating and supporting } \\
\text { a learning community }\end{array}$ \\
\hline \multirow[t]{2}{*}{$\begin{array}{l}\text { Extending mathematical } \\
\text { thinking } \\
\text { - } \quad \text { setting high standards } \\
\text { and expectations of all } \\
\text { students } \\
\text { - encouraging students to } \\
\text { generalize } \\
\text { - encouraging students to } \\
\text { see relationships } \\
\text { between concepts } \\
\text { - cultivating a love of } \\
\text { challenge, by } \\
\text { selecting/using tasks that } \\
\text { foster students' } \\
\text { conceptual advances. } \\
\text { promoting alternative } \\
\text { and efficient solution } \\
\text { methods }\end{array}$} & $\begin{array}{l}\text { Intellectual quality: } \\
\begin{array}{l}\text { - } \\
\text { the students are } \\
\text { primarily engaged in } \\
\text { lower-order thinking } \\
\text { tasks (e.g. recitation } \\
\text { of fact, repetition of } \\
\text { algorithms) or } \\
\text { higher-order } \\
\text { thinking (e.g. } \\
\text { manipulation and } \\
\text { transformation of } \\
\text { information) }\end{array}\end{array}$ & $\begin{array}{l}\text { Selecting/using tasks that } \\
\text { foster students' } \\
\text { conceptual advances }\end{array}$ \\
\hline & $\begin{array}{l}\text { Connectedness } \\
\text { - } \text { content extends } \\
\text { beyond a } \\
\text { mathematical } \\
\text { context } \\
\text { - includes the } \\
\text { students' } \\
\text { background } \\
\text { experience } \\
\text { - is based on real-life }\end{array}$ & $\begin{array}{l}\text { Making sense of } \\
\text { mathematical ideas to be } \\
\text { taught }\end{array}$ \\
\hline
\end{tabular}




\begin{tabular}{|l|l|l|}
\hline & situations. & \\
\hline & Recognition of difference & \\
evidenced by & \\
$\bullet$ & attempts to include & all students in \\
& problems & \\
- & attempts to include & diverse cultures \\
& present in problems & \\
& a narrative or & \\
& expository teaching & \\
style. & \\
\hline
\end{tabular}

\subsubsection{Advanced Children's Thinking}

In their study on how teachers' instructional practices could advance mathematical thinking, Fraivillig et al. (1999) categorized strategies used in the classroom by splitting them into three main components (Table 2.1). This was an extension of the Cognitively Guided Instruction group's ${ }^{5}$ work. The ACT framework is fundamental to the initial analysis of the first aspect of this study, teacher talk.

Teacher talk may incorporate an eliciting strategy by eliciting many solutions to one problem, encouraging elaboration from students, promoting collaborative problem solving, conveying an accepting attitude towards student efforts, monitoring student engagement, or using student explanations as part of the lesson. A supportive teaching strategy may remind students of conceptually similar problems, provide background knowledge, assist individuals to clarify their own solution methods, lead students to answers whilst extending their thinking, or encourage students to seek assistance in problem solving. In extending mathematical thinking, a teacher may set high standards and expectations of all students, encourage students to generalize, encourage students to see relationships between concepts, promote alternative and efficient solution methods, and cultivate a love of challenge by selecting/using tasks that foster students' conceptual advances (Fraivillig et al., 1999).

\footnotetext{
${ }^{5}$ The Cognitively Guided Instruction (CGI) group identified types of teacher knowledge essential to creating a mathematics classroom in which constructivism is promoted (Carpenter, Fennema, Peterson, Chiang, \& Loef, 1989).
} 


\subsubsection{Productive Pedagogies Examined}

The QSRLS study focused on what was occurring in the classroom to promote mathematical learning and termed the beneficial pedagogies they observed 'productive'. The QSRLS study split pedagogies (classroom teaching strategies) into the areas of intellectual quality, connectedness, supportive classroom environment, and recognition of difference (Ailwood et al., 1999; School of Education, University of Queensland, 2001). The productive pedagogies framework has been used as a successful base in studies of teacher voices (e.g., Mills \& Goos, 2007). Similarly, the categories defined are also likely to be useful in this research for analysing the data across all three areas (teacher talk, equipment use, activity style) as they relate closely to teachers' classroom behaviour.

The intellectual quality of the classroom is shown by whether the students are primarily engaged in lower-order thinking tasks (e.g., recitation of fact, repetition of algorithms) or higher-order thinking (e.g., manipulation and transformation of information) (Hayes et al., 2006). Connectedness is shown when the lesson content extends beyond a mathematical context, includes the students' background experience, and is based on real-life situations. A supportive classroom environment would be one where the students are all engaged in mathematics, their behaviour is on task and self-regulating, and where the pace of work is set by the students. Recognition of difference would be evidenced by attempts to include all students, diverse cultures being present in problems, and a narrative or expository teaching style.

\subsubsection{Best Evidence Synthesis}

Anthony and Walshaw (2007) identified teaching strategies deemed effective in increasing student performance. The effective pedagogies were categorized into four principle activities of teaching:

(a) creating and supporting a learning community; (b) analysing and building on students' existing conceptions; (c) making sense of mathematical ideas to be taught; and (d) selecting/using tasks that foster students conceptual advances (Anthony \& Walshaw, 2007, p. 177).

\subsubsection{Other Pedagogic Frameworks}

Further New Zealand and international mathematics education literature has also helped inform this study. 
'Authentic pedagogy' was a term coined in the United States to incorporate those aspects of classroom teaching that allow student performance to be enhanced (Newmann, Marks \& Gammoran, 1996, p. 289). It is characterized by classroom instruction that allows: higher order thinking; substantive conversation; deep knowledge; and connections to the world outside the classroom. Teachers pedagogical content knowledge (Shulman, 1987, p. 17) is important for them to use to carry out the multitude of decisions involved in classroom instruction. A longitudinal Australian study of 311 students found that pedagogical emphasis on cooperative learning with a contextual framework, alongside the implementation of a constructivist way of teaching caused positive outcomes for student achievement and engagement across a transition period similar to that researched in this study (Hine, 2001, p. 221). What is evident from these studies is that teaching strategies have been internationally categorized into similar areas.

The United States National Mathematics Advisory Panel (2008) reported on instructional practices in American mathematics classrooms. They identified core practices for further study that included practices that elicited student thinking, posing problems to start discussions, monitoring student participation, and making sense of students' thinking (Borko \& Whitcomb, 2008).

\subsubsection{Teaching Strategy Summary}

The importance of quality teaching is emphasised by Hayes et al. (2006) in their summary of productive pedagogies. The effect of pedagogy on performance was researched and when all other factors were held constant, it was found that the teacher's pedagogical practices made a difference to student achievement. Consistency of pedagogical practices across transition could be an important aid to students.

The ACT study (Fraivillig et al, 1999), the QSRLS (School of Education, University of Queensland, 2001), and the BES iteration: Effective Pedagogies in Mathematics (Anthony \& Walshaw, 2007) all identify similar aspects to the strategies teachers use in the classroom. For the purposes of this study the categories of teaching strategies identified have been heavily drawn from those identified in these studies (Appendix 1).

\subsection{Pedagogical Choices}

How a teacher chooses to deliver a concept, an idea, or teach a new skill is the pedagogical choice they make each lesson or each part of a lesson. The choice they make may be based 
on a combination of their beliefs and training (Section 2.5.1). Pedagogy may be dictated by the country they teach in and may be prescribed by the education authority. The particular context for New Zealand teachers is described in Section 2.5.2.

\subsubsection{Predisposition to a Strategy}

The strategies that teachers use may be influenced by a large domain of theories: cooperative learning, accelerated learning, cognitive coaching, and teaching for understanding to name a few. Teachers' actions are likely to be a result of their pedagogical content knowledge and their belief systems (Peterson et al., 1989). Teachers' beliefs and the way they teach are formed by a process started when they first entered the school system and that will finish when they stop teaching (Archer, 1999; Pajares, 1992).

According to Thompson (1992) there are four dominant views of how mathematics should be taught:

- learner focused (with an emphasis on the learner construction knowledge);

- content focused (with an emphasis on conceptual understanding);

- content focused (with the emphasis on performance);

- and classroom focused (with the emphasis on having an effective classroom).

Zevenbergen (2000) found that many English teachers in her study used mostly triadic dialogue in the opening and closing phases of the lesson and routine exercises undertaken by the students lead her to the conclusion that many teachers' beliefs about mathematics were based on behaviourist ideas.

The professional community in which teachers operate can affect the type of teaching strategies they use. A professional community plays a significant role in creating standards for teaching and expectations of student performance (Hayes et al., 2006). Louis, Marks and Kruse (1996) in an American study, found that a school-wide professional community was more likely to be present in primary schools. In American secondary schools, Talbert and McLaughlin (2001) found it was the department that was often responsible for establishing common teaching strategies. The most common department-wide pedagogy that Talbert and McLaughlin saw evidence of was traditional teacher-centred strategies.

Teachers' strategies may also be influenced by the curriculum orientation of the school. A vocational/neoclassical orientation where school is thought to be preparation for work; liberal/progressive approach where an autonomous member of society is the outcome of 
schooling; and socially-critical perspective where the school and community interact to produce socially critical and reflective citizens, all bring their own slant to classroom teaching (Kemmis, Cole \& Suggett, 1983).

It is not the purpose of this research to look at the underlying theoretical base or belief system of teachers or schools but to look at what is actually happening in mathematics classrooms. However, it is useful to consider the environmental and other factors which may impact on these decisions, particularly when considering the implications of the findings of this study. Cohen, Raudenbush and Ball (2003) define teaching as:

what teachers do, say and think with learners, concerning context in particular organizations and other environments, in time (p. 126).

This research is confined to what teachers do and say in the classroom situation.

\subsubsection{New Zealand Teaching Strategy Context}

The context of research into teaching strategies in New Zealand schools must acknowledge the NDP as the degree to which the school has undertaken NDP professional development may also influence the strategies the mathematics teachers use.

The NDP was introduced into some New Zealand primary schools in 2000 with the aim of expanding it to all primary schools. A gradual introduction into New Zealand secondary schools started in 2005. The NDP development followed intensive research into how to improve New Zealand students' understanding of Numeracy and it has impacted on teaching practice (e.g., Thomas \& Ward, 2001). Some New Zealand NDP teachers have changed their classroom programmes as a result of their increased mathematical and pedagogical knowledge (Thomas \& Ward, 2001). The teaching resources used alongside the NDP give explicit instructions to teachers regarding the kind of strategy that could be used to teach a topic (e.g., Alphabet Soup, at www.nzmaths.co.nz/numeracy/SNP/TeachingActivities.aspx).

The NDP professional development also aids the teacher by demonstrating best practices. When first introduced, "appropriate teaching methods were suggested and modelled by the facilitators" (Irwin \& Niederer, 2002, p. 13). The use of in-school facilitators ensured that teachers changed their practices to incorporate new numeracy strategies (Higgins, 2002; Ward, Thomas \& Tagg, 2006). Irwin and Woodward (2004) found that teachers who were involved in the Numeracy Project assessment interviews tended to carry over the questioning technique to elicit information used in those interviews into their classroom 
teaching. This meant a change in classroom discourse from primarily that of explaining and questioning to discourse that justified and challenged reasoning (Anthony \& Walshaw, 2006).

The studies on the impact of the Numeracy project show a shift away from teaching algorithmically towards a focus on students' mental strategies. The impact of the NDP on the teaching strategies used may include more use of equipment and more use of questioning and students' explanation in instruction (Thomas \& Ward, 2001). The teacher's choice of equipment may also be influenced by their orientation to mathematics. A conceptual and dialogue-style approach to mathematics as advocated by the NDP places more emphasis on the use of tools and equipment to highlight number properties (Higgins, 2004) than previous practice. The intermediate classrooms in this study are involved in the NDP and may therefore show teaching strategies influenced by the NDP. The secondary school classrooms may be unaffected by the NDP as the secondary school in this study has yet to engage in the NDP.

The New Zealand Curriculum document (Ministry of Education, 2009) defines what content is taught in mathematics classrooms. In this it is similar to most of the countries in the TIMSS study. Curriculum documents are "often supported by ministry directives, instructional guides, school inspections, and recommended textbooks" (Mullis et al., 2004, p. 7). In New Zealand, the latest curriculum document (Ministry of Education, 2009) encourages specific teaching strategies by stating that:

Students learn best when teachers

- Create a supportive learning environment

- Encourage effective thoughts and actions

- Enhance the relevance of new learning

- Facilitate shared learning

- Make connections to prior learning and experiences

- Provide sufficient opportunity to learn

- Inquire into the teacher-learner relationship (p. 36).

The curriculum focus for teachers' over-riding pedagogy is not necessarily consistent with individual teachers' use of particular strategies. 


\subsection{Comparison Between Year Levels}

The comparison between Year 8 and Year 9 classroom practice is valuable as it is in the classroom that individualized teaching strategies are evident. As a unit of comparative study the classroom has not to date been a prominent feature (Mason, 2007, p. 112) and therefore looking at teaching strategies based on the classroom unit is important. The individual strategies of the classroom teacher as a focus of research are relatively new (Mason, 2007).

\subsubsection{Teaching Strategies}

A report commissioned by the New Zealand Education Review Office (subsequently referred to as ERO) in 2006 studied the design and implementation of mathematics programmes in Year 4 and Year 8 classrooms. ERO compared Year 4 and Year 8 teachers' subject and pedagogical knowledge and how they applied this to deliver an effective mathematics programme. Their conclusion was that "There was no statistically significant difference between the two groups of teachers" (ERO, 2006a) in how they applied their subject and pedagogical knowledge to mathematics teaching. The 2006 ERO report also quotes an earlier internal Ministry of Education report that:

The quality of teaching has been identified as potentially the largest single schooling system influence on student achievement, accounting for between 16 and 60 percent of the differences in student achievement in schooling (Ministry of Education , 2002, p. 94).

The 2006 ERO study was focused solely on primary classrooms; this study also examines secondary classrooms.

\subsection{Summary of Relevant Literature}

It has been shown that transition can cause students to display a decrease in achievement, motivation, and engagement in mathematics (Section 2.1). Factors that may negatively impact on students at the transition stage include repetition of topics from primary school, secondary schools not using information from feeder schools, and students' experiences within the mathematics classroom. How teachers teach, the strategies teachers employ to deliver mathematical content, and the pedagogical framework from which teachers operate have been found to be key factors in effective mathematics teaching. Whether or not teaching strategies differ across the transition period in New Zealand classrooms is important to explore and is the focus of his study. 


\section{Chapter 3: Method}

This chapter outlines how the research was conducted, the methodological approach for the study, and its rationale (Section 3.1). Aspects of the research participants' background (age, years of experience, training) that may impact on the teaching strategies they use in the classroom are outlined in Section 3.2. Details of the selection process for participants in this research and the final selection of participants: the schools and the teachers involved in this study are given in Section 3.3. The processes used for data collection, collation, and analysis are elaborated in Section 3.4.

\subsection{Methodological Approach}

This study is a naturalistic qualitative one with some quantitative analysis. It is naturalistic in that the major data collection was undertaken during normal teaching situations and because naturalistic enquiries are well suited to a comparative study (Cohen, Manion \& Morrison, 2007, p. 170). It is qualitative in that the data sought comprised teachers' behaviours (teaching strategies used) and this is data of a non-numeric and nonquantifiable character. Qualitative research is described by Denscombe (2004, p. 267) to be concerned with patterns of behaviour and the data generated is the result of interpretation. Interpretation occurs when the data is categorised and the categories must be sufficiently precise so that another researcher could categorise in the same way,

The basis of the research is a comparative study between two year groups across a transition stage (as outlined in Section 1.2) and therefore in this New Zealand context, two schools. The transition stage is from Year 8 to Year 9, and the schools involved are an Intermediate School (Years 7 and 8) and a Secondary School (Years 9 to 13). The underlying research paradigm is an interpretivist one. This involves explaining the ideas generated from the data by use of previous research and showing how the findings of this research are important (Bogden \& Bilken, 2007, p. 159).

According to Cohen et al. (p. 167, 2007) behaviour is "socially situated, contextdependent, and content-rich". To make sense of the data generated by observation of behaviour (in this instance, teaching) the situation that causes the behaviour must be understood. The context of teaching in New Zealand has been explained in Section 2.5.2. 
This particular research is centred in ethnography by comparing how the teachers in different "cultures' ${ }^{6}$ react to the teaching of mathematics. Intermediate and secondary schools can be considered two distinct cultural entities because of the age range of the students, structure, and organization of the schools. The culture of a school can be an important factor in the type of teaching that occurs. It was therefore important in trying to analyse similarities and differences between Year 8 and Year 9 mathematics classrooms, that the research situation be as close as possible to normal teaching. By observing the classrooms, without being a participant, the normal behaviour of the teacher can be observed. For the purposes of this research the action of teaching is the type of strategies used in teaching mathematics. These strategies are those defined in Section 2.4 and categorised in Appendix 1.

The underlying study method is that of a survey, involving video-taped lesson observations, semi-structured interviews, and document inspection (Denscombe, 2007). A survey is a snapshot of a particular situation at a particular point in time. This study involves the video observation of three mathematics lessons of each of six teachers, three teachers at the intermediate level and three at the secondary level.

Videoing as a method of data collection was chosen for the following reasons. It allows an accurate record of what occurred in the classroom and provides the ability to go back and revisit what has been observed and to share the same reality with another researcher if necessary (Pirie, 1996). The intrusion of video recording and the camera effects that may result from being video-recorded have been demonstrated to wear off quickly if students and teachers are informed about the process (Good \& Brophy, 2003; Jordan \& Henderson, 1995). In order to limit any observer-effects: students and teachers were informed that videoing would occur; the videoer was as unobtrusive as possible; and three lessons with each study teacher were recorded.

What videoing did not allow for were stoppages during the lesson for researcher questions regarding what a teacher was doing at a particular stage in the lesson. This problem was resolved by the use of semi-structured interviewing. A semi-structured interview was carried out both prior to and post-videoing to ascertain any underlying philosophical stance of the teachers involved which predisposes them to the use of particular strategies

${ }^{6}$ Culture can be defined as 'The predominating attitudes and behaviour that characterize the functioning of a group or organization' (American Heritage ${ }^{\circledR}$ Dictionary retrieved April 5, 2009). 
(examples of questions are in Appendix 2). The post-videoing interview also allowed the researcher to clarify any points raised during the observation period, e.g., how often were manipulatives used?

Schools can try to encourage a particular way of lesson delivery on their teachers (Section 2.5). To see if this was relevant to understanding the teaching strategies of the particular teachers in this study a document inspection was carried out. The document inspection was a comparison of the written schemes (planning documents) that the teachers were given at the two schools from which to develop their lesson plans (data from these is in Appendix 2).

\subsection{Pilot Study}

Prior to starting this research, the data gathering methods were trialed in secondary and intermediate schools other than those involved in the final research. One teacher in the secondary pilot school and two teachers in the intermediate pilot school were observed using the draft observation schedule. The original intention was to allocate teaching strategies to categories whilst the researcher was observing the lesson. Examples of each strategy would be annotated on the data recording sheet. Whilst this worked reasonably well in the secondary school situation, it was unwieldy and impossible for the researcher to do in the intermediate school because students in the intermediate school were split up into groups during the lessons (which involved movement from their original desks), moved from their desks to the mat, and brought their work to the teacher for comment.

It became obvious to the researcher that collection of the data would be too difficult without an audio recording. Further reflection on the purpose of the research (teaching strategies used) suggested that a video recording of the teacher followed by a semistructured interview regarding points on the video, if needed, should be used. A video recording would enable the researcher to use an adaptation of Bloom's (1954) stimulated response technique (as cited in Edwardes-Leis, 2006), and therefore clarify what strategies were being used by the teacher. It was found that an unstructured discussion with each teacher was sufficient to clarify any points necessary.

The teachers in the pilot schools were given a questionnaire that was designed to find the underlying belief system that framed the teacher's pedagogy. After reflection on the 
questionnaire data gathered, the questionnaire was not used in the final research as it focused on teachers' perception of their strategies and not necessarily their actual practice.

What the pilot did show was that a permanent record of the lesson was needed to identify all of the teaching strategies being used. The use of video recording was then trialed at the pilot secondary school. This enabled the researcher to work out where to stand to minimise her impact on the teacher and class but ensure that all the teaching strategies were recorded. A trial analysis of the video recording data helped clarify the categories used in the analysis of the final study data.

The two teachers observed at the pilot intermediate school both used different teaching strategies. This highlighted the need that more than one teacher should be observed at each study school.

\subsection{Research participants}

The intent of this research was not to generalise to the whole population but to focus on several particular Year 8 and Year 9 mathematics classrooms, and possibly to inform the teaching practices of those involved. The data itself is non-parametric and therefore cannot be used to make assumptions about populations (Denscombe, 2007). However, the results may shed light on the characteristics present in similar teaching situations.

\subsubsection{Study: Schools}

From each of the two schools, three teachers were videoed teaching their normal mathematics programme. The purpose of this was to a) combat a potential bias of choosing a teacher whose teaching strategies are anomalous to the rest of their peers and b) to allow a range of levels of mathematics ability classes to be observed. Three lessons with each teacher were recorded to allow both students and teacher to relax in the researcher's presence, thereby reducing reflexivity (impact on behaviour caused by the researcher). To further reduce reflexivity, the researcher was not a participant in the class, and tried to be as unobtrusive as possible to minimise the effect being observed may have on classroom practice. Another reason for three lessons is that data needed to be collected over different lessons to minimise the chance of a 'one-off' lesson using strategies atypical of normal classroom practice being observed. 
Schools and teachers were selected using 'non-probability sampling, purposive sampling' (Cohen et al., 2007, p. 113). Whilst this sampling is biased it still allows the 'full scope of issues to be explored' (Cohen et al., 2007, p. 168). Purposive sampling was used in order that the secondary study school would be the researcher's own school, where the researcher is a Co-Head of Department. The reasons for choosing the researcher's own secondary school were twofold, ease of access and the ability to use the research to lead professional development for the 2009 year. If a Year 9 teacher better understands what happens in the Year 8 classroom and vice versa, then an improvement in the transition to a Year 9 mathematics environment may occur.

It was important that the schools used were linked across the transition phase therefore the intermediate school needed to be one of the main contributing schools of the secondary study school. There are three intermediate schools that could have been used for this purpose. The school in closest proximity to the researcher was approached, was pleased to have been asked, and seemingly delighted to be involved. The intermediate school used contributes approximately $20 \%$ of the Year 9 population of the secondary school roll.

The secondary school in this study is classified as a mid-decile school. It is an urban, coeducational school. The city it is situated in has a population of approximately 26,000 people (Statistics New Zealand, 2009). It is the only co-educational school within the city boundaries. Possibly due to a favourable $\mathrm{ERO}^{7}$ report in 2006 coupled with an increase in the population of the urban area it is situated in, the school has increased in popularity. The students are therefore drawn from across the wider community, including the urban area in which the intermediate school used is situated. An enrolment policy is in place to limit enrolments. Due to building limitations the secondary study school is capped at approximately 800 students and in 2008 had fewer than that (tki.org.nz, 2009a). The current school ethnicity mix is mainly New Zealand European with approximately $10 \%$ New Zealand Maori and few other ethnicities, (ERO, 2006b).

The intermediate school is in a slightly different urban area from the secondary study school and is a high decile school. It draws from a community of twelve thousand (Statistics New Zealand, 2009), though it also draws from a wider urban area than its immediate community. In 2008 it had approximately 600 students (tki.org.nz, 2006b). The

\footnotetext{
${ }^{7}$ ERO is a department of the New Zealand government that evaluates the effectiveness of a school.
} 
ethic mix of the intermediate school is similar to that of the secondary school, with mainly New Zealand European, 10\% New Zealand Maori, and few other ethnicities (ERO, 2006b)

Both study schools have relatively stable teaching staff with small annual turnover. Both have, however, had a new principal within the last year. The communities of the two schools are dissimilar in income but that does not detract from the validity of the study because the movement of students between the two schools still occurs. It may emphasise where more work in transition is needed.

\subsubsection{Study: Teachers}

At the secondary study school, all teachers of Year 9 were asked if they would like to participate in the research. All said yes, so selection was made by the researcher purely on when teachers had their Year 9 classes. If two teachers had Year 9 classes in the same time slots each week then only one of those teachers was chosen. A range of age, experience, and ability level of class were also considered as factors. The three teachers eventually chosen were a male teacher with over 30 years, and another male teacher who has over 15 years teaching experience. The third participant was a female teacher who was in her second year of teaching. The classes observed ranged from the third to the sixth ranked class (currently at the secondary school, Year 9 classes are streamed on general academic ability and ranked from one to seven). The study teacher's gender is mentioned here as background but was not considered as a factor in this study due to small sample size.

The teachers from the intermediate school were chosen by the Deputy Principal. His intention was to ensure a range of levels but also to choose teachers who would not be affected by having their teaching videoed. This resulted in the intermediate school study teachers being confident teachers of mathematics (lead teachers for the numeracy programme in their school). The classes ranged from the top mathematics class to the bottom class. Two males and one female were observed, they were all experienced teachers, and one had previously taught in the secondary system for over two years.

The above information is presented in tabulated form (Table 3.1) for ease of reference. Each teacher has been given a number to identify their voices in the vignettes in Chapters 4 and 5 . 
Table 3.1: Breakdown of teachers selected

\begin{tabular}{|l|l|l|l|l|}
\hline \multicolumn{1}{|c|}{ School } & Number & \multicolumn{1}{|c|}{ Gender } & \multicolumn{1}{|c|}{ Experience level } & \multicolumn{1}{c|}{ Level of Class } \\
\hline Secondary & 1 & Male & $30^{+}$years & Mid-low band \\
\hline Secondary & 2 & Male & $15^{+}$years & Mid-high band \\
\hline Secondary & 3 & Female & Less than 2 years teaching & Mid-band \\
\hline Intermediate & 4 & Male & $35^{+}$years & Top stream \\
\hline Intermediate & 5 & Male & $25^{+}$years & Second stream \\
\hline Intermediate & 6 & Female & $10^{+}$years & Bottom band \\
\hline
\end{tabular}

\subsubsection{Study: Lessons}

In an attempt to limit the effect on teachers' practice of video taping, the lessons, where possible, were consecutive. The secondary school time table meant that up to three teachers could be videoed on the same day. No teacher in the secondary school had all their mathematics classes at the same time of the day. This meant in the secondary school a variety of lesson times were videoed. Due to the variation in times of lessons for different days of the week, the lesson lengths varied from 50 minutes to 60 minutes.

In the intermediate school, mathematics occurred in the same time slot four days a week with a variation because of outside influences (e.g., music) on one day. This meant that the teachers could not be videoed concurrently but that the time of day for the lessons was consistent. Lessons at the intermediate were generally 45 minutes but some variation occurred because of school events. Both schools allocated students to mathematics classes based on academic ability.

The content of the lessons varied between the schools as they were both teaching different strands ${ }^{8}$ from the New Zealand Curriculum. The lessons observed in the secondary study school were all on the same strand of the mathematics curriculum: Geometry. The lessons varied in content as each teacher was at a slightly different stage in their delivery of the topic. The lessons in the intermediate study school had more variety of content. The lesson content therefore ranged from learning to tell the time, to exploration of the relationship between different types of proportionality, to adding and subtracting integers.

\footnotetext{
${ }^{8}$ The NZ Mathematics curriculum (Ministry of Education, 1992) is currently separated into 6 strands: Number, Algebra, Measurement, Statistics, Mathematical Processes, and Geometry.
} 
How the lessons were structured at the intermediate school varied between the teachers. One of the teachers at the Year 8 level differed from their colleagues by the use of small groups. After initial common work on a revision problem the class split into three groups. One group worked with the teacher on new work, one group worked out of a text book on individualised work, and the third group worked on practical tasks with a teacher aide. ${ }^{9}$ This class had the luxury of two teacher aides and was the bottom streamed class in the intermediate, so had the students who most struggled with mathematics.

The other two teachers at the Year 8 level used whole class teaching with individual work as a starter for the lesson. One of these teachers did have the class split at some stage during the lesson into groups of three to solve Mathletics ${ }^{10}$ questions. This was not group work related to the lesson of the day but rather a way of promoting problem solving skills in a specific way.

All of the Year 9 study teachers used a similar lesson structure of starter questions, whole class teaching followed by individual practice.

\subsubsection{Ethics}

This research was conducted following the ethical guidelines laid out by the New Zealand Association for Research in Education (1998). Ethical approval for this study was given by the Victoria University Faculty of Education. Each participant school's Principal was given a letter of information and a consent form (Appendix 5). The letter of information contained information about the research and its intent. The consent form clearly outlined what was required from each participating school or teacher. The participant teachers were also given a letter of information and a consent form (Appendix 5).

As this study did involve the video taping of teachers and their classrooms, students were also captured on tape. To ensure this incidental videoing of the students did not interfere with their rights a letter of information and a consent form was given to each student in the class (Appendix 5). The students and their care givers both signed the form. The participating teachers handed these forms out to the students and were responsible for their collection. In the intermediate school the principal also sent a letter home explaining the purpose of the researcher videoing in the classroom. Students, who did not consent to take

\footnotetext{
${ }^{9} \mathrm{~A}$ teacher aide is a paid helper in the classroom. They are not qualified teachers but are trained to assist the class room teacher, given guidance and direction by the class room teacher.

${ }^{10}$ Mathletics is a competition to find which team can solve a series of mathematics problems fastest.
} 
part, were not videoed. Any names mentioned in the analysis are pseudonyms and to preserve their anonymity no real names of students, teachers, principals, or schools have been used.

\subsection{Data Collection Process}

The lessons video taped were not necessarily consecutive but videoed in close succession to allow both teachers and students became accustomed to being videoed. The video was then transcribed, ignoring students' comments because it was the teacher's words and actions that were the focus of this study. This research is interested in teaching strategies and therefore during the video taping of the lesson the researcher aimed to record all behaviour relating to teaching strategies by the teacher. What was not recorded on the video (e.g., actual activities the students undertook) was recorded as field notes attached to the video. All the participant teachers were videoed by the same person to ensure consistency of data recording.

The systematic observation used enabled the naturalness of the setting to be preserved. This was done by videoing unobtrusively from the back of the classrooms, trying not to interact socially with the teachers during the actual lesson, and by being in the classroom for three lessons so the teachers all became accustomed to being videoed (Denscombe, 2004; Good \& Brophy, 2003).

It should be noted that the actual time recorded for each lesson varies as the lessons in the secondary study school were 50,55 or 60 minutes in length dependent on the day observed whilst the normal lesson time in the intermediate study school was 45 minutes. One of the observed lessons in the intermediate study school was shortened due to a rearrangement of their day because of a school group visiting.

After videoing had been totally completed the teachers were asked for a copy of any written schemes that they were given by the person in charge of mathematics at the school from which they derive their lessons. The schemes were analysed to see if any directives as to teaching strategies were given (Appendix 4). 


\subsection{Analysis Techniques}

The lesson transcripts were split into components to aid the analysis process: start of the lesson when students first arrived in the room (starter questions ${ }^{11}$ ); whole class teaching; and individualised work periods. The transcribed lessons were analysed using a content analysis approach. Content analysis is a way of processing data that utilises a rigorous set of rules. According to Cohen et al. (2007) content analysis "uses systematic, replicable, observable, and rule governed forms of analysis" (p. 476).

The use of content analysis for the classroom observations involves the following stages: the data collected is in text form (field notes, transcribed video data), then codes are developed and affixed to notes, from the codes categories/themes are developed, the material is sorted into these themes, and finally any patterns are identified (Berg, 2007; Cohen et al., 2007; Bogden \& Biklen, 2007). The final categories need to be exhaustive as all data is potentially meaningful.

An interpretative approach to data analysis enabled the treatment of observations of teaching strategies to be used as text (Berg, 2007). Each type of collected data was analysed using the same method. In the early stages of analysis, it is possible that not all data will be assigned to categories and initially the categories developed may not be mutually exclusive or exhaustive (Bolton \& Hammersley, 2006, p. 253). Trial observations helped to develop the headings (Appendix 1) used in categorising the teaching strategies used. These were based on those identified by the Advancing Children's Thinking project (Fraivillig et al, 1999); the Queensland School Reform Longitudinal Study (University of Queensland, 2001); and the Best Evidence Synthesis Iteration [BES]: Effective Pedagogies in Mathematics (Anthony \& Walshaw, 2007) (Chapter 2). As the intention of the study was to compare teaching strategies, the research needed to analyse the type of strategies present and a qualitative framework allows identification of a strategy within a broad category. The interpretative nature of qualitative research meant that my own values and judgments are inextricably bound in the final analysis. In order to reduce researcher bias the categories outlined in Appendix 1 were strictly adhered to.

Each occurrence of a particular strategy was recorded and then totals were tallied to find those used most often by each teacher. The placement of statements into their relevant

\footnotetext{
${ }^{11}$ Starter questions are those that a teacher uses at the beginning of a lesson to settle students into the mathematics lesson.
} 
categories involved a degree of subjectivity on the part of the researcher. Consistency was ensured by using just the one researcher to categorise the data collected. During the analysis process further categories were added to ensure that all strategies observed were encapsulated during the recording process. It was obvious that the initial set of categories did not allow for all the strategies used in the observed classrooms. Some categories were added to show that the teachers observed were actually using a strategy which was contrary to a productive pedagogy.

After the initial categorising of data, other areas of differences and similarities in the teaching process than those initially under investigation became apparent. This meant that the content analysis approach was reworked and the video transcripts revisited to give new information regarding teacher talk (e.g., instructional statements were added as a category). The addition of further categories did not conflict with original categories but gave more information on the type of language used by the teachers in the instructional process. These further categories are in Appendix 1. The categories were refined as the analysis process was finalised and examples of the final categories are given in Tables 3.2 and 3.3.

\section{Table 3.2: Examples of the main teacher talk categories}

\begin{tabular}{|l|l|}
\hline Category & Examples drawn from study data \\
\hline Control Statement & $\begin{array}{l}\text { Excuse me, Josh, don't carry on a conversation, this is not your } \\
\text { time, ok? }\end{array}$ \\
\hline $\begin{array}{l}\text { Explanatory } \\
\text { Statement }\end{array}$ & $\begin{array}{l}\text { Put a sign in front of it now, as we are putting signs in front of the } \\
\text { other numbers, just to show positive and negative although we } \\
\text { don't need to put a sign in front of the five. }\end{array}$ \\
\hline $\begin{array}{l}\text { Instructional } \\
\text { Statement }\end{array}$ & $\begin{array}{l}\text { So what I am expecting you to do, 15.3, the first 6 problems, tick } \\
\text { your answers, in your E5 book. }\end{array}$ \\
\hline $\begin{array}{l}\text { Confidence building } \\
\text { Statement }\end{array}$ & Wow, good memory over the weekend! \\
\hline $\begin{array}{l}\text { Initiating/eliciting } \\
\text { Question }\end{array}$ & What did you notice in my movement along the number line? \\
\hline Facilitating Question & $\begin{array}{l}\text { What else could you do? What if you didn't know what } 6 \text { times } 4 \\
\text { was? }\end{array}$ \\
\hline Right/wrong Question & Does anybody know what we call the original figure? \\
\hline
\end{tabular}


Table 3.3 Examples of the main teaching strategy categories

\begin{tabular}{|l|l|}
\hline Strategy & Examples drawn from study data \\
\hline $\begin{array}{l}\text { Extend mathematical } \\
\text { thinking }\end{array}$ & $\begin{array}{l}\text { Hey for two or three minutes just in pairs ask each other questions, } \\
\text { generating, using this to generate the questions. }\end{array}$ \\
\hline $\begin{array}{l}\text { Does not extend } \\
\text { mathematical } \\
\text { thinking }\end{array}$ & $\begin{array}{l}\text { Equal sides, if those are equal sides it means that the angles are the } \\
\text { same_the angles are all the same size so they are going to equal } \\
\text { what? }\end{array}$ \\
\hline Elicit responses & Who can help Josh out? Reggie? \\
\hline $\begin{array}{l}\text { Does not elicit } \\
\text { responses }\end{array}$ & $\begin{array}{l}\text { You've just made a couple of errors. Size stays the same remember, } \\
\text { I thought I had said it several times. }\end{array}$ \\
\hline $\begin{array}{l}\text { Support student } \\
\text { thinking }\end{array}$ & $\begin{array}{l}\text { If you get stuck, call me over or ask Sophie. } \\
\text { know I am just saying if she gets stuck she can ask somebody. You } \\
\text { know you don't have to do it by yourself. }\end{array}$ \\
\hline $\begin{array}{l}\text { Does not support } \\
\text { student thinking }\end{array}$ & $\begin{array}{l}\text { Because what is going to happen to them, are they going to } \\
\text { move? } \\
\text { points that don't do what? } \\
\text { ok? }\end{array}$ \\
\hline
\end{tabular}

To aid the analysis process the categories were defined as both teacher talk and teaching strategies. Whilst the verbalisations of the teacher could be described as statements or questions, they are also examples of particular teaching strategies. It is important to note that the categories are mutually exclusive within each grouping.

The absolute number of occurrences of each strategy used was not an efficient unit for comparison due to the differing length of lessons. The proportion of each strategy evident as a percentage of the total amount of strategies observed was therefore used as the unit for comparison between the year levels. The data was further analysed using confidence intervals to explore the differences between proportions to investigate a possibility that significant differences occurred between Year 8 and Year 9 study teachers' use of particular strategies.

The differences and similarities in teacher talk and teaching strategies evident between the Year 8 and Year 9 study teachers are described in Chapters 4 and 5 respectively. 


\section{Chapter 4: Teaching Strategies Compared 1}

The purpose of this research was to find and compare the prevalent teaching strategies in a small sample of Year 8 and Year 9 mathematics classrooms. This and the next chapter describe the results and analysis of the data collected. Teacher talk, equipment use, and activity style are the focus of this chapter. Results have been split into teacher talk (types of questions used and types of statements made), types of mathematical activity students are engaged in, and then the particular teaching strategies used. Chapter 5 looks in depth at the strategies used by the study teachers in their lesson delivery.

The categories initially used to analyse the data were those outlined in Section 3.4 drawn from the ACT project (Fraivillig et al, 1999); the QSRLS study (University of Queensland, 2001); and the Mathematics BES (Anthony \& Walshaw, 2007) (Appendix 1). These categories included headings such as: elicits many solutions to one problem; encourages elaboration from students; and assists individuals to clarify their own solution methods. Categorisation to this degree of specificity proved cumbersome to analyse. To allow a more effective comparison to be drawn between the teaching strategies used by the study teachers, the original analysis categories of teacher talk were condensed into: questions (right/wrong, facilitating, and initiating/eliciting); and statements (instructional, control, confidence building, or explanatory).

Equipment use and activity style were analysed using the categories in Appendix 1. As outlined in Section 2.3, the type of mathematical activity students can be engaged is broadly categorized. It can be individual, group, or whole class; it can involve open-ended or closed problems; the context can be mathematical or situated in real-life; it can engage higher order or lower order thinking; and it can be the same for everyone or differentiated for different types of learners (Allwood et al., 1999).

Section 4.1 gives the definitions used to classify teacher talk. The type of questions used by the study teachers are discussed in Section 4.2 and Section 4.3 provides description of statements the study teachers used. The activities that the students were given in the study classrooms is analysed in Section 4.4. Section 4.5 summarises the analysis of teacher talk.

Each of the discussion sections presents similarities and differences between the year levels in different aspects of a lesson: whole class teaching; individual or small group teaching; and individual student practice of mathematical skills and problem solving. 


\subsection{Teacher Talk}

Teacher talk in the classroom is the main way mathematical content is delivered. It is the outward manifestation of the strategies that a teacher is using in the classroom. The type of teacher talk used when interacting with students may be influenced by the strategies that the teachers are using to impart mathematical knowledge to their students. The definitions used to categorize teacher questioning and teacher statements will be discussed in turn.

The type of questioning the study teachers used in the classroom was split into three categories: right/wrong; facilitating; and initiating/eliciting questions. Right/wrong questions ask for a repetition of known facts or an answer to a calculation and may be termed 'closed'. A closed question is one which leaves no room for individual expression and has a specific answer as determined by the teacher. Facilitating questions encourage a student to explain or show how to solve a problem. This type of question generally encourages students to clarify their understanding of a concept and scaffolding can be used to assist this. Initiating/eliciting questions were those that posed a problem and asked for suggestions of how to solve it. This approach in general is known to help develop students' conceptual knowledge more than asking for a recitation of known facts (Anthony \& Walshaw, 2007).

Statements were categorized into instructional, control, confidence building, or explanatory. Instructional statements are used by teachers to give students directions. These are of the: do it this way; write this down; or follow directions type of statement. These statements can be also used as a way of explaining how to do a problem. In the data analysis, statements that explicitly gave each step of the process of how to solve a problem were categorized as instructional and not explanatory. In this analysis, instructional statements were taken to include those that give orders (e.g., open your book to page 235) and also those that instruct students how to do a problem.

Control statements were those deemed to be statements made in order to modify student behaviour. Whilst these are not strictly teaching strategies, they are included in the analysis for two reasons: the amount of time spent on student control in the study classrooms; and how control was established appeared to impact on the observed teaching strategies (e.g., study teachers' discussion of mathematical ideas appeared at times to be disrupted causing the termination of discussion).

Confidence building statements are those that show the teacher values a student's effort. They give praise and recognition for: how the student is thinking; correctly answering a 
right/wrong question; and for attempting the teacher specified mathematical activity. They are a way of encouraging student participation and to reassure the student that they are performing to teacher expectations.

The last type of statement is an explanatory statement. These statements contain descriptions of how to approach a problem or the reason why the solution is carried out in a particular way. It shows the student how to perform a skill or clarify a concept. Explanatory statements are those that provide information on why and how something works rather than just telling.

Examples of each category are shown in Table 3.2 (Section 3.5) and their relative prevalence in the study classrooms is shown in Figures 4.1 and 4.2.

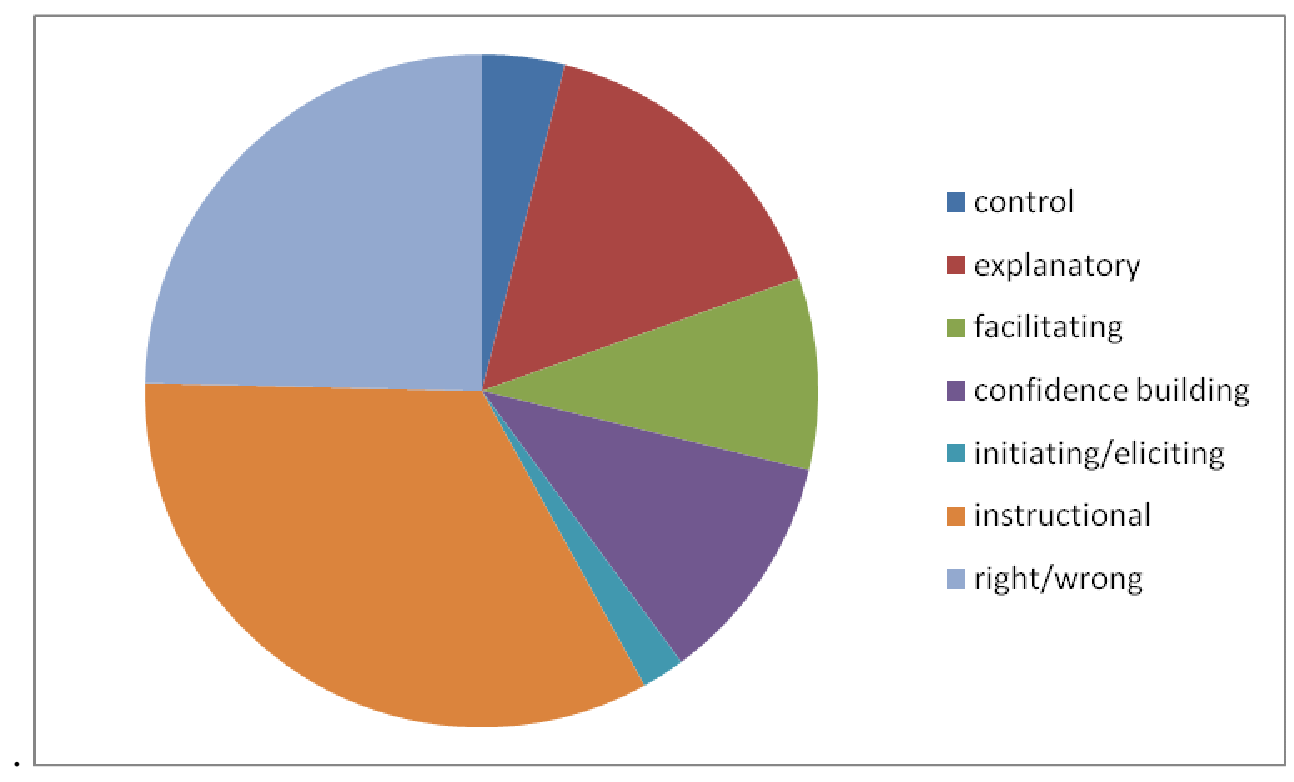

Figure 4.1: All teacher talk in the Year 8 classroom 


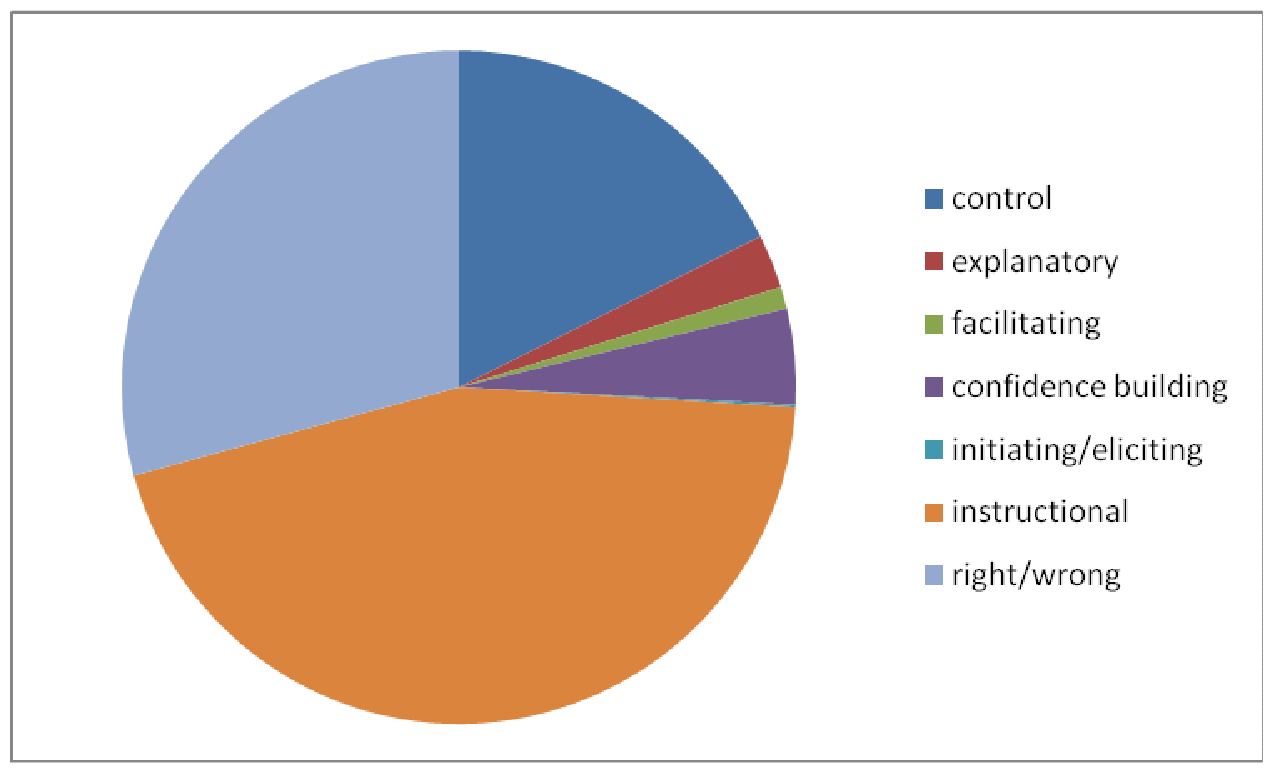

Figure 4.2: All teacher talk in the Year 9 classroom

Sections $4.2-4.4$ provide further explanation and examples of the types of teacher talk used by the study teachers.

\subsection{Question Types}

In both the Year 8 and Year 9 study classrooms the prevalent type of questioning was right/wrong questions with $68 \%$ and $96 \%$ of all questions asked by the Year 8 and Year 9 study teachers respectively being this type of question (Figures 4.3 and 4.4). The variety of questioning in the Year 8 study classrooms (including 26\% facilitating and 6\% initiating) indicate the presence of teaching strategies that support intellectual thinking (Hayes et al., 2006). The Year 9 study classrooms, however, were more reliant on right/wrong questions with only $3 \%$ facilitating and less than $1 \%$ initiating questions asked. It is of concern that only $4 \%$ of all questions asked in the observed Year 9 study lessons required the students to think deeply about an answer. 


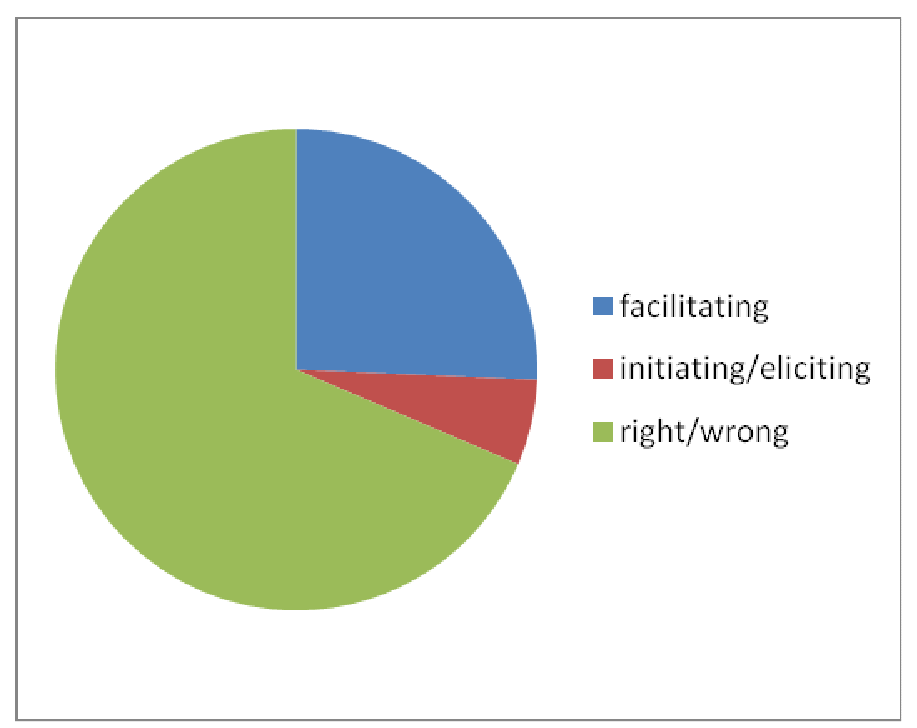

Figure 4.3: The type of questions used in the Year 8 study classrooms

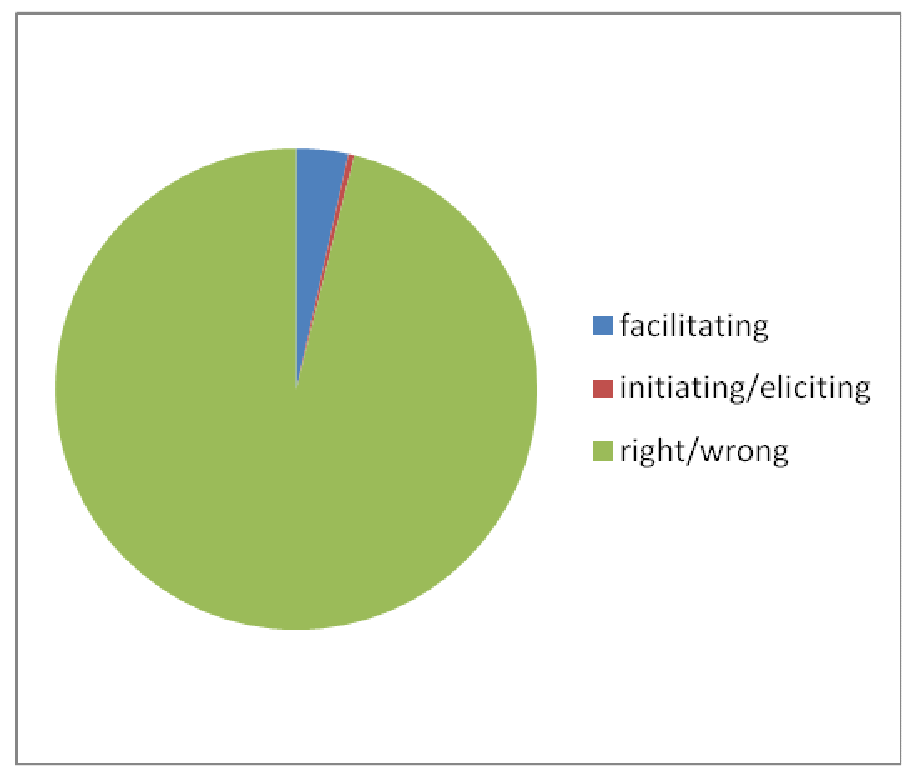

Figure 4.4: The type of questions used in the Year 9 study classrooms

Right/wrong questioning was used, at both year levels, during whole class instruction and when the teachers were interacting with individual students. Three transcript excerpts illustrate how the study teachers used this type of questioning. In the first excerpt the teacher is in the teacher-lecture phase of the lesson and is summarising the new learning:

Just to remind you, North is what bearing? 12 What was East? 090 . If you heading off to that, sort of between North and East, then what must your bearing be? In between there, so you can't head that way [pointing North Eastish on the white board] and have a bearing of

\footnotetext{
${ }^{12}$ The blank spaces indicated that was a student talking. Student comments were not transcribed.
} 
$100^{\circ}$ What is the bearing for South? If you are heading directly South, you are going what bearing? (Year 9, Teacher 2)

Each question asked of the students had one pre-selected answer. Answers given that were deemed incorrect were ignored.

The next excerpt arose when a student asked for help with a problem, during individual student practice.

Ok. You called me over to help you. Excellent. These are two points that are?

Do you remember writing down what invariant is? You don't remember? Points on the line, where do they go, what line are we talking about? Good, they are called what? So see the mirror line, what points are on it? Is that all? Because what is going to happen to them? Are they going to move? We are reflected in this line here and we want to find 3 points that don't do what? They stay right the same, ok? (Year 9, Teacher 1)

The teacher responded, firstly with encouragement that it is acceptable to ask questions, then by talking the student through each step of the solution. The solution was scaffolded for the student but the teacher was doing all the thinking and the student merely filling in the gaps.

This third excerpt is taken from a small group work section of a lesson. The Year 8 class had been working on time in small groups. The teacher was having a session with a small group that initially worked from a text book and then had time with the teacher. The teacher used questions to try to gauge students' level of understanding.

Quickly just to revisit what we know about, I am going to have to rub this all off, what we know about analogue time. 'Cos we will look at digital time but we need to have a look at this here, this is the clock. Ok, it has got 3 hands but I am missing one hand, what hand is not there? The second hand. Ok, what is the second hand's job? All the hands, all the hands get? Yeah all the hands go around the clock don't they? Ok if the, the hand, if the second hand starts, goes from the 12 right round to the 12 , that is a minute. How many ticks does it have to do? 60. (Year 8, Teacher 6) 
In this excerpt each question had one answer and if the answer the students gave was not the one the teacher was looking for then the teacher supplied the answer.

Study teachers from both year levels used this type of questioning to lead students to predetermined solutions. The Year 9 study teachers, as previously stated, appeared to use right/wrong questions to a greater extent (Figures 4.3 and 4.4) than the Year 8 teachers. The individual variation amongst teachers at a year level may account for some of this discrepancy and one teacher's results may have disproportionately affected the results. To explore whether there was a significant difference between the two year levels the proportion of questions in this category were compared statistically. A confidence interval for the difference in the proportion of right/wrong questions used by Year 8 and Year 9 study teachers was calculated at the $99 \%$ confidence level (data in Appendix 2), which gave a range of 0.2 to 0.36 . As zero is not included within this interval there may be a significant difference between the two year levels in their use of right/wrong questions. Study teachers at Year 8 may be less likely to use right/wrong questioning as their Year 9 counterparts.

Year 8 study teachers used proportionally more facilitating questions than the Year 9 study teachers. A confidence interval for the difference of two proportions at the $99 \%$ confidence level gives the interval 0.14 to 0.30 . This means that there may be a significant difference in the incidence of this type of questioning and Year 8 study teachers were more likely to use facilitating questions than the Year 9 study teachers.

Examples of the use of this type of questioning by the Year 8 study teachers include the following excerpts.

Can anyone else see Sam's thinking here? With your model show me. Ok yeah Oh, ok. I can, I can see their thinking. They are saying, ok, this is 20\%, there is one of those to four of these. (Year 8, Teacher 5)

But could we do this, hands up if you know the answer to this. (Writes $1 / 2$ divided by $1 / 2$ on the board). Just do you know the answer, what is a half, now this, now this is really challenging, this is like a (simile), I just want to see if we can jump about three steps by the end of the day to solve that, who knows what a half divided by a half would be? (Year 8, Teacher 5) 
Right now put your pencils down now, Molly is going to tell us, what question did you do? What question did you do? What was that about? mmmm Right so what kind of question was it?

What kind of, what kind of maths were you doing for that? Ratio, ratios, (Year 8, Teacher 4)

Teachers in the first two excerpts use questions that appear to have been designed to get students to understand another student's way of thinking and for the students to show their thinking using a concrete device (a fraction strip). ${ }^{13}$ The second excerpt also introduces a new concept of division of fractions and asks students to think about how they would solve it. This type of question was not present in the Year 9 study classrooms, no questions were asked without students already having the information needed to answer them.

An initiating/eliciting question was observed only once in the nine Year 9 lessons videoed. This equates to less than half a percent of all questions asked. In the Year 8 study classrooms the incidence of this type of questioning was higher with 13 incidents or approximately $5 \%$ of all questions being asked of the initiating/eliciting kind, for example:

Firstly, what is the fraction that you can see? (Year 8, Teacher 5)

This question related to this diagram:

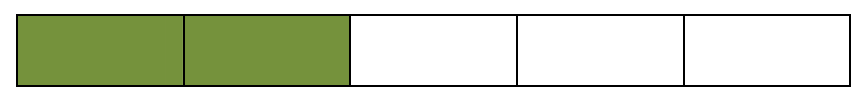

The diagram was drawn on the white board and students were asked to think beyond the normal answer, the idea being that until the 'whole' is defined there are many ways to solve this question.

\subsection{Statement Types}

The proportion of types of statement occurring during the study lessons is shown in Figures 4.5 and 4.6. Both year levels used instructional statements the most. It is at the next most prevalent type of statement where the main variation between year levels occurred.

\footnotetext{
${ }^{13} \mathrm{~A}$ fraction strip is a rectangular piece of paper divided into equal parts to indicate a particular fraction e.g. 8 pieces to illustrate $1 / 8$.
} 


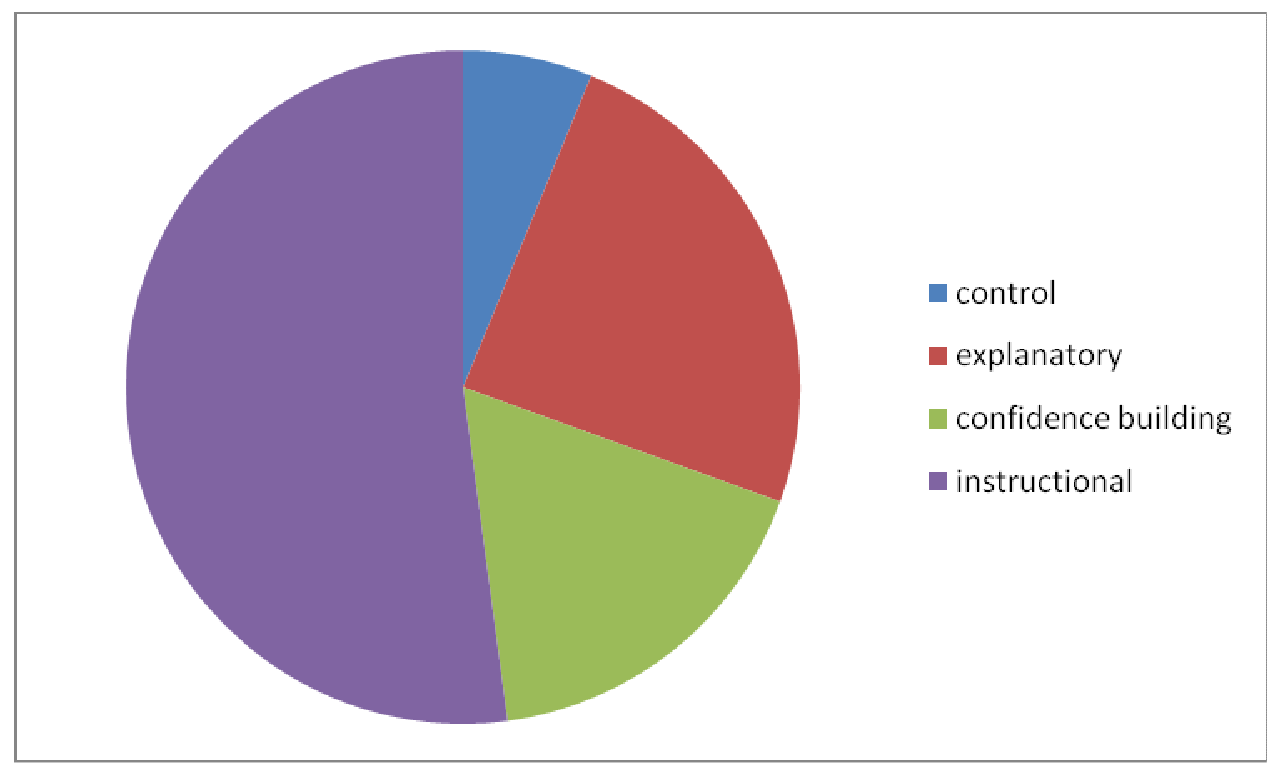

Figure 4.5: The type of statements used in the Year 8 study classroom

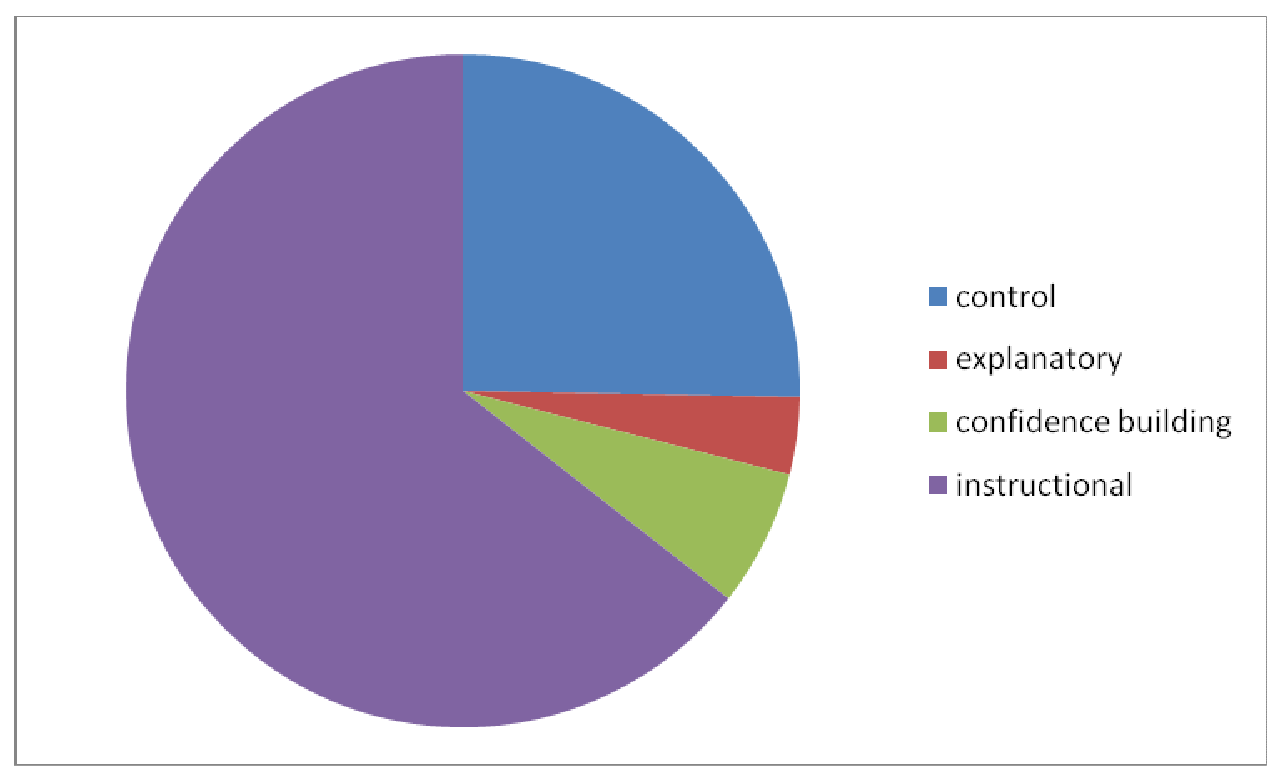

Figure 4.6: The type of statements used in the Year 9 Study classroom

When the two year groups were compared the number of instructional statements in the Year 9 study classrooms appears to constitute a considerably larger proportion of the lesson. A confidence interval at the $99 \%$ significance level for the difference between the proportions of instructional statements issued at Year 8 and Year 9 is -0.20 to -0.04 . As zero is not in this interval there is probably a significant difference in this type of statement usage for the two year levels in the study. Despite both year levels in this study using this type of statement as their most prevalent teacher-talk statement, the Year 8 study teachers used instructional statements less often than the Year 9 study teachers. This may be because the Year 9 study teachers tended to use instructional statements to tell students how to solve problems. 
The following vignettes illustrate this point.

We are doing Ex 15.1. It is just over the page. Before you start can you listen, before you start, that means before you do anything look this way, you need to make sure, it is on little grided areas of paper, make sure you count it out properly. You have got to draw up what's there. You've got to draw the mirror image. Count it out carefully; squares on that page match the squares in your book. So try and actually draw what is there not something out of your own head. So count out squares, look at directions, look at whether a line is going through corners, for the slanted lines how many squares across, how many squares up or down is there from one end of the line to the other of the line. Count it out properly. Ok let's get underway. (Year 9, Teacher 2)

Elias there is a title on 233. It says pointed images. You see where bottom of the page 233, would you read where it says pointed images and onward Elias, (Year 9, Teacher 3);

Ok if we have got a protractor like this and we want to measure the bearing, [diagram on board of bearing of 320] are we going to measure this piece? [pointing to acute angle part of bearing] ----- No, because it is from north and clockwise, how are we going to measure that angle with only half a circle? [Holding protractor up] ___ Double it, so we are going to what? Well done. Ok next, we need to make a line straight down don't we? And draw a $180^{\circ}$ don't we? And then we can take our protractor round, with your protractor,___ ok, you've got 180 and then you put the protractor on here, reading from 0 around which is 140. [Shows on diagram] Alright, I just measured that to be 140 and we know that this side is 180 the bearing is? (Year 9, Teacher 3).

In the third excerpt, the teacher was explaining to students how a bearing of greater than $180^{\circ}$ is measured. The strategy used was whole class instruction, with a few closed questions allowing student participation. What has been taken out of the vignette is that three times during this instruction of how to measure the bearing students were asked to be quiet and pay attention. 
In a Year 8 example of the use of instructional statements as a teaching strategy, again the use of right/wrong questions peppers the teacher's direction for one student of how to do a particular problem.

You started off with one bag is 250, two bags is 500. If two bags give you 500, two bags, two bags give you 500, how many would four bags give you? You had two bags, this is where we're going, we are looking at this adding here (pointing to the working on the number line) two bags gives you 500, ok, two bags of 250 gives you 500 what would another 2 bags give you? Yes, so what is 500 plus 500 ? Ok, so we have just got add this up here, what are we doing? and then we have got another two bags after that haven't we? ___ So if we have got two bags give us a thous, [Teacher stopped mid word and corrected themselves] give us 500 and another two bags give us a thousand, what is happening to the number? (Year 8, Teacher 6)

The teacher leads the student all the way using directional scaffolding that does not allow the student any individual thinking time. The teacher in the above example was working one-to-one with an individual student and no control statements were found necessary.

It was noticeable that a high proportion of the Year 9 study teacher's interactions with students were related to student control. This accounted for $25 \%$ of the statements made by Year 9 study teachers. The Year 9 study teachers were repeatedly asking students to be quiet, pay attention, focus, respect each other, and to do the work.

A confidence interval at the $99 \%$ significance level for the difference in the proportion of control statements issued is -0.24 to -0.14 shows that, as zero is not in this interval, there may be a significant difference in this type of statement. The Year 8 study teachers were less likely to use control statements than the Year 9 study teachers. This may impact on the other strategies that teachers' use, as the proportion of time control statements take from 'teaching time' and the nature of the control statements are likely to affect the development of a community of learning.

The control interactions were generally of a negative nature in the Year 9 study classrooms and appeared to disrupt the thought processes of both students and teachers as highlighted in the following vignette.

Stuart, focus, lets help get the notes down for other people. How do bearings differ from other angles? Jason, if you have somebody else doing the writing 
for you, you need to sit quietly. There shouldn't be any talking. Sophie, shush, Sophie you are going to have to move outside. Yes, you are moving outside, bring your chair. Ok, I have lost my train of thought. How do bearings differ from other angles? Bearings differ from other angles because they must what? ___Not go north but they must what? (Year 9, Teacher 3)

In this vignette the teacher needed to revisit the intent of the lesson, because during the time taken to deal with the disruptive behaviour, the teacher and the other students had become uninvolved in the learning.

In some instances the control statements in the Year 9 study classrooms were also threatening in nature.

Excuse me ladies, the next piece of conversation, you will have your own seats and they won't be together. Remember it is a privilege to sit next to somebody you want to work with but if you are going to abuse the privilege, then you lose the privilege, ok? (Year 9, Teacher 1)

In the study Year 8 classrooms control statements tended to be more positive.

Jamie, I know that you can be much more polite than that so try again please. (Year 8, Teacher 5)

And we just have the usual Monday morning thing of being a little unsettled, eh? Certainly unsettled because of the different time for maths, but never mind, we can overcome that can't we? (Year 8, Teacher 5)

These comparisons support the findings of Eccles and Wigfield (1997, p. 24) who found that in the United States junior high school classes were characterised with a greater emphasis on teacher control and discipline giving students less opportunity for decisionmaking and self-management. This will be discussed further in Chapter 6 .

As a form of encouragement and recognition of students' learning, the use of confidence building statements was prevalent in both year levels. This often took the form of praise for a correct answer. All observed teachers in both study schools were consistent in their use of positive reinforcement of answers attempted by students. This was shown as an accepting attitude to students' answers to questions and included phrases like 'well done' and 'good'. One of the Year 8 teachers was more effusive in their praise than the other 
study teachers and this may have been a result of them having the lower band class that they felt needed more enthusiastic encouragement, as epitomized by the excerpts below.

_ Ok so you explain it. Ok, go on that's cool (Year 8, Teacher 6)

Thinking, gee Mitch, I'm impressed. (Year 8, Teacher 6)

The teacher continually reinforced the concept that the mathematical thinking occurring in their classroom was something of which they were proud, as shown in the above excerpts.

A mixture of vignettes follows to demonstrate the use of confidence building statements at both year levels in the study classrooms.

Why six tenths? Good boy that was exactly your thinking before (Year 8, Teacher 6)

You used a clock, good thinking. You looked at your watch. Cool. And you counted round, good, so Sean what time did you use? The 3 and the

10, excellent. A great way of estimating. (Year 9, Teacher 3)

Ok, now, great some people over here have realised the next step haven't they? (Year 8, Teacher 4)

--- this one is perfect. That one is perfect. Ok. (Year 9, Teacher 1)

--- that one is good. Good. Good. (Year 9, Teacher 2)

A confidence interval for the difference of two proportions of confidence building statements used by Year 8 and Year 9 study teachers at the $99 \%$ level gives the interval 0.05 to 0.26 . As zero is not within this interval there may be a significant difference between the Year 8 and Year 9 study teachers in their use of confidence building statements. The Year 8 study teachers were more likely to use this type of statement than the Year 9 study teachers.

Explanatory statements were used, as a method of mathematical knowledge delivery, approximately $24 \%$ and $4 \%$ of all statements respectively in the Year 8 and Year 9 study classrooms. An example of the use of explanatory statements is given in the following vignette.

I am going to plot zero. Zero, I start always at the origin. I move nowhere along the $x$-axis. I move nowhere along the y-axis, where am I? Where I 
started, right. I wonder if you were watching me when I said I moved nowhere along the $x$-axis and nowhere along the y-axis so I am staying exactly where I am. What about negative one and positive three, where would that be found? Harriet come out to the board and put your finger on the origin. Where am I going to move first $x$ or $y$ ? $x$ or $y$ ? Well, $x$ comes before $y, x$ comes before $y$, so we are going to move negative one in the x-axis, do that, stop there and I am going to move positive three along the y. There you are plot the point for me. [Gives her the pen] (Year 8, Teacher 4)

The Year 8 study teacher explained each step of new learning as it was introduced. There is still evidence of the use of right/wrong questions and instructional statements but the overall nature of the above vignette is explanatory.

A confidence interval for the difference of two proportions in the use of explanatory statements at the $99 \%$ level gives the interval 0.15 to 0.26 . As zero is not within this interval there may be a significant difference between the Year 8 study teachers and the Year 9 study teachers in their use of explanatory statements. Year 8 study teachers were more likely to use this type of statement than the Year 9 study teachers.

\subsection{Mathematical Activities Used}

The context of problems in the classrooms differed for the two year levels. In the Year 9 study classrooms few of the problems were situated in real life or in a non-mathematical context. Where a real life situation was introduced, it was often a cursory reference to frame the mathematics or use of an example from the text book which appeared to have little meaning for the students. This is illustrated in the following vignette.

Um, when was radar first really used? It is radar. Um, when was radar first really used? Somebody just said it. In a war definitely used it in a war. Um, used for spotting planes. Like England, what did they use it for? Well, who whose bombing England in World War Two? We have a history lesson here going on, world war two? Somebody finally mentioned it, who, whose England's enemy? Germany, so who was trying to fly into England and bomb it? Germany. What did they use radar for, why do you think they were using radar? Yeah to see when the planes were coming, then they could get their planes off the ground and try to intercept 
them. Well, I have an exercise for you to do; you can probably guess where it is. Well guessed 15.4, 1 to 8 (Year 9, Teacher 1)

The reference to radar and war was outside the experience of most of the students in the class and it took about ten guesses from the students before Germany was mentioned. The teacher gave a verbal explanation of how radar might be used, and then moved right on to the mathematical activity the students were to do without a pause. The exercise in the text book was in a mathematical context involving reflection of rectangles and triangles: nothing to do with sonar or radar.

At other times the Year 9 study teachers may have briefly recognised students' background experience by referring to concrete items the students should have experienced (e.g. mirrors).

And so you'll all be reasonably happy with reflection from previous school work, and may be having gotten up this morning and washed your face and done your hair or whatever. The fact that you have got mirrors at home and you can see reflection in everyday life. (Year 9, Teacher 2)

This teacher briefly mentioned the use of reflection in the students' lives and then immediately turned to the text book for examples and practice on reflecting polygons.

Year 8 study teachers used examples from real life as a way of framing the lesson where possible and put most of their problems in a contextual situation. The Year 8 study teachers used anecdotal examples that also allowed the students to identify with the teachers as real people and helped situate the problems. They used their own experiences to make the lesson more real for their students as shown in the following vignette.

We talked about things that take more than a minute, and they were things like ___ cooking a roast. 'Cos how long does a roast normally take? __ Yeah, and if you are not very good at cooking, it could take longer. And do you know that these get used? (Holding up an eggtimer) Sometimes, people use these when they are cooking.___ 'Cos you don't want to overcook eggs, bleah, and then we talked about 2 minute noodles, because they are 2 minutes and it is more than a minute.(Year 8, Teacher 6)

The teacher here is framing the use of telling the time and using examples that the students could relate to, including the teacher's dislike of overcooked eggs. 


\subsection{Type of Language Summarised}

In this research Year 8 study teachers were less likely to use right/wrong questions than the Year 9 study teachers. Year 8 study teachers had more variety in the type of questions used. Year 8 teachers were less likely to use control and instructional statements that the Year 9 study teachers. The impact on these findings will be discussed in Chapter 6 . 


\section{Chapter 5: Teaching Strategies Compared 2}

Chapter 5 focuses on the teaching strategies used during the study mathematics lessons. The teaching strategies identified are those used in the content analysis process (Section 3.4) as informed by the Advancing Children's Thinking project (Fraivillig et al., 1999); the Queensland School Reform Longitudinal Study (University of Queensland, 2001); and the Best Evidence Synthesis Iteration [BES]: Effective Pedagogies in Mathematics (Anthony \& Walshaw, 2007).

The teaching strategies were broadly categorised as those that did or did not: extend mathematical thinking; elicit responses; support student thinking. Definitions and expansion of each of the teaching categories is given in Section 2.4. As stated in Section 3.4, the categories are mutually exclusive. An example of each of the teaching strategy categories is given in Table 3.3. (Section 3.5).

Figures 5.1 and 5.2 illustrate the frequency of each type of teaching strategy found in the study classes. Percentages are used as they allow for the proportion of teaching strategies in each category to be shown; the number of occurrences would distort the data due to different lesson lengths in the study schools (actual data is in Appendix 2).

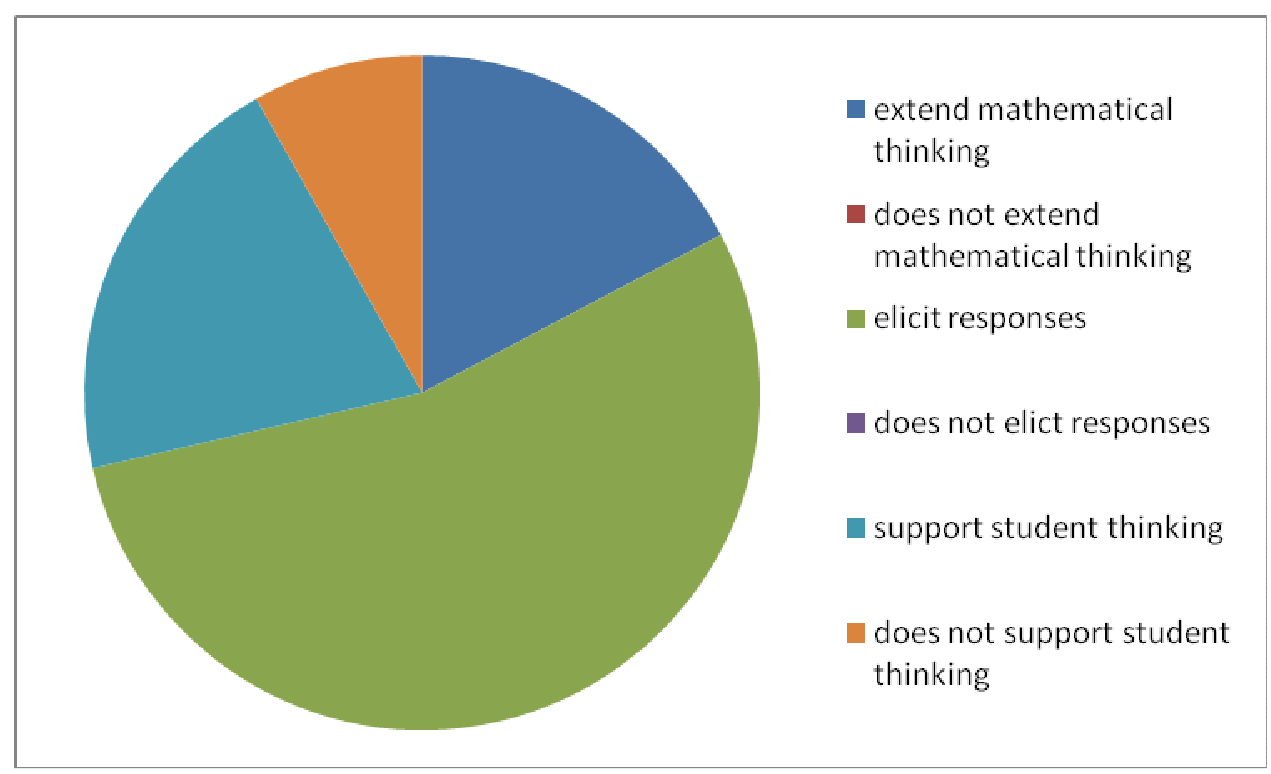

Figure 5.1: Main teaching strategies used in the Year 8 classroom 


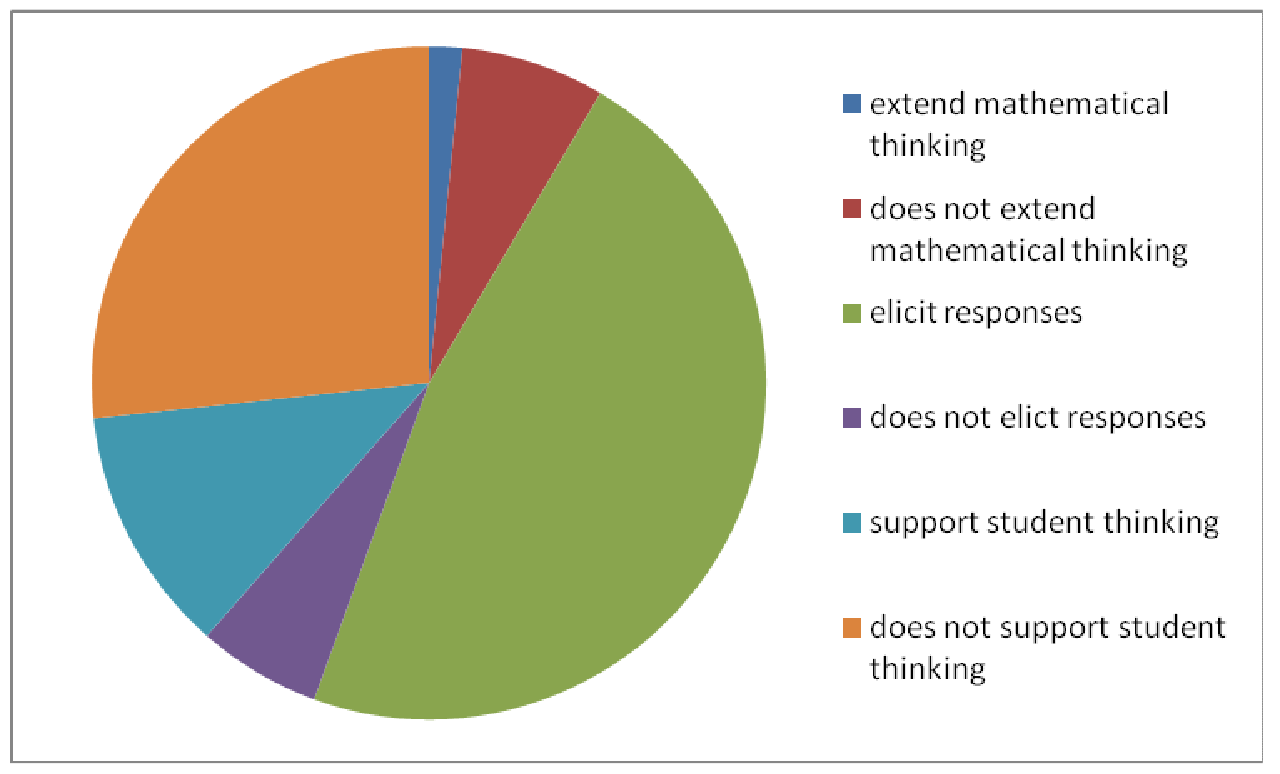

Figure 5.2: Main teaching strategies used in the Year 9 classroom

How these teaching strategies are used in different parts of the mathematics lessons will be discussed in this chapter. Vignettes used in this chapter illustrate particular teaching strategies and whilst the vignettes are also examples of teacher talk (Chapter 4), the context of this chapter highlights the strategy used not the type of teacher talk used. Teacher verbalisation has a dual purpose in this study: to identify types of teacher talk and to represent a teaching strategy.

The parts of the lesson correspond, in the main, to the most common instructional activities identified by the TIMSS 2003 study. These were 'teacher lecture, teacher-guided student practice, and students working on problems on their own' (Mullis et al., 2004, p. 10). Teacher lecture was adapted here to describe the part of the lesson when the teacher is using whole class instruction. Teacher-guided student practice was deemed to be when the teacher was working with an individual or small group. Students working on problems on their own was defined in this research to be the times when the teacher had instructed the students to work from a text, worksheet, or from the whiteboard.

The study classrooms all showed evidence of teacher lecture followed by students working on problems on their own. In two of the Year 8 study classrooms the lesson, however, did not always have a teacher-guided student practice part. The teachers in the Year 8 study classrooms tended to teach the class as a whole with short periods of individualised or group work. An additional part to the lesson was added in this study as all study teachers used the start of the lesson for revision purposes. 
Section 5.1 describes the start of the observed lessons and the teaching strategies used. In Section 5.2 how new content was delivered is outlined with the teaching strategies used described. Practice of the new content by students is discussed in Section 5.3. Section 5.4 deals with lesson closure. The final sections of this chapter discuss whether the study teachers have displayed a predisposition to a constructivist or a behaviourist orientation (Section 5.5) and summarise the key ideas of the chapter (Section 5.6).

\subsection{Starting Lessons}

This section focuses on the teaching strategies the study teachers used at the start of the mathematics lesson. It encompasses the initial settling phase as the students start their mathematics lesson.

All of the teachers in this research started all of their lessons with revision of previous work. Some of the study teachers used 'starter' ${ }^{14}$ questions to revise previously taught work. These questions were given to the whole class on the whiteboard, or from homework assignments. The questions given to the whole class from the whiteboard were all closed in nature and all the study teachers, except for one Year 8 study teacher, used mathematical contexts for their starter questions e.g., $378 \div 8=$ ?

The starter questions were often on the white board when the students came in to the lesson and were part of a strategy study teachers used to settle the students into the mathematics lesson. The questions were generally not designed to be challenging and in some cases, as illustrated below, the teachers scaffolded the problems for students before they started to work on them.

Ok you need to get on with the starter questions. Those dashes on the side what do they mean?___Equal sides. If those are equal sides it means that the angles are the same. The angles are all the same size, so they are going to equal what? (Year 9, Teacher 3)

Tell me which one is heavier and then I want you to show me the way you have worked it out. Just like we did yesterday. Just like we did yesterday. So have a look, so what do we need to remember though, Joe? 'Cos you were really good at this yesterday. How many grams make a $\mathrm{k} g$ ? (Year 8, Teacher 6)

\footnotetext{
${ }^{14}$ Deemed starter questions as they start the lesson
} 
The answers that the study teachers accepted for the starter questions indicated that these were closed questions, with teacher pre-determined answers (Section 4.2) that did not extend mathematical thinking. The following vignette demonstrates a Year 9 study teacher accepting answers from students that allowed the teacher to solve the problem for the students without investigating how the students had solved the problem.

Prime number, less than 40, two digits and if you double it and take away 9 you get a square number. That is a little bit trickier. Kevin? Let's see if it works, 13, double it, it is 26 take away 9 from 26 and you get? Is 17 a square number? Nope, so that isn't going to work. A prime number, any other thoughts on it? 14 a prime number? Charles? 11, lets check that out, so if I double it 22, take away 9 13 and is that a square number? What are square numbers? [writes student responses on the white board] Ok numbers that you get by squaring. So what is the prime number that, you double it and take away 9 , that you get a square number? So let's go to all of these and if we are going to work back, and we did this with algebra, if we are going to work back, what do we need to do to all these numbers? Add 9, that gives us 10, 13, 18 [writes the rest on the white board] Ok instead of doubling it what would you do? What is opposite of double? Divide by 2. [Points to odd numbers on white board] Those won't work. [Writes 5 on white board] But that is only a single digit and we want a 2 digit number. 13 by 2 is going to give us point 5 , what about 34 ? And is 17 prime? And is it 2 digits, so does it do that? So that makes 17 a good candidate. (Year 9, Teacher 2)

In the above vignette the Year 9 study teacher was using closed questions that scaffolded the students to the required answer. It displays no teaching strategies that extend mathematical thinking.

The choice of starter question as a closed, revision type question was also evident in all three Year 8 study classrooms. At the start of the lesson students were asked to work individually on set problems, written on the whiteboard or from a worksheet. After a set period of time, the class then solved the problem together but as in the Year 9 study classrooms these solutions tended to be teacher driven. The following is an excerpt from a Year 8 study teacher solving a division problem on the white board. 
Just super quickly please, 8 7's are 56 and 2 over. And so we do exactly the same thought process here, 8 7's are 56 and there is 2 over [this one set out like long division] and bring down the 7 there, notice in both cases we have got 27 haven't we?(Year 8, Teacher 5)

This excerpt shows the teacher telling the students mathematics, though trying to maintain student engagement with words like 'notice'.

An alternative to the use of starter questions was marking homework.

You did not get a chance to ask questions on 15.1 and 15.2, if you didn't understand one that you had to fix. So I am going to give you the opportunity to take a look at 15.1 and 15.2 and if there is a problem there that you did not match the answer to and you do not know why the answer is what it is now this is your opportunity to step forward (Year 9, Teacher 1)

The Year 9 study teacher was using a supportive strategy that allowed the students to see that it is acceptable to not be able to do all the required work without help. The teacher is encouraging the students to ask questions. Unfortunately in this particular instance, no students took the opportunity though some had had problems with their homework (the teacher noticed this when he walked around checking the homework).

A Year 8 study teacher who used homework to start his lesson also emphasised number strategies from the NDP as he elicited answers to the homework questions.

Alright we are going to start jogging our memories this morning. We are going to, ah going to open our exercise books; worksheet 18 is what we want...... They are a set of Mathletics questions we did that week; it must have been around Mathletics time. Away you go. Right so 15 questions, you are dealing with, 15 questions, and 3 marks for right and 1 mark off for wrong. [Writes this information on the board] Right, and he got 29, that was his score. So how many did he get right and how many did he get wrong, where do we start? Who could give me a possible strategy? Antonio? (Year 8, Teacher 4)

This teacher used the start of the lesson to start the students thinking and was prepared to use students' explanations in the solution of the problem. 
The study teachers all used starter questions as revision of immediately previous learning or as revision of concepts taught in previous topics. The teaching strategies involved in this part of the lesson were mainly those that did not extend student thinking.

\subsection{Delivery of New Content}

This section relates to the teacher-lecture component of the lesson as identified in TIMSS 2003 (Mullis et al., 2004). This section looks at the prevalent strategies used during the teacher-lecture phase of the lesson from content analysis of the videoed lessons. The prevalent teaching strategies involved in the delivery of new content in the study classrooms will be analysed (extending students' mathematical thinking; eliciting student responses; and supporting students' thinking) first by Year level and then by comparing the Year levels.

In two of the Year 8 study classrooms the teacher-lecture component of the lesson also followed the starter questions but then continued for the majority of the lesson with short breaks when students were asked to individually perform a task as part of the delivery of the new content. The third Year 8 study teacher did not use teacher-lecture to the whole class at all, but dealt only with a small group (six students) for the delivery of new content. The Year 8 study teachers were dissimilar in their teaching styles. One used an expository style with some student delivered drama; one used manipulatives to provide concrete evidence of the new concepts; and the other Year 8 study teacher utilised groups to allow her to teach new content to a small portion of the class (approximately 6 students).

Examples of each of these styles follow:

I thought today we would have some drama, so, the characters, wait on, Jimmy, give a round of applause for Jimmy, doesn't he look wonderful and then we have zero, there is zero all the way from the number line, zero. (Year 8, Teacher 4)

A little more about proportional thinking, so what I need you to do is, see this here (pointing to drawing on white board) on a piece of paper, one of these (holds up a blank strip of paper). I want you to just to make that for me and shade in 2 strips, or two of the segments. Just like that. (Year 8, Teacher 5) 
Sharks are with me today and we are working down on the mat, so you will, you will need to bring, just bring your books and your pencils please. The Sharks working with me. Ok off you go you guys. That group can go out on the deck and I am working with these other kids.(Year 8, Teacher 6)

The Year 8 study teacher who used drama also used metaphor to convey mathematical ideas. For example, integers were introduced, as above, by some of the students reading a play, and then developed by the use of the metaphor of hills and dales.

Now another way that we can show it [draws a straight line on the board] imagine that is flat land, now we have got a piece of flat land here, positive 3, 3 hills, [draws that]positive 3 and I want to add negative 2, 2 dales [draws those] and there is the picture. And the answer can be seen because those two dales those two dales here have got to be filled in, now we can fill it in with a couple of those hills can't we? Do it for us [hands a student a pen] do it for us? Just shade in one of the hills, shade it in, yeah that is it now take all that dirt and put it into one of your dales, fill in there so that is all filled out, take the other hill put it into the other dale, so they are both gone now, the two dales are gone and what are we left with?(Year 8, Teacher 4)

In the Year 9 study classrooms the teacher-lecture component of the lesson took place immediately following the starter questions and lasted for approximately 10 minutes (about a fifth of total lesson time). The Year 9 study teachers all taught similarly to one another. The format of their lessons was a set objective for the lesson delivered via teacher talk or text book notes. In the following example the teacher is using the text book as a source of knowledge for the lesson objective. No input was asked of the students; mathematical thinking did not appear to be expected of them; nor were they encouraged to think of other solutions. This may be a result of the specific topic (Geometry) being taught but informal interviews with the teachers concerned suggest that this type of instruction is the norm.

The vignettes that follow exemplify this point.

How about turning your books, your Alpha books to p229 [writes the page number on the white board] and Mark can we get you to volunteer and where I would like you to read, is you will probably see it kinda towards the bottom of the page, its in a dark print, do you see what I am talking about? Ok start there. Ok, so let's hit that thing again. Read that last sentence one 
more time. That's good. Read on, take a look at this example.

Ok, so, they gave you the number 4 [draws this on the white board] and they gave you this dotted line, this is called the? And what initial did they give you for it? (Year 9, Teacher 1)

Ok, what do we know, looking at this top line, about bearings already, what do you guys know about bearings? Steven, do you want to share what you know about bearings? A wheel. Small balls like bike wheels. Like rings. Shish. measuring tape.

It is for measuring, we are doing measurement.___class control statements]__ Ok we have heard about bearings, little metal balls and that which they are. Shish 9xx. Bearings are on our bikes and things like that. Bearings making motors turn but bearings are something else that we are going to learn about today and it is going to do with maths. Ok we have got a small reading and our focus questions here. What are the text features? Who can remind me text features? Hand up if you can remember what text features are? (Year 9, Teacher 3)

The Year 9 study teachers' practice varied in their introduction of new content. In the first vignette the teacher had no preamble to the topic but went straight to the text. In the second vignette the teacher tried to introduce the topic by asking students what they knew about the topic. The teacher then directed the students to the text book as a way of learning the 'new' concept. There was no evidence, that the researcher observed, of an attempt to bring in the students' background experience or to use a real life context in either example.

The teacher in the second vignette was involved in a literacy programme at the secondary school which had been very directive on using text books for teaching and this, as well as the department scheme ${ }^{15}$, because of the teacher's relative inexperience in teaching, was likely to be a major influence in their choice of strategy.

At both year levels the delivery of mathematical content tended to be teacher-centred and consistent with behaviourist principles. It involved teacher statements of fact, or text book notes, and students learning these. As shown in Chapter 4 the most frequently occurring questions were those of the right/wrong type and the most frequently occurring statements

\footnotetext{
${ }^{15}$ This is the scheme of work given to each mathematics teacher at the secondary school to follow (Appendix 4).
} 
were instructional in nature for both year levels. This was consistent throughout all phases of the lesson.

Teacher delivery did, however, vary within these parameters. The teaching strategies used to deliver the new content were markedly different in the Year 8 and Year 9 study classrooms. Each of extending mathematical thinking, eliciting student responses, and supporting mathematical thinking will be discussed.

Figure 5.3 shows that the use of extending mathematical thinking strategies was minimal at both year levels in the study classrooms, though slightly greater at the Year 8 level.

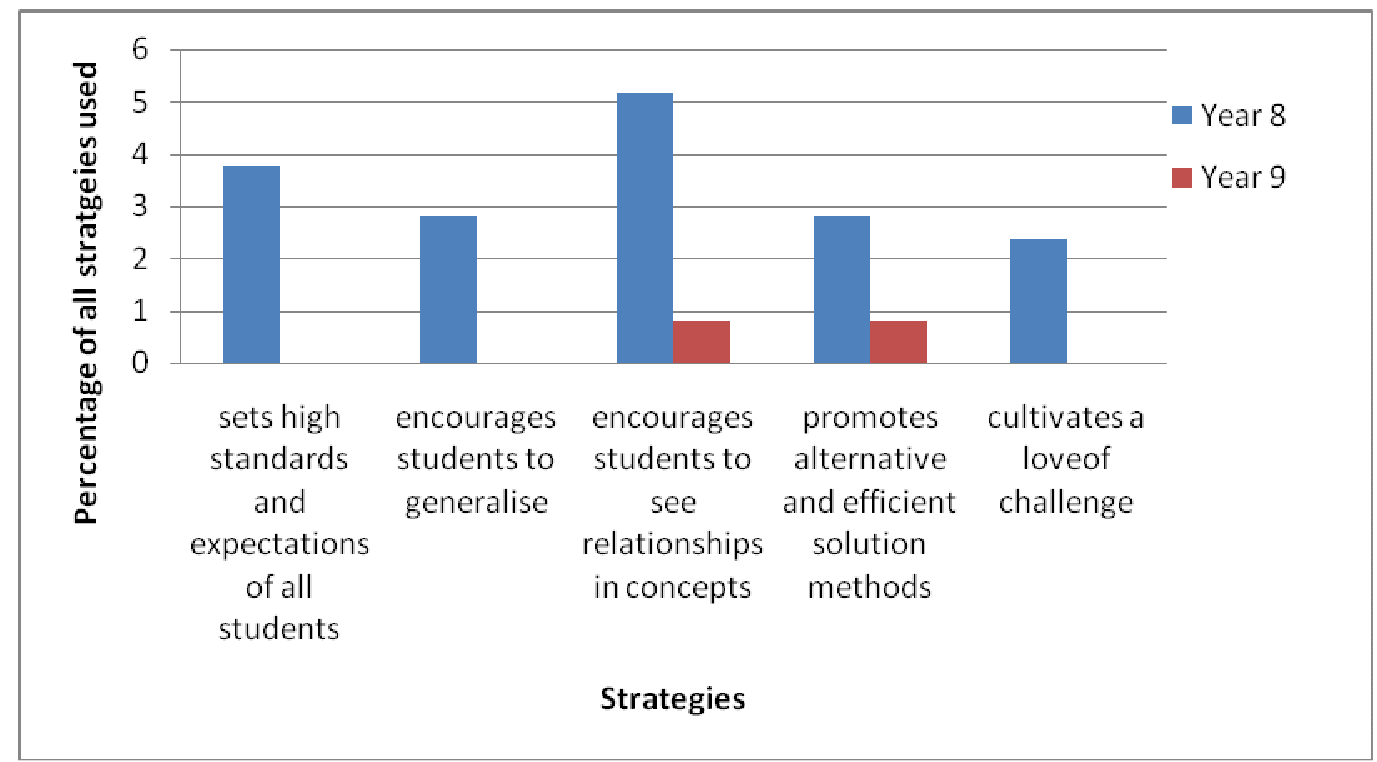

Figure 5.3: Comparison of the use of extending mathematical thinking strategies by Year 8 and Year 9 teachers

The occurrence of strategies that may be perceived to be counterproductive to the development of mathematical thinking was also noted (Figures 5.1 and 5.2).

In one of the observed Year 9 lessons, the study teacher had the potential to extend student thinking (in the researcher's opinion) but the teacher reverted to an instructional strategy and led the students to the result the study teacher wanted. The following excerpt illustrates this; the study teacher is trying to get students to reflect light from outside on a grass field, up a stairwell, and into the classroom.

Ok, so we are going to start from here, one group will be here. If they are here, where would they be reflecting their light to? Down there, so which group is going to be here? You guys here, your mirror, let's see if you can get it shining into the hallway. Over here Gordon, now, no 
leave it. Ok, so they have got it over there, we need to have a group over there that catches it. Let's all of us go on. You guys stay there. All the rest of you, this way.

This Year 9 study teacher is using an exercise that has the potential to promote higher order thinking and student cooperative problem solving. The teacher tells the students how to go about the exercise which is consistent with a conceptual system identified by Murphy and Brown (1970, p. 530) as unilateral dependence ${ }^{16}$. Year 9 study teachers often chose an algorithmic way of doing a problem and in the lessons observed did not appear to encourage mathematical thinking. When students were asked to undertake individualized work it was formulaic in nature with the students being instructed how to solve the problems step-by-step.

We are doing ex 15.1. It is just over the page. Before you start can you listen, before you start, that means before you do anything look this way, you need to make sure, it is on little grided areas of paper, make sure you count it out properly. You have got to draw up what's there. You've got to draw the mirror image. Count it out carefully; squares on that page match the squares in your book. So try and actually draw what is there not something out of your own head. So count out squares, look at directions, look at whether a line is going through corners, for the slanted lines how many squares across, how many squares up or down is there from one end of the line to the other of the line. Count it out properly. Ok let's get underway. (Year 9, Teacher 2)

A student following these instructions does not have to think what the question is asking but just follow the process. This was doubly reinforced by the use of text book questions where the answers were closed and only lower-order thinking was expected.

Individualised work with students was often in traditional IRF format (Kyriacou \& Issit 2008) in the Year 9 study classrooms (Section 2.3.2).

Degrees? Can you remember how many in a right angle like this [uses the window frame to illustrate] 90 and how many in this right angle here? [Using other side of window frame] How many would be straight across without that pole in the middle? (Year 9, Teacher 3)

\footnotetext{
${ }^{16}$ Teachers are the authority and will deliver the information to students.
} 
In the above vignette a student has asked for help in solving a problem involving adjacent angles on a straight line. The student had just wanted the answer, as that involved no thinking and the teacher tried to assist the student but was in effect leading them to an answer without extending their thinking.

The Year 9 study teachers showed a predisposition to product rather than process.

Ok, all I want to say is, are you ticking your answers? 'Cos it looks like you are doing good work but don't forget to tick your answers before you move on. (Year 9, Teacher 1)

This teacher was concerned that students mark their work: showing that the end product is the right one and that he was not necessarily concerned with how students got there.

The Year 9 study teachers often made statements showing that they did not expect their students to have much knowledge, of the world or of mathematics. Lack of mathematical expectations, by the Year 9 study teachers, is shown in the next vignette.

Anyone know, no you won't know so I will tell you, it is called the Fibonacci sequence. Da Vinci code .used Fibonacci numbers. He was an Italian mathematician, way, way back. It is actually very interesting if you look at things in nature, sun flower seeds, they spiral out and it follows that. (Year 9, Teacher 2)

The teacher did not expect the students to have heard of the Fibonacci sequence so answered their own question but did not carry on with an explanation or use the Fibonacci sequence as a teaching opportunity.

The Year 9 study teachers' expectation regarding work output and level was low. The Year 9 study teachers' set the quantity of work at a level that was often achievable by most of the class with time to spare. Students then caused control problems. This is illustrated in the following example.

What are you doing [two students being silly], you could have started your homework. (Year 9, Teacher 1).

That the Year 9 study teachers did not always expect work of a high quality is shown in the following vignettes: 
A poster, a nice big picture of the angle itself using rulers telling us what it is, what's the rule about yeah, if they are good enough we can hang them up, the wall's a bit bare at the moment.(Year 9, Teacher 3)

And when you get the first side done which is actually the easier side, flip it over and those are the ones that are a little bit more difficult. How many people are still working on the front side, ok when you get done with the front side, do the first one on the backside and then stop. Just the first one on the back side. Just the first one on the back side. (Year 9, Teacher 1)

In the first excerpt the teacher implies that not all of the students' work will make the grade (in fact none did as the poster was not collected in). In the second excerpt the teacher tells the students that the second side of the work sheet is difficult and then reinforces this by asking students not to go past question one as the teacher expected the students not to be able to work out the problem with out teacher help.

Monitoring of students' learning was at a consistent level for both of the year levels, $18 \%$ and $15 \%$ of all teaching strategies used at Years 8 and 9 respectively (Figure 5.5).

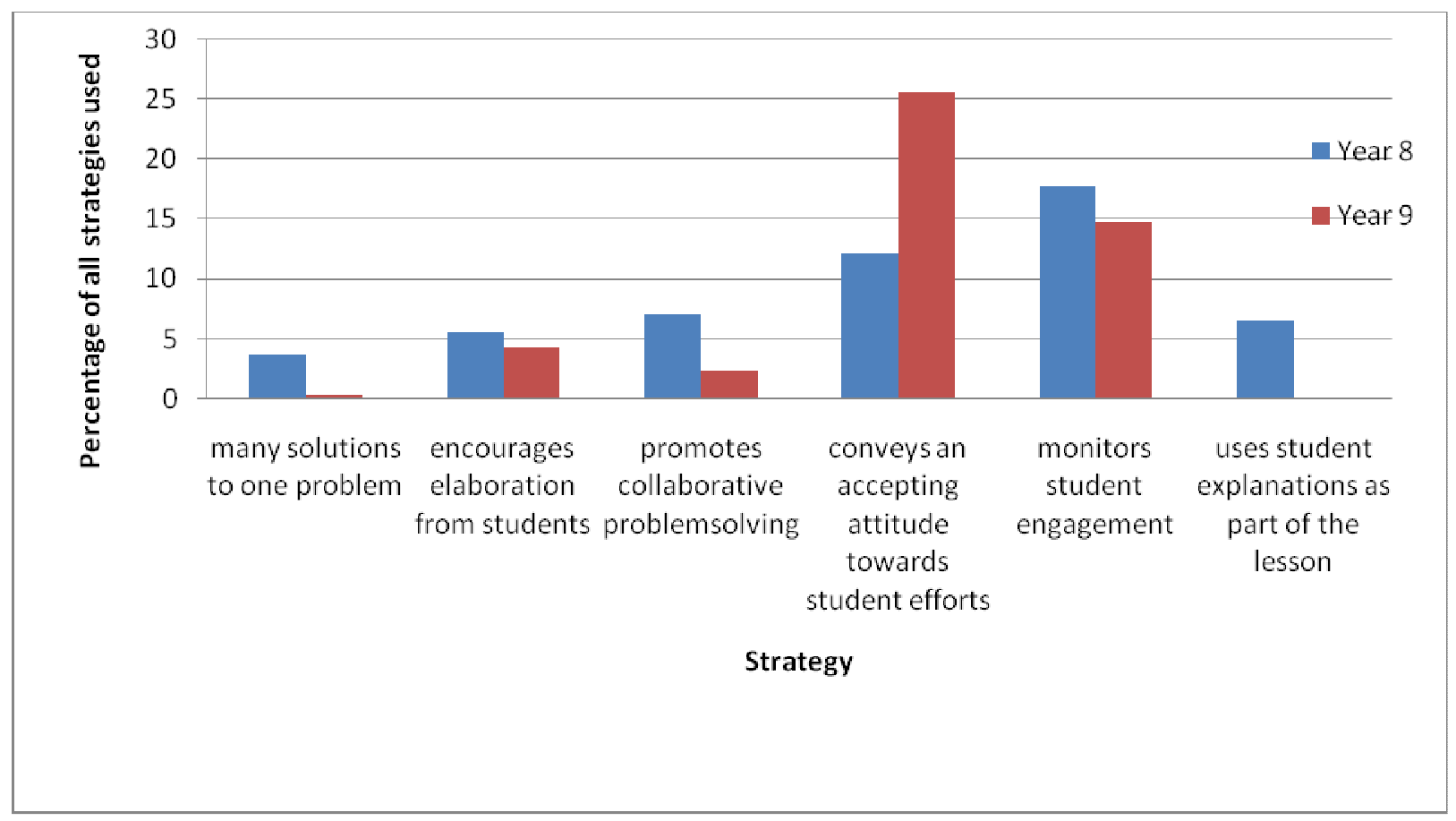

Figure 5.4: Comparison of eliciting strategies used by Year 8 and Year 9 teachers

Monitoring of student engagement was the most prevalent strategy for Year 8 teachers (Figures 5.4). The $99 \%$ confidence interval for difference in proportions is -0.06 to 0.12 , and as zero is within this interval there is may be no significant difference in the use of this strategy. This is an indication that all teachers at both year levels kept an eye on the 
engagement of the students in the lesson. They all displayed a desire to ensure that students were up-to-date with the work.

Ok, so. Everyone focus please. Johnny. Annie. What do we remember about the activity we looked at on Friday about the angles of a triangle? 1, 2, 3, angles. What do we remember finding. Johnny__ they did. Everybody remember that? (Year 9, Teacher 3)

This teacher is ensuring that students are listening by choosing students to ask questions of at random and then asking the whole class as well.

When students were working on their own, this monitoring of student engagement continued with the Year 9 study teacher walking around the class and continually checking on students. The Year 8 study teachers had less individualized time but were observed to follow the same pattern as Year 9 teachers with the teacher wandering around ensuring students were on task, understanding the mathematical activity, and engaged in solving the given problems. Examples of this strategy are:

David are you finished? Jasmine, yep use that. You alright, what's the problem? (Year 9, Teacher 2).

Yep, write the values in Yep, it is fifths and you are going to halve it and halve it again. Done that, write the values in.(Year 8, Teacher 5) you right there? (Year 9, Teacher 1)

The teachers monitored engagement and simultaneously checked understanding. Both year level teachers during whole class instruction, monitored student engagement by asking questions of different students at different stages of the lesson. They also used phrases like 'Does everyone understand that?' to try to gauge whether the topics were being understood.

All Year 8 study teachers at some stage in their lessons tried to elicit many solutions to a problem (Figure 5.4). This included the teacher who had a bottom stream class with some students still at the Stage 1 in the New Zealand Numeracy levels (refer to Appendix 3 for definitions of the stages). During the teacher lecture phase of the lesson all of the study teachers used student elaboration to explain the way they did a problem to the whole class at some stage. Whilst this was not the most prevalent strategy it is present $5 \%$ and $4 \%$ of the time at Year 8 and Year 9 respectively (Figure 5.4). 
The Year 8 study teachers tried to get students to explain their thought processes and work out approaches to solving problems that suited the individual student. They generally emphasised the importance of process and that there were many ways to solve a question.

Who knows the strategy for that? You can all do these easily. Vaughn? yep any one else do it that way? There is a much easier way isn't there? Ok Sean, what did you do? Yeah yeah (Year 8, Teacher 6)

In the Year 8 study classrooms teachers emphasised students using different methods to solve problems.

Ok so what strategy? What could we use? Yesterday we were using something. Put it down there guys ( some students brought notices into the room) and then we will just do that. Thinking time and then we will share. We will just see what ideas you can come up with, cos some people might have got different ways that we can actually do it. I can see two different ways already written down there.

(Year 8, Teacher 3)

Year 8 study teachers used a collaborative problem solving approach that was not evident in the Year 9 study classrooms (Figure 5.4). The Year 8 students seemed very comfortable working in small groups with the entire group contributing to the final solution. At times the whole Year 8 study class participated in solving a problem with each student being agreed or disagreed with by other students and the opinions of other students freely accepted.

Right. It is time we swung in to action I think and we have got, let's see. We have got, mmm, we have got this question here, in your groups, ready, go. \{hands question out to all groups, they problem solve it in the group, teacher checks solution and hands out new question if right](Year 8, Teacher 4)

This Year 8 study class was used to working in groups to solve problems and needed no further direction.

The Year 9 study students were encouraged to solve the problem by themselves and use their peers as a resource tool if they were struggling. If a student volunteered an answer that was 'wrong' their peers often let them know. This was not being collaborative as an 
exchange of ideas did not occur. Communities of learning were not evident in the Year 9 study classrooms.

Student explanations in the Year 8 study classrooms were encouraged and built upon. At no time was this observed to occur in the Year 9 study classrooms (Figure 5.4).

Can anyone else see Sam's thinking here? with your model show me. ok yeah oh, ok. I can, I can see their thinking they are saying ok this is 20\%, there is one of those to four, eh, (Year 8, Teacher 5)

This teacher used Sam's explanation and developed it as a point of instruction. Whilst the class eventually came to another conclusion, this teacher had shown that Sam's input was valued.

Year 8 study teachers also used student explanation when students were asked to come to the whiteboard and work a problem out, showing all steps of their thinking.

For the first one, what was heavier, 7250 gram bags of potatoes or a $3 \mathrm{~kg}$ bag? We have just worked out here, Miles and I what 7250 gram bags are, how much in total, who would like to show? Andrew? go up. You can do, it is alright you are going to show me how you worked it out here, (removes some posters from the board) here is your working space. You can show me the first one. What do you think is heavier 7250 gram bags of potatoes or a $3 \mathrm{~kg}$ bag? $o k$, how did get it, you show us ok, did draw anything in your book? __ Ok so you explain it ok, go on that's cool so go on Andrew, how did you work out what 7250 gram bags of potatoes added up to? and what answer did you get, - you got what, love, two thousand did you work out, you went 7 lots of 250, what is that yep so you went 7 times 200,(Year 8, Teacher 6)

The student was encouraged by the teacher to show how they worked the problem out and at each stage told the class what they were thinking. The teacher used facilitating questions to allow students to explain and extend their thinking. The student's efforts were reinforced by confidence building statements.

Only one of the Year 9 study teachers had a student write on the whiteboard and when they did the student was directed to how they should solve the problem. 
I've only got two dots so far what would be another good one to take, do you think? Ok, come on right up here please Bruce, we'll let him free hand it. [gets student to come to white board to do next point]. So he is going to do the bottom one, where are you going to go? Ok now he is just free handing it so you have got to give him a break, it won't be world accurate, you've got rulers. Ok and let's get a young lady volunteer, who is going to do the last one?

Ok Cassie, the class volunteered you for it. That's alright, come on. She is going to do what I would call the last important spot right, she picks the right spot to do. Yeah, pretty good, she went right down that same line ok, and can you draw in the 4, what does the final reflection look like? (Year 9, Teacher 1)

The two students both followed the example from the teacher who had already put two of the points in. During the student solution the teacher encouraged Cassie (though with mild praise 'pretty good') whilst for Bruce, accepted a low standard.

The strategies that were least evident in the study classrooms were those that were supportive of student thinking. As shown in Figures 5.2 the opposite strategy of 'did not support student thinking' was a frequent occurence.

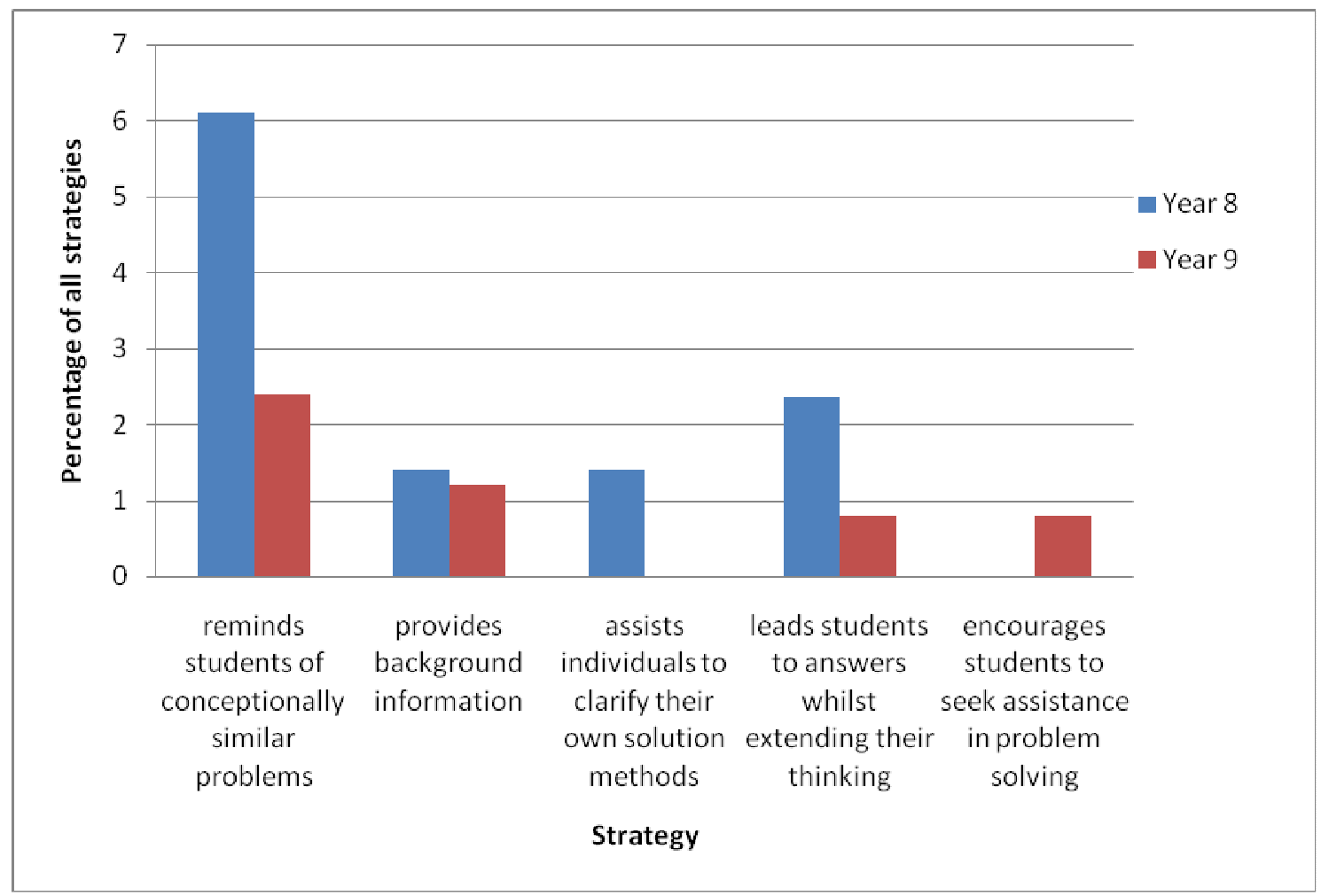

Figure 5.5: Comparison of supportive strategies used by Year 8 and Year 9 study teachers 
The Year 9 study teachers used as their most prevalent strategy 'leading students to answers without extending their thinking' (27\% of all strategies). An example of the type of strategy that 'leads students to answers without extending their thinking' is in the following vignette, the teacher is asking students to help solve a problem: 'How can we measure a reflex angle?'

How are we going to measure that angle with only half a circle? [holding protractor up] ___ Double it, so we are going to what? Well done. Ok next, we need to make a line straight down, don't we? And draw a $180^{\circ}$, don't we? And then we can take our protractor round. Ok, you've got 180 and then you put the protractor on here, reading from 0 around which is 140. [shows on diagram] Alright, I just measured that to be 140 and we know that this side is 180 , the bearing is? (Year 9, Teacher 3)

The students were just expected to fill in the gaps with the teacher providing the problem solving strategy through the use of right/wrong questions (Section 4.1).

The use of this strategy accounted for $8 \%$ and $27 \%$ of the strategies observed in the Year 8 and Year 9 study classrooms respectively. A confidence interval for difference of two proportions at the $99 \%$ confidence level gives an interval of -0.27 to -0.10 . As zero is not enclosed within this interval there may be a significant difference in the use of this strategy between the year levels. The Year 8 study teachers were less likely to use this strategy than Year 9 study teachers.

\subsection{Practice of New Content}

This section deals with how new mathematical concepts were introduced to students. The Year 8 study data is described first and then the Year 9 data and a comparison of the study classes' use of manipulatives and technologies is presented.

In the Year 8 study classrooms, the students were given little opportunity for individual work on new concepts. Opportunity for individual work was usually as part of the teacherlecture process when the teacher paused and gave students some quick questions or a short task to undertake.

Right here we go, in our heads we are going to say this and you will give me the answer, positive 3 add negative 6 equals? Negative 3. Negative 8 add 
negative 14 ? Negative 22, good. 6 or positive 6? Add negative 5.

Positive 1. Negative 4 subtract 4 , in your head you will be able to say negative 4 add? Negative 4 add? Add? Negative 4 add?

Which is? Negative 8. Who had negative 8? (Year 8, Teacher 4)

This teacher was using individual work from students during whole class instruction to check whether the concept taught had been universally understood.

The one Year 8 study teacher who set independent individual work used a text book that promoted hands on learning but for the topic observed this was at a lower-order thinking level.

New content was practised in the Year 9 study classrooms through problems that were closed, required lower order thinking, and were not connected to the real world. Two of the three Year 9 teachers relied heavily on text books, both for notes on the topic being learnt, and for individual student work. The third Year 9 teacher used a worksheet as well as a text book and for one of the observed lessons tried to involve the students in a problem solving exercise. The commonality was that all three Year 9 study teachers set individual (or paired) student work in text form, then circulated around the classroom checking on student engagement, effort, and understanding. The students were expected to follow sets of rules to answer problems, rather than to think them through for themselves.

That will stay up there; we are going to finish off the exercise we started yesterday, exercise 16.2 and do 16.3. All you have to be able to do is know left, right, up, down and count out squares (Year 9, Teacher 2).

This excerpt shows teacher instruction on how to rotate a shape by multiples of 90 degrees. What stayed on the board was a table showing that a rotation of 90 degree turned the point left, 180 degrees went down etc. Students needed no understanding of rotation but just needed to follow the pattern.

Manipulatives were observed to be used in five and one of the nine observed Year 8 and Year 9 lessons respectively. Two of the Year 8 study teachers used manipulatives to reinforce the concepts being taught. One used cardboard clocks as a telling time aid and the 
other fraction strips ${ }^{17}$ so students could visualise proportionality and its operations. The Year 9 study classrooms were all teaching a Geometry module so were using appropriate tools (protractors, rulers) with one using mirrors as an aid to visualizing a reflection. In post-videoing interviews the Year 8 study teachers stated that it was common for them to use manipulatives as a concrete tool focus of learning but the Year 9 study teachers said that it was uncommon for them to use manipulatives.

All Year 8 and one of the Year 9 study classrooms had use of a data projector. The majority of the time, when it was used, the data projector was used as a device to display starter questions or notes. The Year 9 study teacher who used it in one lesson showed the students the effect of rotation on a rectangle. The shape on the screen spun, but the teacher used paper to illustrate and told the students what happened. The use of the data projector was more for reinforcement than for exploration of a concept.

This is just a reminder and I will leave it up, ok $90^{\circ}$ there is your directions, up, down, left, right. You turn $90^{\circ}$; remember it is anti clockwise that is what happens to up, down, left and right. [On data projector image, shape rotates $90^{\circ}$ ].They have changed, what was up becomes left. What was left becomes down and so on [shows by turning a piece of paper with those directions written on it] ok you have already got this table from yesterday, if I do $180^{\circ}$ [rotates shape on screen] up and down swap, left and right swap, remember that April, so it is easy, you look at the original and how you get from the centre to a point. You count out squares, how many squares up, how squares left how many squares right; you then change your directions and count out the right amount of squares to get the image. you should already have this down. And 270 rotates around like that [shape spins on screen] [and spins the piece of paper] so your directions, just change. I will leave this up here on that for you to look at. (Year 9, Teacher 2)

One Year 8 study teacher used their computer as a timing device so students could experience a minute with a loud ring at the end of time. The other Year 8 study teachers did not use any technology during the observation period. When asked they said that it was not normally a strategy they employed as they preferred other methods that were more hands on for students e.g., fraction strips.

\footnotetext{
${ }^{17}$ A fraction strip is a rectangular piece of paper that is divided into equal parts to show fractions e.g. 4 parts for quarters.
} 
Teachers at both year levels set the same work for the whole class. The Year 8 study class that worked in groups rotated the groups through a series of identical activities. There was no differentiation of work for individual students.

\subsection{End of the Lesson}

This section describes how the study teachers brought their mathematics lessons to a conclusion. Similarities and differences between the study teachers are discussed.

The Year 8 study teachers recapped the lesson at the end in an attempt to ensure that all students had understood any new concepts taught. The following is an excerpt from one of the Year 8 study teachers that illustrates this point.

Ok listen up. Thank you. Eyes here. Now for my last perfect moment that is so important to me. Petunia. Kids we didn't get any where near where I wanted to and I am just a little surprised at a couple of kids who weren't quite as good at this as I would have thought. It is really easy you know, (picks up a strip of paper and folds it) one, halves, quarters, eighths and, and later we are going to use things like (holds the strip up) and some more to put them all together to start working out operations with fractions. And you can see it practically, ok thanks kids. (Year 8, Teacher 5)

All Year 9 teachers chose to close their lesson with asking the students to mark their work, and write down the homework in a diary, specifically for that purpose. There was little evidence of a recap of the important points and in most of the lessons the end seemed to be rushed.

Ok, um, I need every body's attention back here for a minute or two so save your conversation, you have had a little group time, ah if you didn't get all the book work done that is fine, I'll take a look and see how far you got during interval.

What was the type of idea we were working on today reflection and how can you check your reflections?___ fold how? Over how? Over the mirror line. We have some homework, so just settle. Just a second, gentlemen I appreciate you are trying to get your books away but I am trying to give out an assignment. Wayne, Edith. We want your attention up front; your home work is fairly simple. In your E5 
books I want you to write the capitals of the alphabet, A, B, C all of them, then, then put a mirror underneath each one and do what with them reflect them, use capitals as accurate as you can A-Z.(Year 9,Teacher 1)

You need to be getting your homework diaries out please 15.1 written in your homework diaries, when you have done that you may pack up please. Stay in the room. Cool. Get all the books away please, homework diaries. Thank you everyone. (Year 9, Teacher 3)

In the first excerpt the Year 9 teacher takes time to reinforce a learning objective of the lesson. The year 9 teacher in the second excerpt has no time to recapitulate the lesson and merely ensures that everyone knows the homework task.

\subsection{Pre-disposition to a Strategy}

The Year 8 study teachers had regular meetings that allowed them to talk about what was being taught and how it was being taught. This included NDP professional development and the Numeracy strategies inherent in it.

The Year 8 study teachers' scheme was developed from the NDP and therefore, whilst it stated specific learning outcomes it also showed a preferred way to teach: constructivist, problem based, contextual, and situated in real life. The Year 8 study teachers' lessons all showed evidence of the teachers trying to follow these guidelines.

The Year 9 study teachers had departmental meetings with (based on my previous attendance at these meetings) an administrative rather than a pedagogical focus. These teachers could be said to operate in 'professional isolation' (Hayes et al., 2006, p. 176). Very little discussion regarding effective pedagogy generally occurs at the meetings. This may change if the school joins in the secondary NDP (Harvey \& Averill, in press). Lesson delivery was implemented from the schemes the teachers were given at the start of the year.

The Year 9 scheme gave learning objectives from the New Zealand curriculum document (Ministry of Education, 1992) and specified page numbers from a text book that had relevant exercises. This may have led the teachers to be predisposed to a behaviourist, structured, and skills practice way of teaching. The Year 9 study lessons were all of a didactic nature, similar to what Kyriacou and Issitt (2008) discovered in England. No 
evidence of a pedagogical practice that encouraged student mathematical thinking was evident in the Year 9 study classrooms.

\subsection{Summary}

All study teachers used similar strategies at the start of the lesson. Year 8 study teachers tended to use strategies that extended and supported mathematical thinking when delivering new content. Year 9 study teachers' most prevalent strategy in all parts of the lesson was one that did not extend mathematical thinking. Strategies that elicited responses were strongly represented at both study year levels (Figures 5.1 and 5.2). The implications of these results will be discussed in Chapter 6 . 


\section{Chapter 6: Discussion/Conclusion}

This research set out to identify prevalent teaching strategies (with specific focus on teacher talk, equipment use, and activity style) used in Year 8 and in Year 9 mathematics classrooms. Three Year 8 and three Year 9 teachers of mathematics each had three lessons observed and video taped. Content analysis of the transcribed lessons was used to identify the prevalent strategies. This chapter provides a summary of the results from the previous two chapters with the purpose of showing how this research adds to the understanding of this stage in the educational lives of New Zealand students. Whilst due to the small sample size used in this study, generalisations cannot be inferred to all Year 8 and Year 9 mathematics classrooms in New Zealand; this research provides a starting point for consideration of teaching strategies across the transition stage.

Teacher talk will be discussed in Section 6.1, equipment use in Section 6.2, and activity style in Section 6.3. Section 6.4 presents limitations that might have impacted on the reliability and transferability of the findings of this research. Implications to be made from this research are indicated in Section 6.5. Further research ideas that arise from this study are proposed in Section 6.6.

\subsection{Teacher Talk}

Teacher talk in this study consisted of the statements made and questions asked by the observed teachers during their mathematics lessons (Section 4.1). This section explores the differences that were observed between the Year 8 and Year 9 study teachers and how teacher talk relates to the teaching strategies outlined in Section 2.4.

As shown in Figure 6.1, both year levels in this study used a high proportion of right/wrong type questions but there was a significant difference, as indicated by confidence interval analysis, in the proportion used. The Year 9 study teachers tended to use only right/wrong questions. The Year 8 study teachers incorporated facilitating and eliciting questions into their lessons. The difference in the type of questioning used in the classroom was one way, (the researcher felt) the Year 8 study teachers promoted mathematical thinking in their classrooms. 


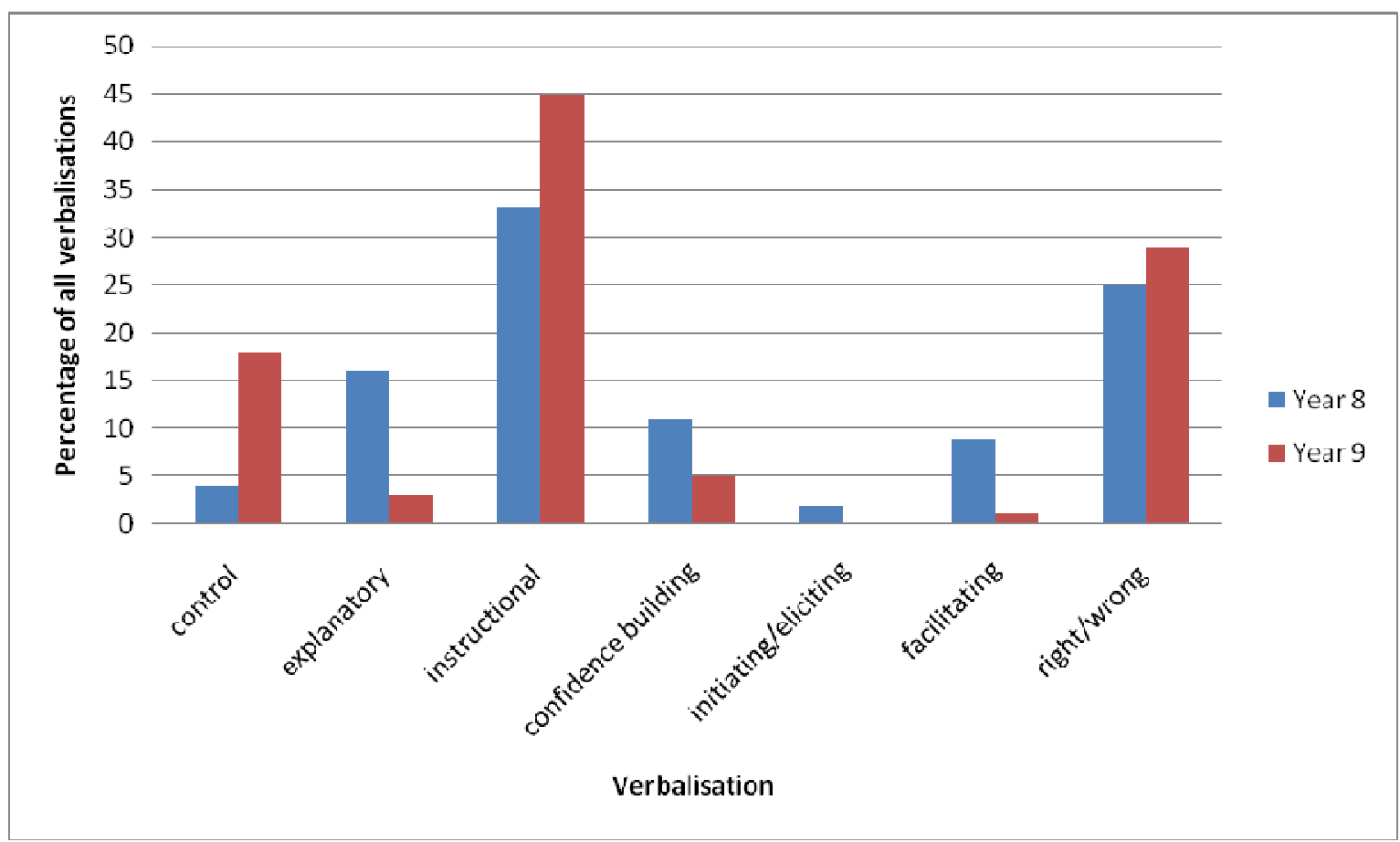

Figure 6.1: Verbalisations in the classrooms

In the type of statements used (Section 4.1) there were significant differences (as indicated by confidence interval analysis) between the two year levels in their use of instructional, control, explanatory, and confidence building statements. The Year 9 teachers used instructional and control statements more than the Year 8 study teachers. As this type of statement is more dominant in a didactic classroom (Boaler \& Greeno, 2000) this result was expected. That Year 8 teachers had a higher percentage of explanatory statements was also an expected outcome as the introduction of the NDP in the Year 8 classrooms has promoted the process of solution rather than straight computation (Higgins, 2002; Ward, Thomas \& Tagg, 2006). The higher use of confidence building statements by the Year 8 teachers in this study is evidence of the supportive nature of these teachers' strategies (Hayes et al., 2006).

Instructional statements were the most prevalent teacher talk used by both Year 8 and Year 9 study teachers. There was, however, a difference in the content of the instructional statements (Section 4.3.1). Instructions given in the Year 8 study classrooms were mainly used to direct students to their work for the day. The Year 9 study teachers also used instructional statements to impart mathematical knowledge. This had the effect of focusing lessons on lower-level cognitive strategies and did not extend the students' thinking (Hayes et al, 2006). This type of instruction also may not allow the students any sense of ownership, autonomy, or control in decision making and is likely to have an adverse effect 
on student engagement (Eccles et al., 1993; Mizelle \& Mullins, 1997; Eccles \& Wigfield, 1997). The boredom that this may cause students was shown in Pietarinen's (2000) Finnish case study.

As suggested by McGhee et al. (2004) the observed Year 9 classrooms did have an emphasis on teacher control and discipline. This was evidenced by the number of control statements $(18 \%)$ made by the Year 9 study teachers, whilst control statements only accounted for $4 \%$ of the verbalisations in the Year 8 study classrooms. The Year 9 study teachers did not seem to have developed a community of learning (Hayes et al., 2004) to the same extent as the Year 8 study teachers and therefore the environment may not have been as supportive of students or physically satisfying (Pointon, 2000). The use of few control statements in the Year 8 study classrooms may be indicative of the level of engagement of the students and the high level of expectation of attention from the teachers.

The Year 8 and Year 9 study teachers tended to use right/wrong questions as their question of choice. Right/wrong questions are closed in nature and involve the predominant use of teacher-talk that is of an initiation-response-feedback format. The Year 8 teachers in this study also used initiating/facilitating questions frequently (11\% of verbalisations). The use of facilitating and eliciting statements and questions were also possibly a result of the teachers' involvement in the NDP consistent with the findings of Irwin and Woodward (2004), Higgins (2002) and Ward et al. (2006). Use of other questioning strategies meant that the Year 8 teachers promoted the use of higher-order thinking (see Section 4.2). Their students were asked to see relationships between concepts and asked to generalize. The Year 8 study teachers challenged their students to see past the straight procedural method and look for deeper understanding.

The Year 9 study teachers exhibited a prevalent teaching strategy of 'leading students to answers without extending their thinking' as stated by Hayes et al. (2006). Checking on student engagement and the use of encouraging statements for correct responses to right/wrong questions were also prevalent teaching strategies in the Year 9 study classrooms. The Year 9 teachers in this study, whilst frequent in their use of praise, did not exhibit strategies that showed they expected a high mathematical standard from their students. The Year 8 study teachers' use of explanatory and confidence building statements showed that they were creating a supportive learning environment as discussed by Anthony \& Walshaw (2007). 
All study teachers, in the researcher's opinion, had established communities of learning with supportive classrooms. Practices used were consistent with the supportive strategies of the productive pedagogy framework (University of Queensland, 2001) as their prevalent teaching strategies. Encouraging student elaboration, using student explanations, and monitoring student engagement were all well represented in the Year 8 study classrooms. Year 9 study teachers were not observed to use student explanations but did encourage student elaboration and monitor student engagement to a similar extent to the Year 8 study teachers.

The major differences between Year 8 study teachers' and Year 9 study teachers' teacher talk appears to be the emphasis that the Year 8 study teachers placed on those elements of teacher talk that improve the intellectual quality of the classroom: use of eliciting and facilitating questions, encouragement of higher-order thinking, and less use of control statements.

\subsection{Equipment Use}

The use of manipulatives and other tools were not evident as strategies in the Year 9 study classrooms. The Year 9 teachers in this study, in informal discussions post videoing, indicated that they infrequently used manipulatives or tools as a strategy to stimulate mathematical thinking. In contrast the Year 8 study teachers used a variety of equipment. The use of manipulatives (e.g., fraction strips) and other tools is an expected consequence of the Year 8 study teachers involvement in the NDP (Thomas \& Ward, 2001).

Data projectors were evident in all the Year 8 study classrooms but only used once as a timing device. The use of technology (data projector) was restricted, during the observation period, in the Year 9 classrooms to being used for display of starter questions and notes. When it was used in its capacity to manipulate shapes, it was used as reinforcement of previously given notes. This may be an area for future professional development for teachers at both year levels.

\subsection{Activity Style}

This section looks at the delivery of the content, the structure of the lesson, and resources utilised for student practice. Delivery of content is considered from the philosophical view. Lesson structure observed is compared to the structure found internationally in the TIMSS (2003) study. Resource use incorporates textbook, worksheet, and whiteboard usage, and 
teacher dictated resources. Resource usage identifies whether the work given to students demonstrated connectedness (Section 2.4.2).

The Year 8 study teachers appeared to use mainly constructivist approaches with all emphasising how knowledge is constructed (Section 5.4.5). Year 8 study students' understanding was developed through accepting different ways of doing a problem (Section 5.4.1). The Year 8 study classrooms exhibited a content focus (Thompson, 1992) with an emphasis on conceptual understanding. The emphasis seemed to the researcher, to be on the approach to a problem and not its solution in the Year 8 study classrooms. The interpretation of conceptual understanding in the Year 8 study classrooms appeared to be consistent with

having meaning for mathematical symbols and operations, interpreting results, making connections amongst ideas or representations and understanding why particular procedures work (Lobato, 2008, p. 596).

The Year 9 study teachers seemed to be behaviourist in their approach to delivery of content. A focus on results and not process was evident in the content delivery. The Year 9 study classrooms exhibited a content focus (Thompson, 1992) with an emphasis on performance. Year 9 teachers in this research demonstrated, in the researcher's view, a meaning of conceptual understanding that did not attempt to engage student thinking. Best defined by Lobato (2008) "concept is used to mean topic and understanding to mean computational fluency" (p.596), the Year 9 study teachers appeared satisfied if students could solve problems following given instructions. The Year 9 study teachers were content focused and emphasised performance. The Year 9 study teachers spent a large proportion of the time on giving the students notes, asking the students to copy from a text, or to perform tasks that relied on repetition and practice. The Year 9 study classrooms observed were didactic (Boaler \& Greeno, 2000) in nature: defined by text books, rules, and procedures. Students were given an algorithmic way to solve problems with little or no mathematical thinking needed. This was consistent with Ward's (2000) New Zealand study of students across a similar transition.

The format of the observed Year 9 lessons was similar to international mathematics classrooms (Mullis et al., 2004): teacher-lecture and practice. The teacher-lecture component in the Year 9 study classrooms was behaviourist in nature with teachers using an instructional strategy that did not seem to facilitate, elicit, or encourage mathematical thinking. The strategy was predominately teacher initiation-response-feedback (Kyriacou 
and Issit, 2008) but with the teacher as the sole decision maker during whole class discussion as in the findings of Ball and Bass (2000).

Whole class tasks were used by all the Year 8 study teachers and the structure of the lessons consistent with the most prevalent internationally: teacher-lecture and student practice (Mullis et al., 2004). In other ways, the Year 8 study teachers were dissimilar to each other in their approach to classroom organization and teaching style. One teacher utilized small groups and teacher aides, and rotated the groups to give all students within a week some time with the teacher using teacher-guided student practice. The other two teachers taught the whole class with individual practice the norm for a part of the lesson when the teacher needed to see how much had been understood.

The Year 9 teachers in this study all showed a similar teaching style to one another: emphasis on factual knowledge delivered using teacher-centred strategies. The format of the lesson was the same for all the Year 9 teachers observed: starter activity; teacherlecture; individual practice of a new skill; and homework given. This was grounded in the mathematical scheme that all the teachers worked from and on instructions issued at department meetings as the way to best control students (Section 5.3). The organisation of the Year 9 study teachers within a department may be responsible for this similarity (Talbert \& McLaughlin, 2001).

Resources used varied between the year levels. Only one of the Year 8 teachers used a text book as the basis of their lessons and it was only used by one group of three, at any one time, in the classroom. The other two groups did practical tasks or experienced interactive time with the teacher. The other two Year 8 study teachers used a variety of different activities: work sheets; whiteboard questions; Mathletics questions; and problems that the teachers invented. The Year 9 study teachers all used a text book as the basis for two out of the three lessons observed, both for notes and for practice questions. In other lessons worksheets were used, whole class problem solving tried, and the creation of a poster suggested.

Connecting mathematical ideas to the world was also evident in the observed Year 8 classrooms. The Year 8 study teachers all incorporated the use of real life problems, students' background experiences, and prior knowledge. One teacher used a narrative/expository style that encouraged the students to use metaphor and drama to help construct their understanding of mathematical concepts (Section 4.5). The Year 9 study 
teachers reliance on a text book meant that the tasks students were asked to perform had little relevance to them and displayed little connectedness to the world (Section 4.4).

\subsection{Conclusions}

It is evident from this study that students undergoing this particular transition experience a change in the way they are taught mathematics. This may be a contributing factor in the drop in achievement at this point in a student's life. Achievement before and after transition was not measured in this research but there is no reason to suspect that the students undergoing this transition are any different to those in the studies previously cited (Anderson et al., 2000; Barone et al., 1991; Birmingham Core Skills Development Partnership, 1998; Ministry of Education, 2008; National Middle School Association, 2006).

The Year 8 teachers in this study used strategies that fall into the productive pedagogy areas of intellectual quality, connectedness, and supportiveness. They exhibited characteristics that promoted higher-order thinking, had a base in real life, and behaviour was on task with all students' engaged in mathematical activities. The Year 9 classrooms in this study showed the converse. Strategies used promoted lower-order thinking, were based in a mathematical context, and students frequently needed reminding to stay focused.

The Year 9 classrooms observed were dependent on textbooks and the activities were all closed in nature and set in mathematical contexts. In contrast, the Year 8 teachers in this study were not reliant on text books and used some open questions with real-life contexts relevant to the students. The activities undertaken by the Year 8 students showed more variety in type including practical explorations, open-ended problems, practicing of a skill, and using manipulatives to demonstrate concepts. The majority of the Year 9 activities were repetitive practice of a skill and did not require higher-order thinking.

\subsection{Limitations}

The data gathering for this research was undertaken approximately three-quarters of the way through the New Zealand school year. The timing of this may have impacted on the teaching strategies used. Towards the end of the school year, Year 8 teachers may have been starting to 'prepare' their students for secondary school and may have been using strategies they felt to be similar to those used in Year 9. The Year 9 teachers may have 
moved away from strategies they felt were appropriate across the transition and into those they felt would help prepare students for National Qualifications starting in Year 11.

The use of the researcher's own school may have limited the reliability of the data in that the teachers observed may have been trying to teach in ways they thought the researcher would like them to. The researcher's emphasis that the videoing was solely for the purposes of research and not for other purposes (e.g., appraisal ${ }^{18}$ ) may have mitigated this but the effect of having an authority figure, their Head of Department, in the class room may still have affected the data. Similarly, the intermediate teachers' practice may have been affected by a perception that the researcher had more expertise than they in the area of mathematics teaching (being a specialist in the field) and they may have tried to teach lessons that they thought the researcher would approve of.

The research was limited in scope to only one secondary school and one intermediate school. This was a limitation imposed by the size of a masterate study and time constraints. However, as the schools involved in the research are directly linked and therefore any findings are relevant to the intermediate-secondary transition. It is important to acknowledge that whilst comparison can be made for the two schools involved, it cannot necessarily be extrapolated to the larger population of schools in New Zealand. It can though be used as a starting place to explore transitions in other geographical areas, other transitions in a student's life, and transitions across the same point in different curricula areas.

The teachers observed may not have been representative of all the teachers at that Year level as only three teachers at each of the Year levels were observed. The timing of observation, in terms of the calendar year meant that the teachers were compared teaching different strands of the New Zealand Curriculum and this may have impacted on the strategies that the teachers employed because teachers may use different strategies for different strands or parts of strands (Section 3.3.3).

The use of the categories for analysis whilst based on The Advanced Children's thinking study (Fraivillig et al., 1999), the Queensland School Reform Longitudinal Study (School of Education, University of Queensland, 2001), and the Best Evidence Synthesis Iteration [BES]: Effective Pedagogies in Mathematics (Anthony \& Walshaw, 2007) was subjective

\footnotetext{
${ }^{18}$ In NZ secondary school the Head of Department appraises the teachers within that department for certification and quality assurance purposes.
} 
and other researchers may have categorised exhibited strategies slightly differently. A greater number of researchers involved in categorizing the strategies than allowed by masterate study may have led to a more vigorous analysis process.

Some of these limitations may be mitigated if the research was extended in the following ways:

- all feeder schools to this particular secondary school were observed;

- conversely, the other secondary schools that this particular intermediate feeds were observed;

- the research could be conducted at a time when the teachers in both schools are teaching the same topic, allowing a truer comparison of teaching strategies as similar content would be being delivered; and

- the observation of all teachers at both year levels in these schools.

None of these limitations negates the finding that the prevalent teaching strategies employed by the Year 8 and Year 9 teachers were different.

\subsection{Further Areas for Research}

This research indicates a variation in teaching strategies across the Year 8, Year 9 transition. This research raises questions about the impact of different teaching strategies and questions that could be explored in other studies are:

- Does a difference in teaching strategies make a difference to student outcomes for this particular transition?

- What are students' perceptions and opinions regarding changes in teaching strategies between intermediate schools and secondary schools?

- How do teaching strategies influence student motivation? and

- Does good communication between schools help students manage the transition process?

- What impact does the involvement in the NDP have on secondary schools? (research currently being undertaken by Harvey and Averill (In Press) 


\subsection{Implications}

Despite the limitations discussed above, this study indicates there is a disparity in the teaching strategies used in Year 8 and Year 9 classrooms. More communication about what and how mathematics is being taught between schools may help to reduce the disparities between schools and help develop an understanding of what occurs in the classroom at each year level. Year 9 students could benefit from their teachers building communities of learning like those in the Year 8 classrooms. The level of mathematical thinking encouraged at Year 8 seems to be lower in Term 3 of Year 9. The introduction of more authentic questioning (Anthony \& Walshaw, 2007; Cazden, 2001; Fraivillig et al, 1999; University of Queensland, 2001) exhibiting a connectedness to the environment may help sustain a higher level of thinking at Year 9.

McGhee et al.s' (2004) findings that most secondary schools were characterised by greater emphasis on teacher control and discipline with less opportunity for decision making than primary school mathematics classrooms was supported by this study. Their finding that secondary teachers were more likely than primary teachers to use whole class teaching is not supported by this study as five of the six teachers observed used whole class teaching as their main mode of delivery.

Students have claimed boredom and a lack of challenge in the secondary classroom (Office of Her Majesty's Chief Inspector of Schools, 2002; Suffolk Education Department, 1997; Ward, 2000) and if many New Zealand secondary classrooms exhibit the lack of extension of mathematical thinking shown by those in this study then this may be a serious concern for us. Lower cognitive strategies were used, there was an absence of ownership of the learning, and decreased decision making at secondary school, therefore the personenvironment fit (Eccles et al., 1993; Eccles and Wigfield, 1997; Mizelle and Mullins, 1997) was not maximised.

Reform movements towards a more constructivist approach as defined by Fraivillig et al. (1999), were not evident in the secondary classrooms in this study. Secondary teachers gave more notes than the intermediate teachers, consistent with Ward's (2000) findings. Students themselves have requested less 'copy' and more variation in their mathematics classrooms (Ministry of Education, 2008).

The use of facilitating and eliciting questions in the Year 8 study classrooms is further evidence of the 'new' language brought about by their participation in the NDP (Anthony 
\& Walshaw, 2006). This further supports Thomas and Ward's (2001) finding that an outcome of the NDP is more use of equipment, eliciting, and facilitating questioning as well as an increased use of student explanation as part of instruction.

Year 9 teachers in this study are similar to the United States teachers described by Hiebert (1999) in that they presented the problem, showed the solution, and then students practised solving similar problems. This process does not enhance the intellectual quality of the classroom and is a strategy that may contribute to students being disengaged in their learning.

Connectedness to the environment was lacking in the secondary classroom but present in the Year 8 classrooms. The amount of connectedness may have an impact on student enthusiasm for learning and hence their engagement. The Ministry of Education [Research Division], (2008) found the work in the secondary classroom was often irrelevant to the students and this led to the students' enjoyment of mathematics dropping. The number of control statements the secondary teachers used may be a consequence of this.

The observed secondary school mathematics classrooms exhibited teacher centred teaching with emphasis on specific knowledge, similar to Talbert and McLaughlin's (2001) findings. The Year 9 teachers used text book questions and notes significantly more often than the Year 8 teachers. The secondary school is more likely to have a vocational/neoclassical orientation (Kemmis, Cole \& Suggett, 1983) because of the emphasis placed on the national examination structure and a government focus on preparation for work. This may mean that in Year 9 the person-environment fit is not satisfactory for the student as they are not yet at this developmental stage.

Hayes et al. (2006) are emphatic that teachers' pedagogical practices do make a difference. The strategies that teachers employ are a result of their pedagogical content knowledge (Peterson et al., 1989). Involvement in the NDP and other similar professional development opportunities have positive consequences for the type of strategies the teacher employs as was shown in this study by the strategies the Year 8 teachers chose. It was a goal of the NDP to improve teachers' understanding of number concepts, student strategies, and instructional practice (tki.org.nz, 2008). There has been a pedagogical shift away from algorithmic teaching as a consequence (Young-Loveridge, 2007). This research suggests that in the study intermediate school some teachers are using the strategies that the NDP proposes. 
In a broader context, communication between schools may be something that needs to be developed. Year 9 and Year 8 classrooms exhibit completely different cultures, standards, expectations, rules, and norms of behaviour. Year 8 teachers could pass on information about what they have been teaching and this could be compared to the expectations of Year 9 teachers, without either year level being dictatorial. As the seamless nature of the curriculum has not improved the negative impact of transition (Higgins \& Knight, 1997), other aspects of curriculum delivery need to be studied. It is how teachers deliver the curriculum that makes a difference (Galton \& Willocks, 1983).

This study indicates that discussion of pedagogy and how it affects students, particularly across the transition period, needs to take place within secondary mathematics departments. More communication between Year 8 and Year 9 mathematics teachers to compare pedagogical approaches to teaching particular topics may aid students' transition. The impact of this study may be an alteration in the teaching strategies used in the Year 9 classrooms of the researcher's secondary school to incorporate more of the productive pedagogies that encourage students to think mathematically.

\subsection{Implications for the Wider Education Community}

The findings of this study have implications for a variety of stakeholders in the education sector. Year 8 teachers could be encouraged to interact with Year 9 teachers regarding what the mathematics taught in Year 8, how it is taught, and why it is taught. Year 9 teachers could be encouraged to take more notice of what is occurring in Year 8 mathematics classrooms and try to incorporate some similar strategies into their lessons, make more allowance for prior learning, and try to include problems that recognise students' experiences.

Introduction of new curricula and new ideas need the full support of the government to allow schools time to implement the changes required at the teaching strategy level. Discussions that involve Year 8 and Year 9 teachers jointly may help students adjust to transition.

Parents could be more aware of schools' transition programmes as part of their decision making process when they choose the secondary school for their child. Prior learning could be something that parents discuss at parent-teacher interviews at the new secondary school. 
This research will enable a better understanding of mathematics instruction occurring in New Zealand classrooms at Year 8 and Year 9 which may be used as a starting point for professional development in our school in the future and may inform the professional development of others. This research may help to inform practices that will aid students in the transition between the two year levels and help teachers in Year 9 to understand the pre-conceptions/pre-conditioning of their students, with respect to the teaching and learning of mathematics, prior to entry in their classrooms.

In summary, this research has found that students do experience mathematics teaching at Year 9 that uses teaching strategies significantly different to those of their Year 8 teachers. It is important that the effects of these differences be investigated further. Reduction in the differences in teaching strategies across the transition stage may halt the decline in mathematics achievement, enthusiasm, and engagement that is currently evidenced at this stage in students' lives. 


\section{References}

Ailwood, J., Chant, D., Gore, J., Hayes, D., Ladwig, J., Lingard, B., Luke, A., Mill, M., \& Warry, M. (1999, November). Productive pedagogies: A multidimensional model of classroom practice. Paper presented at the meeting of the Australian Association for Research in Education, Melbourne, Australia.

Anderson, P. (2005). The meaning of pedagogy. In J. L. Kincheloe (Ed.), Classroom teaching: An introduction (pp. 53-70). New York: Peter Lang.

Anderson, M., \& Fergusson, P. (2007, November). Accessing teachers' views on their practices. Interviews using mixed methods. Paper presented at the annual conference of the Australian Association for Research in Education, Fremantle, Australia.

Anderson, L., Jacobs, J., Schramm, S., \& Splittgerber, F. (2000). School transitions: beginning of the end or a new beginning? International Journal of Education Research, 33(4), 325-339.

Annan, B., The numeracy development projects: A successful policy-research-practice collaboration. Findings from the New Zealand Numeracy Development Projects. Retrieved August 3, 2007 from http://www.tki.org.nz/r/literacy_numeracy/num_projects_e.php

Anthony, G., \& Walshaw, M. (2006). Numeracy practices and change. Wellington: Teaching and Learning Research Initiative.

Anthony, G., \& Walshaw, M. (2007). Effective pedagogy in mathematics/pāngarau: Best evidence synthesis iteration. Wellington: Ministry of Education.

Archer, J. (1999, November). Teachers' beliefs about successful teaching and learning in mathematics. Paper (ARC99491) presented at the combined meeting of the Australian Association for Research in Education and the New Zealand Association for Research in Education, Melbourne, Australia.

Artzt, A. F., \& Armour-Thomas, E. (1998). Mathematics teaching as problem solving: A framework for studying teacher metacognition underlying instructional practice in mathematics. Instructional Science, 26(1-2), 5-25.

Ball, D. L. (1993). With an eye on the mathematical horizon: Dilemmas of teaching elementary school mathematics. The Elementary School Journal, 93(4), 373-397.

Ball, D. L., \& Bass, H. (2000) Interweaving content and pedagogy in teaching and learning to teach: knowing and using mathematics. In J. Boaler (Ed.), Multiple perspectives on mathematics teaching and learning (pp. 83-105). Westport, CT: Ablex Publishing.

Barone, C., Aguire-Deaudreis, A. L., \& Trickett, E. J. (1991). Means-ends problem-solving skills, life stress, and social support as mediators of adjustment in the normative transition to high school. American Journal of Community Psychology, 19(2), 207225.

Berg, B. (2007). Qualitative research methods for the social sciences (6 ${ }^{\text {th }}$ ed.). Boston: Pearson Education Inc. 
Birmingham Core Skills Development Partnership. (1998). Bridging the gap from primary school to secondary. Retrieved April 2, 2008, from http://www.coreskills.co.uk/activities/pupilsatschool/bridgingthegap.html

Boaler, J., \& Greeno, J. G. (2000). Identity, agency and knowing in mathematics worlds. In J. Boaler (Ed.), Multiple perspectives on mathematics teaching and learning (pp. 171-201). Westport, CT: Ablex Publishing.

Bogden, R., \& Biklen, S. (2007). Qualitative research for education: An introduction to theory and methods $\left(5^{\text {th }}\right.$ ed.). United States of America: Pearson Education.

Bolton, D., \& Hammersley, M. (2006). Analysis of unstructured data. In R. Sappsford \& V. Jupp (Eds.), Data collection and analysis (2nd ed.) (pp. 243-259). London: Sage.

Borko, H., \& Whitcomb, J.A. (2008). Teachers, teaching and teacher education: Comments on the National Mathematics Advisory Panel's Report. Educational Researcher, 37 (9), 565-572.

Brooks, J. G., \& Brooks, M. G. (1993). In search of understanding: A case for the constructivist classroom. Alexandria, VA: Association for Supervision and Curriculum Support. Retrieved January 9, 2009 from http://www.sedl.org/scimath/compass/v01n03/1.html

Brown, C. A., \& Smith, M. S. (1997). Supporting the development of mathematical pedagogy. The Mathematics Teacher, 90(2), 138-143.

Carpenter, T. P., Fennema, E., Peterson, P. L., Chiang, C. P., \& Loef, M. (1989). Using knowledge of children's mathematics thinking in classroom teaching: An experimental study. American Educational Research Journal, 26(4), 499-531.

Cazden, C. B. (2001). Classroom discourse: The language of teaching and learning. Portsmouth: Heinemann.

Clarke, D. (1985). The impact of secondary schooling and secondary mathematics on student mathematical behaviour. Educational Studies in Mathematics, 16(3), 231257.

Cobb, P. (1994). Where is the mind? Constructivist and sociocultural perspectives on mathematical development. Educational Researcher, 23(7), 13-20.

Cocklin, B. (1999). A Journey of transition: From Gumly Gumly public to secondary school. Wagga Wagga: Charles Sturt University. Retrieved June 4, 2008, from http://www.aare.edu.au/99pap/coc99595.htm .

Cohen, L., Manion, L., \& Morrison, K. (2007). Research methods in education (6 $6^{\text {th }}$ ed.). New York: Routledge

Cohen, D. K., Raudenbush, S. W., \& Ball, D. L. (2003). Resources, instruction and research. Educational Evaluation and Policy Analysis, 2 (2), 119-142.

Collins, J., \& Harrison, B. T. (1998). Claiming and reclaiming an education: the experience of multilingual school students in transition from primary to secondary school.

Unicorn, 24(1), 16-29.

Delamont, S. (1983). The ethnography of transfer. In M. Galton \& J. Willocks (Eds.), Moving from the primary classroom (pp. 95-154). London: Routledge.

Denscombe, M. (2004). The good research guide for small scale social research projects. Buckingham: Open University Press.

Department for Children, Schools and Families. (2008). Strengthening transfers and 
transitions: Partnerships for progress. Retrieved August 1, 2008, from http://www.dcsf.gov.uk/index.htm

Eccles, J. E., \& Wigfield, A. (1997). Young adolescent development. In J. L. Irvin (Ed.), What current research says to the middle level practitioner? (pp. 15 - 29).

Columbus, OH: National Middle School Association.

Eccles, J. S., Wigfield, A., Midgely, C., Rueman, D., Mac Iver, D., \& Feldlaufer, H. (1993). Negative effects of traditional middle schools on students' motivation. The Elementary School Journal, 93(5), 553-574.

Education Review Office. (2002). Maori students: School making a difference. Retrieved 31 January, 2009, from http://www.ero.govt.nz/ero/publishing.nsf/Content/M\%C3\%A4ori\%20Students:\%C2\%A0 Schools\%20Making\%20a\%20Difference\#Establishing\%20good\%20practice

Education Review Office. (2006a). The quality of teaching in years 4 and 8: Mathematics, June 2006. Retrieved June 5, 2008, from http://ero.govt.nz/ero/publishing.nsf/Content/QTMathsJun06Contents

Education Review Office. (2006b). Educational review report. Retrieved January 5, 2009, from http://www.tki.org.nz/e/schools (note schools not identified due to confidentiality).

Edwards-Leis, C. (2006, November). Variations to stimulated recall protocols to enhance student reflection: I did, I saw, I remembered. Paper presented to the Australian Association for Research in Education conference, Adelaide, 2006.

Evangelou, M., Taggart, B., Sylva, K., Melhuish, E., Sammons, P., \& Siraj-Blatchford, I. (2008). What makes a successful transition from primary to secondary school? Findings from the effective pre-school, primary and secondary education, (EPPSE) project (pp.3-14). Department for Children, Schools and Family. Retrieved May 5, 2008, from http://www.dcsf.gov.uk/research/

Farrell, M.A. (Ed.) (1993). Rethinking how we teach: Learning mathematical pedagogy. The Mathematics Teacher, 86(1),75-79.

Fennema, E., \& Franke, M. L. (1992). Teachers' knowledge and its impact. In D. Groews (Ed.), Handbook of research on mathematics teaching and learning (pp. 147-164). New York: MacMillan.

Foster, P. (2006). Observational research. In R. Sappsford \& V. Jupp (Eds.), Data collection and analysis ( $2^{\text {nd }}$ ed.) (pp. 57-92). London: Sage.

Fraivillig, J., Murphy, L., \& Fuson, K. (1999). Advancing children's mathematical thinking in everyday mathematics classrooms. Journal for Research in Mathematics Education, 30(2), 148- 171.

Galton, M. (1983). Problems of Transition. In M. Galton \& J. Willocks (Eds.), Moving from the primary classroom (pp. 5-22). London: Routledge.

Galton, M., Gray, J., \& Ruddock, J. (1999). The impact of school transitions and transfers on pupil progress and attainment. Retrieved May 20, 2006, from www.dfres.dov.uk/research/data/uploadfiles/RR131.doc

Galton, M., Gray, J. \& Ruddock, J. with others (2003). Transfers and transitions in the middle years of schooling: continuities and discontinuities in learning (7 -14). Department for Education and Skills, Research Report 443. London: DfES. 
Galton, M., Morrison, I., \& Pell, T. (2000). Transfer and transition in English schools: reviewing the evidence. International Journal of Educational Research, 33(4), 341-363.

Good, T., \& Brophy, J. (2003). Looking in classroooms (9 $9^{\text {th }}$ ed.). United States of America: Pearson Education.

Harvey, R. \& Averill, R. (in press). Senior Secondary Numeracy Practices in Successful Schools. Findings from the New Zealand Numeracy Development Projects Numeracy Research Compendium. Wellington: Ministry of Education.

Hayes, D., Lingard, B., \& Mills, M. (2000). Productive pedagogies. Education Links, 60 (Winter), 10-13.

Hayes, D. M., Mills, M., Christie, P., \& Lingard, B. (2006). Teachers \& schooling: productive pedagogies, assessment and performance: Making a difference. Crows Nest, NSW: Allen \& Unwin.

Higgins, J. (2002). An evaluation of the advanced numeracy project 2001. Wellington: Ministry of Education. Retrieved July 3, 2008, from http://www.tki.org.nz/r/literacy_numeracy/num_projects_e.php\#reports

Higgins, J. (2004). Equipment in use in the numeracy development project: Its importance to the introduction of mathematical ideas. In Ministry of Education, Numeracy Compendium (pp. 89-96). Wellington: Ministry of Education. Retrieved May 14, 2008, from http://www.nzmaths.co.nz/numeracy/References/compendium.aspx

Hine, P. (2001). Classroom environment and the transition to secondary schooling. Curtin: Curtin University of Technology, Faculty of Education.

Huggins, M., \& Knight, P. (1997). Curriculum continuity and transfer from primary to secondary school: The case of history. Educational Studies, 23(3), 333-348.

Irwin, K. C., \& Niederer, K. (2002). An evaluation of the numeracy exploratory study (NEST) and the associated numeracy exploratory study assessment (NESTA): Years 7-10. Wellington: Ministry of Education. Retrieved June 30, 2008, from http://www.tki.org.nz/r/literacy_numeracy/pdf/nest_text.pdf

Irwin, K. C., \& Woodward, J. (2004). A snapshot of the discourse used in mathematics where students are mostly Pacifica (A case study in two classrooms). In Ministry of Education, Numeracy Compendium (pp. 66-73). Wellington: Ministry of Education. Retrieved May 14, 2008, from http://www.nzmaths.co.nz/numeracy/References/compendium.aspx

Jordan, B., \& Henderson, A. (1995). Interaction analysis: Foundations and practice. The Journal of the Learning Science, 4(1), 39-103.

Kemmis, S., Cole, P., \& Suggett, D. (1983). Orientations to curriculum and transition: Towards the socially-critical school. Victoria: Victorian Institute of Secondary Education.

Kyriacou, C., \& Issitt, J. (2008). What characterises effective teacher-initiated teacherpupil dialogue to promote conceptual understanding in mathematics lessons in England in Key Stages 2 and 3: a systematic review. Technical report. In Research evidence in education library. London: EPPI- Centre, Social Science Research Unit, Institute of Education, University of London. Retrieved May 21, 2008, from http://eppi.ioe.ac.uk/cms/Default.aspx?tabid=2368

Lobato, J. (2008). On learning processes and the National Mathematics Advisory Panel 
Report. Educational Researcher, 37(9), 595-601.

Louis, K., Marks, H. M., \& Kruse, S. D. (1996). Teacher professional community in restructuring Schools. American Educational Research Journal, 33(4), 757-798.

Mason, M. (2007). Comparing places. In M. Bray, B. Adamson, \& M. Mason (Eds.), Comparative education research: Approaches and methods (pp. 85-122). Hong Kong: University of Hong Kong.

McGhee, C. (1989). Crossing the divide: Transitions from primary to secondary school. SET: Research Information for Teachers, 1(8), 1-4.

McGhee, C., Ward, R., Gibbons, J., \& Harlow, A. (2004). Transition to secondary school: A literature review. Hamilton: Waikato Institute for Research in Learning \& Curriculum, School of Education, University of Waikato.

Midgley, C., Feldlaufer, H., \& Eccles, J. S. (1989). Student/teacher relations and attitudes toward mathematics before and after the transition to junior high school. Child Development, 60(4), 981-992.

Mills, M., \& Goos, M. (2007, November). Productive pedagogies: Working with disciplines and teacher and student voices. Paper presented at the annual conference of the Australian Association for Research in Education, Fremantle, Australia.

Ministry of Education. (1992). New Zealand Curriculum. Wellington: Learning Media.

Ministry of Education. (2001). An Evaluation of the Year 4-6 Numeracy Exploratory $\underline{\text { Study. }}$. Wellington: Learning Media.

Ministry of Education. (2002). Education indicators 2002. A report on the health of the New Zealand education system, (Report for internal distribution, November 2002).

Ministry of Education. (2007). New Zealand Curriculum. Wellington: Learning Media.

Ministry of Education. (2008). A study of students' transition from primary to secondary school. Retrieved January 8, 2009 from

http://www.educationcounts.govt.nz/publications/schooling/31844/31846

Ministry of Education. (2009). Implementation project goals and objectives. Retrieved 2 February, 2009, from http://nzcurriculum.tki.org.nz/implementation_project_overview/implementation_ project goals and objectives

Mizelle, N. B., \& Mullins, E. (1997). Transition into and out of middle school. In J. L. Irvin (Ed.), What current research says to the middle level practitioner (pp. 303313). Columbus, OH: National Middle School Association.

Mullins, E., \& Irvin, J. (2000). Transition into middle school. Retrieved May 15, 2008, from http://www.chappaqua.k12.ny.us/ccsd/buildprj/tims.htm

Mullis, I. V. S., Martin, M. O., Gonzalez, E. J., \& Chrostowski, S. J. (2004). TIMSS 2003 international mathematics report: Findings from IEA's trends in international mathematics and science study at the fourth and eight grades. Chestnut Hill, MA: Boston College.

Murphy, P. D. \& Brown. (1970). Conceptual systems and teaching styles. American Education Research Journal, 7(4), 529-540.

National Mathematics Advisory Panel. (2008) Foundations for success: The final report of the National Mathematics Advisory Panel, Washington, DC: U.S. Department of Education. 
National Middle School Association. (2006). Research summary: transition from -middle school to high school. Retrieved July 24, 2008, from

http://www.nmsa.org/Research/ResearchSummaries/TransitionfromMStoHS/tabid/ $\underline{1087 /}$ Default.aspx

Newman, F., Marks, H. M., \& Gamoran, A. (1996). Authentic pedagogy and student performance. American Journal of Education, 104(4), 280-312.

New Zealand Association for Research in Education. (1998). Ethical guidelines. Retrieved May 25, 2008, from http://www.nzare.org.nz/pdfs/NZARE_ethical_guidelines.pdf

Office of Her Majesty's Chief Inspector of Schools. (2002). Changing schools: Evaluation of the effectiveness of transfer arrangements at age 11 (HML 550: Version 21 June 2003). London: Office for Standards in Education, Retrieved May 29, 2008 from http://www.ofsted.gov.uk/assets/309.pdf

Pajares, M.F. (1992). Teachers' beliefs and educational research: Cleaning up a messy construct. Review of Educational Research, 62(3). 307-332.

Peterson, P. L., Fennema, E., Carpenter, T. P., \& Loef, M. (1989). Teachers' pedagogical content beliefs in mathematics. Cognition and Instruction, 6(1), 1-40.

Pietarinen, J. (2000). Transfer to and study at secondary school in Finnish school culture: developing schools on the basis of pupils' experiences. International Journal of Educational Research, 33(4), 383-400.

Pirie, S. E. B. (1996, October). Classroom video-recording: When, why and how does it offer a valuable data source for qualitative research? Paper presented at the annual meeting of the North American chapter of the International group for the psychology of mathematics education, Panama City Beach, FL.

Pointon, P. (2000). Students' views of environments for learning from the primary to the secondary school. International Journal of Education Research, 33(4), 375-382.

Queensland University (2001). The Queensland school reform longitudinal study. Brisbane: The State of Queensland (Department of Education).

Sekiguchi, T. (2004). Toward a dynamic perspective of person-environment fit. Osaka Keidai Ronshu, 55(1), 177-190. Retrieved July 29, 2008, from www.osaka-ue.ac.jp/gakkai/pdf/ronshu/2004/5501_ronko_sekiguti.pdf .

Sellar, S., \& Cormack, P. (2006, November). (Re) conceptualizing middle years pedagogy. Paper presented as part of the symposium 'Pedagogical reform in the middle years' at the Australian Association for Research in Education conference, Adelaide.

Shulman, L. S. (1987). Knowledge and teaching: Foundations of the new reform. Harvard Educational Review, 57(1), 1-22.

Statistics New Zealand. (2009a). Retrieved January 5, 2009 from http://www.stats.govt.nz/census/censusoutputs/quickstats/snapshotplace $2 . h t m ? i d=2000030 \&$ type $=$ ta\&ParentID=1000006

Stigler, J. W., \& Hiebert, J. (1999). The teaching gap. New York: The Free Press.

Suffolk Education Department. (1997). School improvement: A transfer review. Retrieved August 19, 2008, from

http://www.suffolk.gov.uk/EducationAndLearning/Schools/SuffolkSchoolOrganisa tionReview/Pupilperformanceresearchfindings.htm

Talbert, J. E., \& McLaughlin, M. W. (2001). Professional communities and the work of 
high school teaching. Chicago, IL: University of Chicago Press.

Telese, J. A. (2004).Middle school mathematics classroom practices and achievement: a TIMSS-R analysis. Focus on learning problems in mathematics,26(4), 19-31.

Thomas, G., \& Ward, J. (2001). An evaluation of the early numeracy project 2001.

Wellington: Ministry of Education. Retrieved June 30, 2008, from

http://www.tki.org.nz/r/literacy_numeracy/num_projects_e.php

Thompson, A. (1992). Teachers' beliefs and conceptions: a synthesis of the research. In D.

E. Grouws (Ed), Handbook of research on mathematics teaching and learning (pp. 127-146). New York: MacMillan.

tki.org.nz (2008). Retrieved August 8, 2008, from

http://www.tki.org.nz/r/literacy_numeracy/num_projects_e.php\#devel

Ward, J., Thomas, G., \& Tagg, A. (2006) Numeracy sustainability: Current initiatives and future development needs. Retrieved July 3, 2008, from

http://www.nzmaths.co.nz/Numeracy/References/compendium06.aspx

Ward, R. (2000). Transfer from middle to secondary school: a New Zealand study. International Journal of Education Research, 33(4), 265-374.

Willocks, J. (1983). Pupils in transition. In M. Galton \& J. Willocks (Eds.), Moving from the primary classroom (pp. 25-62). London: Routledge.

Wylie, C., Hogden, E., \& Ferral, H. (2006). Completely different or a bigger version? Experiences and effects of the transition to secondary school. Evidence from the competent children, competent learners project. Wellington: Ministry of Education.

Young-Loveridge, J. (2007). In Ministry of Education, Findings from the New Zealand numeracy development projects 2007 (pp. 116-127). Wellington: Learning Media Limited.

Zevenbergen, R. (2000). 'Cracking the code' of mathematics classrooms. In J. Boaler (Ed.), Multiple perspectives on mathematics teaching and learning (pp. 201225). Westport, CT: Ablex Publishing. 


\section{List of Tables}

$\begin{array}{ll}\text { Table 2.1: Comparison of teaching strategies categorisation } & \text { p. } 23\end{array}$

$\begin{array}{ll}\text { Table 3.1: Breakdown of teachers selected } & \text { p. } 38\end{array}$

$\begin{array}{ll}\text { Table 3.2: Examples of categorised teacher talk } & \text { p. } 42\end{array}$

$\begin{array}{ll}\text { Table 3.3: Examples of categorised teaching strategies } & \text { p. } 43\end{array}$

Table A.1.1: Raw data of types of teacher talk in the mathematics classroom p. 108

Table A.1.2: Raw data of strategies used in the classroom during whole class teaching p. 108

$\begin{array}{lr}\text { Table A.1.3: Type of work engaged in } & \text { p. } 109\end{array}$

Table A.1.4: Use of eliciting strategies (Percentage of all statements) p. 109

Table A.1.5: Use of supportive strategies (Percentage of all statements) p. 110

Table A.1.6: Use of extending mathematical thinking strategies

$\begin{array}{ll}\text { (Percentage of all statements) p. } 110 & \text { p }\end{array}$

$\begin{array}{ll}\text { Table A.3.1: Data from categorisation of teacher talk p. } 110 & \end{array}$ 


\section{List of Figures}

Figure 4.1: Teacher talk in the Year 8 classroom p. 46

$\begin{array}{ll}\text { Figure 4.2: } \text { Teacher talk in the Year } 9 \text { classroom } & \text { p. } 47\end{array}$

Figure 4.3: Type of questions used in the Year 8 classroom p. 48

Figure 4.4: Type of questions used in the Year 9 classroom $\quad$ p. 48

Figure 4.5: Type of statements used in the Year 8 classroom p. 52

Figure 4.6: Type of statements used in the Year 9 classroom p. 52

Figure 5.1: Main teaching strategies used in the Year 8 classroom p. 60

Figure 5.2: Main teaching strategies used in the Year 9 classroom p. 61

Figure 5.3: Comparison of extending mathematical thinking strategies used by Year 8 and Year 9 teachers p. 68

Figure 5.4: Comparison of eliciting strategies used by Year 8 and $\begin{array}{ll}\text { Year } 9 \text { study teachers } & \text { p. } 71\end{array}$

Figure 5.5: Comparison of supporting student thinking strategies used by Year 8 and Year 9 study teachers p. 75

$\begin{array}{ll}\text { Figure 6.1: Verbalisations in the classrooms } & \text { p. } 83\end{array}$ 


\section{List of Appendices}

Appendix 1: Video and Written Scheme Analysis Categories p. 105

$\begin{array}{ll}\text { Appendix 2: Data Tables and Figures } & \text { p. } 108\end{array}$

$\begin{array}{ll}\text { Appendix 3: Numeracy Stages } & \text { p. } 111\end{array}$

Appendix 4: Mathematics Scheme Excerpts p. 112

Appendix 5: Informed Consent Letters p. 113 


\section{Appendix 1: Analysis categories}

Note each type of statement has varying levels e.g. encouraging could also be discouraging, facilitating has a different degree of scaffolding within it. Examples of each type of statement used are in Tables 3.2 and 3.3. This table below shows headings developed from The Advanced Children's thinking study (Fraivillig et al, 1999), the Queensland School Reform Longitudinal Study (University of Queensland, 2001) and the Best Evidence Synthesis Iteration [BES]: Effective Pedagogies in Mathematics (Anthony \& Walshaw, 2007). The actual recording sheet allows for room to add all incidences of each type of statement to be recorded. Some statements may be included in more than one category.

\section{Statements made by teacher during whole class instruction}

\begin{tabular}{|l|}
\hline elicits many solutions to one problem \\
\hline encourages elaboration from students \\
\hline promotes collaborative problem solving \\
\hline conveys an accepting attitude towards student efforts, \\
\hline monitors student engagement \\
\hline uses student explanations as part of the lesson \\
\hline reminds students of conceptually similar problems \\
\hline manipulatives/tools/technologies used: what type, how and for how long \\
\hline provides background knowledge \\
\hline assists individuals to clarify their own solution methods \\
\hline leads students to answers whilst extending their thinking \\
\hline encourages students to seek assistance in problem solving \\
\hline sets high standards and expectations of all students \\
\hline encourages students to generalize \\
\hline encourages students to see relationships between concepts \\
\hline promotes alternative and efficient solution methods \\
\hline $\begin{array}{l}\text { cultivates a love of challenge, by selecting/using tasks that foster students' conceptual } \\
\text { advances. }\end{array}$ \\
\hline lesson content extends beyond a mathematical context \\
\hline lesson content includes the students' background experience \\
\hline lesson content is based on real-life situations \\
\hline attempts to include all students, and diverse cultures present in problems \\
\hline a narrative or expository teaching style used. \\
\hline
\end{tabular}




\section{Statements made by teacher during student work time}

\begin{tabular}{|l|}
\hline elicits many solutions to one problem \\
\hline encourages elaboration from students \\
\hline promotes collaborative problem solving \\
\hline conveys an accepting attitude towards student efforts, \\
\hline monitors student engagement \\
\hline uses student explanations as part of the lesson \\
\hline reminds students of conceptually similar problems \\
\hline manipulatives/tools/technologies used: what type, how and for how long \\
\hline provides background knowledge \\
\hline assists individuals to clarify their own solution methods \\
\hline leads students to answers whilst extending their thinking \\
\hline encourages students to seek assistance in problem solving \\
\hline sets high standards and expectations of all students \\
\hline encourages students to generalize \\
\hline encourages students to see relationships between concepts \\
\hline promotes alternative and efficient solution methods \\
\hline $\begin{array}{l}\text { cultivates a love of challenge, by selecting/using tasks that foster students' conceptual } \\
\text { advances. }\end{array}$ \\
\hline lesson content extends beyond a mathematical context \\
\hline lesson content includes the students' background experience \\
\hline lesson content is based on real-life situations \\
\hline attempts to include all students, and diverse cultures present in problems \\
\hline a narrative or expository teaching style used. \\
\hline
\end{tabular}

\section{Type of work engaged in}

(This will be recorded as field notes if deemed that it would not be evident from the video)

\begin{tabular}{|l|l|l|}
\hline Individual & Group & Whole class \\
\hline $\begin{array}{l}\text { Problem solving: } \\
\text { Open ended or closed }\end{array}$ & $\begin{array}{l}\text { Problem solving: } \\
\text { Open ended or closed }\end{array}$ & $\begin{array}{l}\text { Problem solving: } \\
\text { Open ended or closed }\end{array}$ \\
\hline $\begin{array}{l}\text { Manipulatives/tools/ } \\
\text { technologies }\end{array}$ & $\begin{array}{l}\text { Manipulatives/tools/ } \\
\text { technologies }\end{array}$ & Manipulatives/tools/technologies \\
\hline $\begin{array}{l}\text { Contextual, i.e. situated at } \\
\text { the students' experience as } \\
\text { perceived by the teacher. }\end{array}$ & $\begin{array}{l}\text { Contextual, i.e. situated at the } \\
\text { students' experience as } \\
\text { perceived by the teacher. }\end{array}$ & $\begin{array}{l}\text { Contextual, i.e. situated at the } \\
\text { students' experience as perceived } \\
\text { by the teacher. }\end{array}$ \\
\hline $\begin{array}{l}\text { Engaged in lower-order } \\
\text { thinking tasks (e.g. } \\
\text { recitation of fact, repetition } \\
\text { of algorithms) }\end{array}$ & $\begin{array}{l}\text { Engaged in lower-order } \\
\text { thinking tasks (e.g. recitation } \\
\text { of fact, repetition of } \\
\text { algorithms) }\end{array}$ & $\begin{array}{l}\text { Engaged in lower-order thinking } \\
\text { tasks (e.g. recitation of fact, } \\
\text { repetition of algorithms) }\end{array}$ \\
\hline $\begin{array}{l}\text { Engaged in higher-order } \\
\text { thinking (e.g. manipulation }\end{array}$ & $\begin{array}{l}\text { Engaged in higher-order } \\
\text { thinking (e.g. manipulation }\end{array}$ & $\begin{array}{l}\text { Engaged in higher-order thinking } \\
\text { (e.g. manipulation and }\end{array}$ \\
\hline
\end{tabular}




\begin{tabular}{|l|l|l|}
\hline $\begin{array}{l}\text { and transformation of } \\
\text { information) }\end{array}$ & $\begin{array}{l}\text { and transformation of } \\
\text { information) }\end{array}$ & transformation of information) \\
\hline Skills practice & Skills practice & Skills practice \\
\hline $\begin{array}{l}\text { Worksheet/ } \\
\text { Text: same for everyone? }\end{array}$ & $\begin{array}{l}\text { Worksheet/ } \\
\text { Text: same for everyone? }\end{array}$ & $\begin{array}{l}\text { Worksheet/ } \\
\text { Text: same for everyone? }\end{array}$ \\
\hline $\begin{array}{l}\text { Board/data projector/ } \\
\text { Overhead/ verbal }\end{array}$ & Board/data projector/ & Board/data projector/ \\
Overhead/ verbal & Overhead/ verbal \\
\hline
\end{tabular}

Activities will be recorded in terms of the categories in the table below. The length of time students are involved in each activity will also be recorded. If different activities are happening simultaneously, they will all be recorded with the number of students engaged in each and the duration of each.

\section{Type of language statements made}

Control: only interactions with students during this time are for control

Explanatory: explains the skill/ concept being taught

Facilitating: asks students to explain/show how to solve but with some scaffolding Confidence building (including valuing): the statement recognizes student effort and praises the thinking behind it

Initiating/eliciting: poses a problem and asks for suggestions as to how to solve Instructional : gives directions for the students to follow e.g. write this down, do this Right/wrong: the questions asked only elicit a response that the teacher deems correct or not

Manipulatives/tools/technologies used: what type, how and for how long 


\section{Appendix 2: Tables of the Data Collected}

Table A.1.1: Raw data of types of teacher talk in the mathematics classroom

\begin{tabular}{|l|l|l|l|l|l|l|l|}
\hline & control & explanatory & instructional & $\begin{array}{l}\text { confidence } \\
\text { building }\end{array}$ & $\begin{array}{l}\text { initiating/ } \\
\text { eliciting }\end{array}$ & facilitating & $\begin{array}{l}\text { right/ } \\
\text { wrong }\end{array}$ \\
\hline $\begin{array}{l}\text { Year } \\
8\end{array}$ & 25 & 98 & 210 & 70 & 13 & 58 & 155 \\
\hline $\begin{array}{l}\text { Year } \\
9\end{array}$ & 150 & 22 & 382 & 39 & 1 & 9 & 249 \\
\hline
\end{tabular}

Table A.1.2: Raw data of strategies used in the classroom during whole class teaching

\begin{tabular}{|l|l|l|l|l|l|l|l|l|l|l|l|}
\hline Strategy & $\mathbf{1}$ & $\mathbf{2}$ & $\mathbf{3}$ & $\mathbf{4}$ & $\mathbf{5}$ & $\mathbf{6}$ & $\mathbf{7}$ & $\mathbf{8}$ & $\mathbf{9}$ & $\mathbf{1 0}$ & $\mathbf{1 1}$ \\
\hline Year 8 & 8 & 0 & 12 & 0 & 15 & 0 & 26 & 0 & 38 & 0 & 14 \\
\hline Year 9 & 1 & 2 & 11 & 1 & 6 & 1 & 64 & 8 & 37 & 1 & 0 \\
\hline Strategy & $\mathbf{1 2}$ & $\mathbf{1 3}$ & $\mathbf{1 4}$ & $\mathbf{1 5}$ & $\mathbf{1 6}$ & $\mathbf{1 7}$ & $\mathbf{1 8}$ & $\mathbf{1 9}$ & $\mathbf{2 0}$ & $\mathbf{2 1}$ & $\mathbf{2 2}$ \\
\hline Year 8 & 0 & 13 & 12 & 3 & 3 & 5 & 17 & 0 & 8 & 0 & 6 \\
\hline Year 9 & 1 & 6 & 2 & 3 & 0 & 2 & 67 & 2 & 0 & 15 & 0 \\
\hline Strategy & $\mathbf{2 3}$ & $\mathbf{2 4}$ & $\mathbf{2 5}$ & $\mathbf{2 6}$ & $\mathbf{2 7}$ & $\mathbf{2 8}$ & $\mathbf{2 9}$ & $\mathbf{3 0}$ & $\mathbf{3 1}$ & $\mathbf{3 2}$ & $\mathbf{3 3}$ \\
\hline Year 8 & 11 & 6 & 5 & 0 & 2 & 0 & 0 & 3 & 4 & 1 & 13 \\
\hline Year 9 & 2 & 2 & 0 & 3 & 4 & 1 & 2 & 7 & 1 & 0 & 0 \\
\hline
\end{tabular}

\section{Key to Strategies}

1. Elicits many solutions to one problem

2. Discourages other solutions

3. Encourages elaboration from students

4. Discourages elaboration from students

5. Promotes collaborative problem solving

6. Discourages collaborative problem solving

7. Conveys an accepting attitude towards student efforts

8. Is unaccepting towards student efforts

9. Monitors student engagement

10. Has no idea of who is working

11. Uses student explanations as part of the lesson

12. Does not use student explanations

13. Reminds students of conceptionally similar problems

14. Manipulatives/tools/technologies used

15. Provides background information

16. Assists individuals to clarify their own solution methods

17. Leads students to answers whilst extending their thinking 
18. Leads students to answers without extending their thinking

19. Encourages students to seek assistance in problem solving

20. Sets high standards and expectations of all students

21. Does not sets high standards and expectations of all students

22. Encourages students to generalise

23. Encourages students to see relationships in concepts

24. Promotes alternative and efficient solution methods

25. Cultivates a love of challenge

26. Does not cultivate a love of challenge

27. Lesson context extends beyond a mathematical context

28. Lesson context doesn't extend beyond a mathematical context

29. Lesson content includes student's background experiences

30. Lesson content refers to previous mathematics lessons

31. Lesson content based on real life situations

32. Attempts to include all students

33. Narrative or expository style used

Table A.1.3: Type of work engaged in

\begin{tabular}{|c|c|c|c|c|c|c|c|c|}
\hline & $\begin{array}{c}\text { Individual } \\
\text { problem } \\
\text { solving } \\
\text { closed }\end{array}$ & $\begin{array}{l}\text { Individual } \\
\text { problem } \\
\text { solving open } \\
\text { ended }\end{array}$ & $\begin{array}{l}\text { Manipulatives } \\
\text { tools/ } \\
\text { technologies }\end{array}$ & $\begin{array}{l}\text { Situated at the } \\
\text { students } \\
\text { experience as } \\
\text { perceived by } \\
\text { the teacher }\end{array}$ & $\begin{array}{l}\text { Engaged in } \\
\text { lower order } \\
\text { thinking } \\
\text { tasks }\end{array}$ & $\begin{array}{c}\text { Skills } \\
\text { practice }\end{array}$ & $\begin{array}{c}\text { Same } \\
\text { for } \\
\text { every } \\
\text { one? }\end{array}$ & $\begin{array}{l}\text { Where } \\
\text { from? }\end{array}$ \\
\hline 8 & Mainly yes & Some times & $\begin{array}{c}\text { Fraction strips } \\
\text { stopwatches }\end{array}$ & Mainly yes & $\begin{array}{c}\text { Half the } \\
\text { time }\end{array}$ & little & Yes & $\begin{array}{c}\text { Text, } \\
\text { worksheet, } \\
\text { teacher }\end{array}$ \\
\hline 9 & yes & no & $\begin{array}{c}\text { Some props e.g. } \\
\text { curtains, hands } \\
\text { Protractors } \\
\text { Data projector }\end{array}$ & $\begin{array}{c}\text { Mainly no but } \\
\text { the occasional } \\
\text { question }\end{array}$ & yes & no & yes & $\begin{array}{c}\text { Text } \\
\text { Worksheet }\end{array}$ \\
\hline
\end{tabular}

Table A.1.4: Use of Eliciting Strategies, Percentage of statements (Fravillig, Murphy \& Fuson, 1999)

\begin{tabular}{|c|c|c|c|c|c|c|}
\hline & $\begin{array}{c}\text { many } \\
\text { solutions } \\
\text { to one } \\
\text { problem }\end{array}$ & $\begin{array}{c}\text { encourages } \\
\text { elaboration } \\
\text { from } \\
\text { students }\end{array}$ & $\begin{array}{c}\text { conveys } \\
\text { promotes } \\
\text { collaborative } \\
\text { problem solving } \\
\text { accepting } \\
\text { attitude } \\
\text { towards } \\
\text { student } \\
\text { efforts }\end{array}$ & $\begin{array}{c}\text { monitors } \\
\text { student } \\
\text { engagement }\end{array}$ & $\begin{array}{c}\text { uses student } \\
\text { explanations } \\
\text { as part of the } \\
\text { lesson }\end{array}$ \\
\hline Year 8 & 4 & 5 & 7 & 12 & 17 & 6 \\
\hline Year 9 & 0 & 4 & 2 & 25 & 15 & 0 \\
\hline
\end{tabular}


Table A.1.5: Use of Supportive Strategies, Percentage of statements (Fravillig, Murphy \& Fuson, 1999)

\begin{tabular}{|l|l|l|l|l|l|}
\hline & $\begin{array}{l}\text { leads } \\
\text { reminds students of } \\
\text { conceptionally } \\
\text { similar problems }\end{array}$ & $\begin{array}{l}\text { lackides } \\
\text { packround } \\
\text { information }\end{array}$ & $\begin{array}{l}\text { assists } \\
\text { individuals to } \\
\text { clarify their } \\
\text { own solution } \\
\text { methods }\end{array}$ & $\begin{array}{l}\text { answers } \\
\text { ahilst } \\
\text { extending } \\
\text { their thinking }\end{array}$ & $\begin{array}{l}\text { encourages students to } \\
\text { seek assistance in } \\
\text { problem solving }\end{array}$ \\
\hline Year 8 & 6 & 1 & 1 & 2 & 0 \\
\hline Year 9 & 2 & 1 & 0 & 1 & 1 \\
\hline
\end{tabular}

Table A.1.6 : Use of Extending Mathematical Thinking Strategies, Percentage of statements (Fravillig, Murphy \& Fuson, 1999)

\begin{tabular}{|c|c|c|c|c|c|}
\hline & $\begin{array}{l}\text { sets high } \\
\text { standards and } \\
\text { expectations of all } \\
\text { students }\end{array}$ & $\begin{array}{l}\text { encourages } \\
\text { students to } \\
\text { generalise }\end{array}$ & $\begin{array}{l}\text { encourages } \\
\text { students to see } \\
\text { relationships in } \\
\text { concepts }\end{array}$ & $\begin{array}{l}\text { promotes } \\
\text { alternative and } \\
\text { efficient } \\
\text { solution } \\
\text { methods }\end{array}$ & $\begin{array}{l}\text { cultivates a } \\
\text { love of } \\
\text { challenge }\end{array}$ \\
\hline Year 8 & 4 & 3 & 5 & 3 & 2 \\
\hline Year 9 & 0 & 0 & 1 & 1 & 0 \\
\hline
\end{tabular}

Table A.3.1: Data from observations in the categories

\begin{tabular}{|c|c|c|c|c|c|c|c|}
\hline & control & explanatory & facilitating & $\begin{array}{l}\text { confidence } \\
\text { building }\end{array}$ & initiating/eliciting & instructional & right/wrong \\
\hline $\begin{array}{c}\text { year } \\
8\end{array}$ & 25 & 98 & 58 & 70 & 13 & 210 & 155 \\
\hline $\begin{array}{c}\text { year } \\
9\end{array}$ & 150 & 22 & 9 & 39 & 1 & 382 & 249 \\
\hline
\end{tabular}

\section{Questions asked in semi-structured interviews}

What was the purpose of starter questions?

Were the lessons observed in a usual format?

Do you regularly use manipulatives as part of your lessons? 


\section{Appendix 3: Glossary}

\section{Numeracy Stages:}

The following definitions have been retrieved from http://www.nzmaths.co.nz/Numeracy/Intro.aspx (March 3, 2009)

The following table describes the key features of each strategy stage of the Number Framework.

\begin{tabular}{|c|c|}
\hline Stage 0: Emergent & $\begin{array}{l}\text { The student is unable to consistently count a given number of objects because they lack knowledge of counting } \\
\text { sequences and/or one-to-one correspondence. }\end{array}$ \\
\hline $\begin{array}{l}\text { Stage 1: One-to-one } \\
\text { Counting }\end{array}$ & $\begin{array}{l}\text { The student is able to count a set of objects or form sets of objects but cannot solve problems that involve joining } \\
\text { and separating sets. }\end{array}$ \\
\hline $\begin{array}{l}\text { Stage 2: Counting from } \\
\text { One on Materials }\end{array}$ & $\begin{array}{l}\text { The student is able to count a set of objects or form sets of objects to solve simple addition and subtraction } \\
\text { problems. } \\
\text { The student solves problems by counting all the objects. }\end{array}$ \\
\hline $\begin{array}{l}\text { Stage 3: Counting from } \\
\text { One by imaging }\end{array}$ & $\begin{array}{l}\text { The student is able to visualize sets of objects to solve simple addition and subtraction problems. } \\
\text { The student solves problems by counting all the objects. }\end{array}$ \\
\hline $\begin{array}{l}\text { Stage 6: Advanced } \\
\text { Additive/Early } \\
\text { Multiplicative Part-Whole }\end{array}$ & $\begin{array}{l}\text { The student can estimate answers and solve addition and subtraction tasks involving whole numbers mentally by } \\
\text { choosing appropriately from a broad range of advanced mental strategies (e.g. place value positioning, rounding } \\
\text { and compensating or reversibility). } \\
\text { The student uses a combination of known facts and a limited range of mental strategies to derive answers to } \\
\text { multiplication and division problems, (e.g. doubling, rounding or reversibility). }\end{array}$ \\
\hline $\begin{array}{l}\text { Stage 7: Advanced } \\
\text { Multiplicative Part-Whole }\end{array}$ & $\begin{array}{l}\text { The student is able to choose appropriately from a broad range of mental strategies to estimate answers and } \\
\text { solve multiplication and division problems. These strategies involve partitioning one or more of the factors, (e.g. } \\
\text { place value partitioning, rounding and compensating, reversibility). }\end{array}$ \\
\hline
\end{tabular}

(c) Ministry of Education, Wellington, New Zealand 


\section{Appendix 4: Schemes of work}

\section{Excerpt from Year 8}

Strand: Measurement

A.O Create and use appropriate units and devices to measure weight (mass)

Session Starter Focus: General knowledge weight questions

Teaching points: Grams/kg. Conversions-kilos to grams. Packaging into boxes-cubes. Compare mass. Add and subtract measurements

Resources: $1 \mathrm{~kg}$ bag of rice, scales

\section{Excerpt form Year 9}

Time Achievement Objective Activity

3 periods Integers: Can solve problems involving integers Alpha p. 46

Ex $3.1-3.17$ 


\section{Appendix 5: Informed Consent letters}

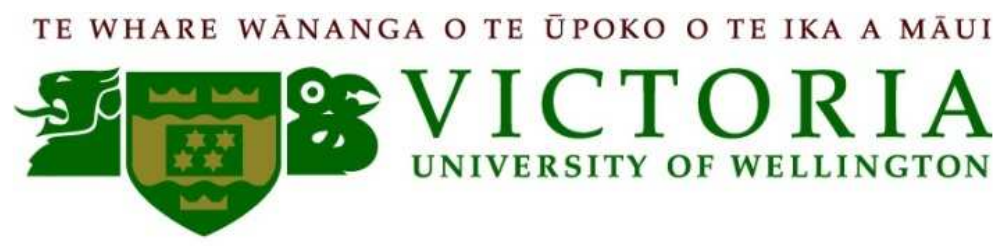

Kay Matheson

$x x x x x x x x x x x$

$x x x x x x x x$

Phone: $x x x x x x x$

August 2008

Information sheet for a study of teaching strategies in Mathematics classrooms.

(Teachers copy)

My name is Kay Matheson. I am a masterate student at Victoria University of Wellington College of Education. I am conducting a research project into the teaching strategies of Year 8 and Year 9 mathematics classrooms. This masterate research project is supervised by Robin Averill [Telephone 04463 9714] Senior Lecturer, School of Primary and Secondary Teacher Education at Victoria University of Wellington.

I would like to invite you to participate in my research project.

\section{Purpose of this research}

This masterate thesis investigates the teaching strategies used in the mathematics classroom. The findings of this research aim to help improve our understanding of mathematics teaching. It is concentrating on two year levels, Year 8 and Year 9. The research project comprises three components: videoed classroom lessons, of three teachers, at each year level, for up to three lessons per teacher; an interview (with the videoed teachers, individually) about the strategies they have used in the classroom; and an analysis of written schemes/plans of work.

I aim to have the videoing completed by the end of November. This research project will not interfere with classroom teaching in any way.

The information gathered will be treated with strict confidentiality. No one apart from my supervisors and me will see the data. The final report will not identify the schools, teachers, other adults or any students involved in the research. All data will be kept securely and destroyed two years after the completion of this research project. The thesis will be submitted to the School of Education for marking and a copy kept by the University Library. It may also be used as a basis for conference papers and journal articles.

A summary of the conclusions will also be made available to you if you would like one. 
This research project has been approved by the Victoria University of Wellington Faculty of Education Human Ethics Committee, subject to written consent of those involved.

It is important that you understand that you have the right to withdraw from this project at any stage without any consequences. Your data will then be destroyed.

If you would like any further information about this study please contact me (ph 8773908), or my supervisor Robin Averill, (ph 04463 9714) at any time.

If you are happy to be part of this study please sign and return the attached consent form.

Yours sincerely

Kay Matheson

Masterate Student

College of Education

Victoria University of Wellington. 
TE WHARE WĀNANGA O TE ŪPOKO O TE IKA A MĀUI

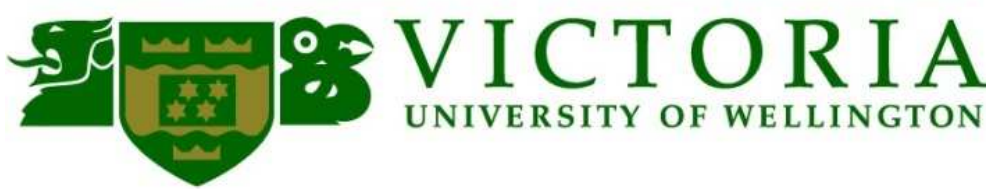

Victoria University College of Education

Consent for participation in a research project (Teacher)

Research into teaching strategies in Mathematics classrooms

I have been given and have understood the information about this research project. I have had an opportunity to ask questions and have them answered to my satisfaction

I understand that I may withdraw from this study (before data collection and analysis is complete) without having to give a reason of any sort. The data collected involving me will then be destroyed.

I understand that any information provided will be kept confidential to the researcher (Kay Matheson) and the project supervisor (Robin Averill), that the published results will not use my name or my school's name or any student's name, and that none of the information collected will be presented in any way that will identify any individuals. I understand that at the end of the project all data gathered will be destroyed.

I understand that the data provided will not be used for any purpose other than those explained in the research information sheet.

I would like to receive a summary of the results of the research when it is finished.

I agree to provide the researcher with a copy of the mathematics scheme of work/ unit plan of work.

I agree to the researcher videoing, up to three of, my mathematics lessons.

I agree to participate in a follow up interview to discuss the video of my teaching.

Name:

Signature:

Date: 
Kay Matheson

$x x x x x x x x x$

$x x x x x x x x x$

August 2008

Phone: $x x x x x x x$

\section{Information sheet for a study of teaching strategies in Mathematics classrooms. (Principals/Board of Trustees chair copy)}

My name is Kay Matheson. I am a masterate student at Victoria University of Wellington College of Education. I am conducting a research project into the prevalent teaching strategies of Year 8 and Year 9 mathematics classrooms. This masterate research project is supervised by Robin Averill (Telephone 04463 9714) Senior Lecturer, School of Primary and Secondary Teacher Education at Victoria University of Wellington.

I would like to invite your school to participate in this research.

\section{Purpose of this research}

This masterate thesis investigates the teaching strategies used in the mathematics classroom. The findings of this research aim to help improve our understanding of mathematics teaching. It is concentrating on two year levels, Year 8 and Year 9 . The research project comprises three components: videoed classroom lessons, of three teachers, at each year level, for up to three lessons per teacher; an interview (with the videoed teachers, individually) about the teaching strategies they have used in the classroom; and an analysis of written schemes/plans of work.

I aim to have the videoing completed by the end of November. This research project will not interfere with classroom teaching in any way.

The information gathered will be treated with strict confidentiality. No one apart from my supervisors and me will see the raw data. The final report will not identify the schools or teachers involved in the research. All data will be kept in a secure place and destroyed two years after the completion of this research project. The thesis will be submitted to the School of Education for marking and kept by the University Library. It may also be used as a basis for conference papers and journal articles. A summary of the conclusions will also be made available to you if you would like one.

This research project has been approved by the Victoria University of Wellington Faculty of Education Human Ethics Committee, subject to the written consent of those involved. If some students do not consent to be involved, then we need to ensure that they will not be videoed by providing alternative arrangements for those students. 
It is important that you understand that you have the right to withdraw your school from this project at any stage. Any data already collected will be destroyed.

If you would like further information about this study please contact me (ph 8773908), or my supervisor, Robin Averill, (ph 04463 9714), at any time.

If you are happy for your school to be part of this study please sign and return the attached consent form.

Yours sincerely

Kay Matheson

Masterate Student

College of Education

Victoria University of Wellington. 


\section{Victoria University College of Education}

Consent for a school to participate in a research project (Principal /Board Chair)

\section{Research into teaching strategies in Mathematics classrooms}

I have been given and have understood the information about this research project. I have had an opportunity to ask questions and have them answered to my satisfaction.

I understand that I may withdraw my school from this study (before data collection and analysis is complete) without having to give a reason of any sort. The data collected involving my school will then be destroyed.

I understand that any information provided will be kept confidential to the researcher (Kay Matheson) and the project supervisor (Robin Averill), that the published results will not use my name or my school's name, and that none of the information collected will be presented in any way that will identify any individuals. I understand that at the end of the project all data gathered will be destroyed.

I understand that the data provided will not be used for any purpose other than those explained in the research information sheet.

I would like to receive a summary of the results of the research when it is finished.

I agree that my school is able to take part in this research.

I agree to provide alternative arrangements for those students who do not consent to being involved in this project

Signed

Name

School

Date 
TE WHARE WĀNANGA O TE ŪPOKO O TE IKA A MĀUI

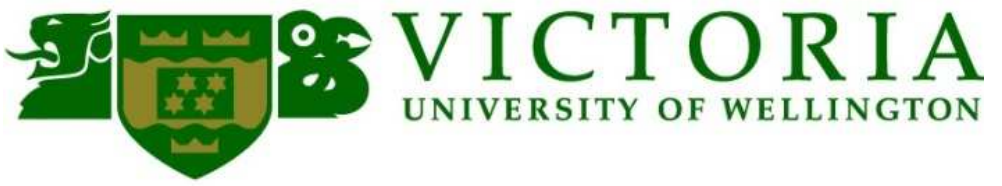

Kay Matheson

$x x x x x x x x x$

$\mathrm{xxXXXXXXX}$

August 2008

Phone: $x x x x x x x$

Information sheet for a study of teaching strategies in Mathematics classrooms. (Parent/ care giver/whānau copy)

My name is Kay Matheson. I am a masterate student at Victoria University of Wellington College of Education. I am, also, the co-Head of Mathematics at xxxxxxxxxxx. I am conducting a research project into the prevalent teaching strategies of Year 8 and Year 9 mathematics classrooms. This masterate research project is supervised by Robin Averill (ph 04463 9714), Senior Lecturer, School of Primary and Secondary Teacher Education at Victoria University of Wellington.

I will be in the classroom to video the teaching strategies your child's teacher uses in the teaching of mathematics. This will not interfere with classroom teaching. The aim of my research is to help me understand the differences and similarities between the teaching strategies used in Year 8 and Year9 mathematics classrooms.

The purpose of the video is to focus on the teaching strategies used and ensure that the data collected is accurate. Whilst I am videoing the teacher some students may also inadvertently appear on the recording. No record of individual students will be made when analysing and transcribing the video and no information that will identify any individual students will be kept. The videos will be kept in a secure place and will be viewed only by the mathematics teacher, myself and my supervisor. At the completion of my research all video and transcribed data will be destroyed.

This research project has been approved by the Victoria University of Wellington Faculty of Education Human Ethics Committee, subject to the written consent of those involved. Any one has the right to withdraw from this research at any stage. The finished thesis will be submitted to The School of Education and put in the Victoria University Library.

If you would like more information please do not hesitate to call me. I very much hope that you will agree to be involved in this research.

Please return the attached form to your child's mathematics teacher.

Kay Matheson

Masterate Student

College of Education

Victoria University of Wellington 
TE WHARE WĀNANGA O TE ÜPOKO O TE IKA A MĀUI

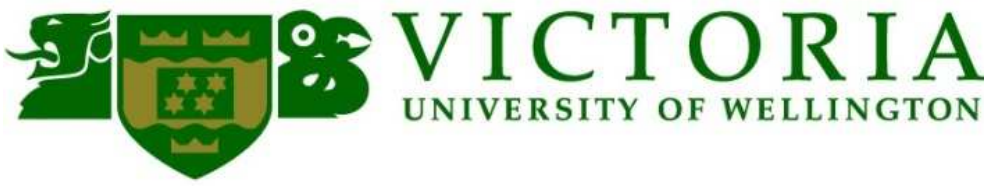

Victoria University College of Education

\section{Consent for a student to participate in a research project}

Project title: Research into teaching strategies in Year 8 and Year 9 Mathematics classrooms

I agree to be a part of this research project. I have had it explained to me. I know that being part of the project means I agree to:

$\square \quad$ Possibly being videoed while the class is doing maths

I understand that:

$\square \quad$ no one will know which students were videoed

$\square \quad$ I can say no to being part of the project

$\square \quad$ I can stop being part of the project if I want at any stage

$\square$ The researcher will keep the video until the project has finished and then destroy it.

(Please tick each box)

I (Student's name) agree to be part of this research project.

My Signature:

My Parent's/ Care givers/Whānau signature

The Date is 
TE WHARE WĀNANGA O TE ŨPOKO O TE IKA A MĀUI

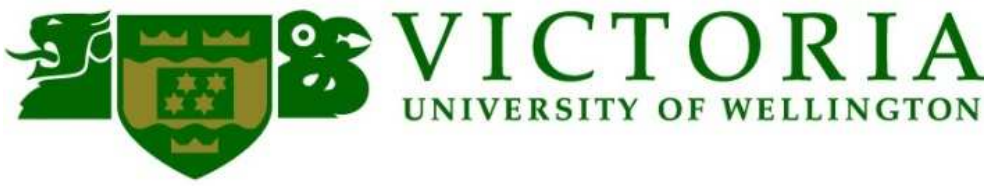

Information sheet for a study of teaching strategies in Mathematics classrooms. (Student's copy)

My name is Kay Matheson and I am a masterate student at Victoria University of Wellington. I am doing research into how your teacher teaches your class mathematics.

I will be in the class videoing the teacher. Sometimes you might be on the video too. When I transcribe what is happening on the video, it is only the teacher's actions that I am looking at.

The research is being done so that I can find out what happens in the Year 8 and Year 9 mathematics classrooms. The research will help teachers improve how they teach mathematics. I would really like all the class to be part of the research, so your mathematics teacher can just teach normally.

The research is anonymous. This means that no one apart from the people in the project know who the people in the project are.

If you agree to be part of the project, you can stop being part of it any time by telling your teacher, your parent/guardian or me that you want to stop.

If you have any questions, please ask your teacher or me.

Thank you very much

Kay Matheson

Masterate Student

College of Education

Victoria University of Wellington 